Cahiers $d u$ MONDE RUSSE

\section{Cahiers du monde russe}

Russie - Empire russe - Union soviétique et États indépendants

\title{
Kazahskie činovniki Rossijskoj Imperii XIX v.: osobennosti vosprijatija vlasti
}

Les fonctionnaires kazakhs de la Russie impériale au xixe siècle : particularités de la perception du pouvoir Kazakh civil servants in nineteenth-century Imperial Russia: Specific aspects of the perception of power

\section{Gul'Imira S. Sultangalieva}

\section{(2) OpenEdition}

\section{Journals}

Édition électronique

URL : https://journals.openedition.org/monderusse/8214

DOI : $10.4000 /$ monderusse. 8214

ISSN : $1777-5388$

Éditeur

Éditions de l'EHESS

\section{Édition imprimée}

Date de publication : 1 octobre 2015

Pagination : 651-679

ISBN : 978-2-7132-2507-9

ISSN : $1252-6576$

Référence électronique

Gul'Imira S. Sultangalieva, «Kazahskie činovniki Rossijskoj Imperii XIX v.: osobennosti vosprijatija vlasti», Cahiers du monde russe [Онлайн], 56/4 | 2015, Выложить онлайн 01 octobre 2018, Наводить справки в 28 juin 2022. URL: http://journals.openedition.org/monderusse/8214 ; DOI: https://doi.org/ $10.4000 /$ monderusse.8214

Ce document a été généré automatiquement le 29 septembre 2020.

(c) École des hautes études en sciences sociales 


\section{Kazahskie činovniki Rossijskoj Imperii XIX v.: osobennosti vosprijatija vlasti}

Les fonctionnaires kazakhs de la Russie impériale au xixe siècle : particularités de la perception du pouvoir

Kazakh civil servants in nineteenth-century Imperial Russia: Specific aspects of the perception of power

\section{Gul'Imira S. Sultangalieva}

1 ПРИОРИТЕТНОЙ ЗАДАЧЕЙ РОССИЙСКОЙ ВЛАСТИ ПРИ СТРОИТЕЛЬСТВЕ ИМПЕРИИ ЯВЛЯЛОСЬ АДМИНИСТРАТИВНО-ТЕРРИТОРИАЛЬНОЕ ОФОРМЛЕНИЕ НОВЫХ ПРОСТРАНСТВ ПОСРЕДСТВОМ ИНКОРПОРАЦИИ ТРАДИЦИОННЫХ ИНСТИТУТОВ УПРАВЛЕНИЯ В ЕДИНУЮ ПОЛИТИЧЕСКУЮ СИСТЕМУ ГОСУДАРСТВА. ЕСТЕСТВЕННО, ЧТО ПРИНЦИПЫ ФОРМИРОВАНИЯ АДМИНИСТРАТИВНОГО УСТРОЙСТВА И УПРАВЛЕНИЯ НА ИНОЭТНИЧНЫХ ТЕРРИТОРИЯХ (ВОЛГО-УРАЛЬСКИЙ РЕГИОН, КАВКАЗ, СИБИРЬ, КАЗАХСКАЯ СТЕПЬ И ДР.) ОТЛИЧАЛИСЬ ОТ ВНУТРИРОССИЙСКИХ ГУБЕРНИЙ ${ }^{1}$ ИМПЕРИИ. ВМЕСТЕ С ТЕМ, СОВРЕМЕННЫЕ ИССЛЕДОВАНИЯ ПОКАЗЫВАЮТ, ЧТО, НЕСМОТРЯ НА РАЗНЫЕ ПРИРОДНО-ГЕОГРАФИЧЕСКИЕ УСЛОВИЯ РЕГИОНОВ, ОСОБЕННОСТИ ОБРАЗА ЖИЗНИ, БЫТА, КУЛЬТУРЫ МЕСТНЫХ НАРОДОВ, УРОВЕНЬ СОЦИЛЬНО-ПОЛИТИЧЕСКОГО РАЗВИТИЯ, ПРАВИТЕЛЬСТВО ИСПОЛЬЗОВАЛО НА ПЕРЕХОДНОМ ЭТАПЕ СХОЖИЕ ФОРМЫ УПРАВЛЕНИЯ НА ОКРАИННЫХ ТЕРРИТОРИЯХ. К ПРИМЕРУ, ОКРУЖНАЯ СИСТЕМА УПРАВЛЕНИЯ (КАЗАХСКАЯ СТЕПЬ, СИБИРЬ, СЕВЕРНЫЙ КАВКАЗ), ${ }^{2}$ ИНСТИТУТ ПРИСТАВСТВА (СЕВЕРНЫЙ КАВКАЗ, КАЗАХСКАЯ СТЕПЬ), ПОПЕЧИТЕЛЬСТВО (ЮЖНЫЙ УРАЛ, КАЗАХСКАЯ СТЕПЬ) ${ }^{3}$, ИСПОЛЬЗОВАННЫЕ РОССИЙСКОЙ ВЛАСТЬЮ В РАЗНЫЕ ХРОНОЛОГИЧЕСКИЕ ПЕРИОДЫ ПО ОТНОШЕНИЮ К ЭТИМ РЕГИОНАМ ОКАЗАЛИСЬ ДЕЙСТВЕННЫМИ В ПРОЦЕССЕ ПОСТЕПЕННОЙ ИНТЕГРАЦИИ НАРОДОВ ЭТИХ ТЕРРИТОРИЙ В ЕДИНУЮ АДМИНИСТРАТИВНО-УПРАВЛЕНЧЕСКУЮ СИСТЕМУ ГОСУДАРСТВА. МНОГОЕ В РАЗРАБОТКЕ СТРАТЕГИИ ПРАВИТЕЛЬСТВА ПО ОТНОШЕНИЮ К МНОГОНАЦИОНАЛЬНЫМ ОКРАИНАМ ЗАВИСЕЛО ОТ ПЕРВЫХ ЛИЦ РЕГИОНАЛЬНЫХ АДМИНИСТРАЦИЙ (ГЕНЕРАЛ-ГУБЕРНАТОРСТВ $)^{4}$, КОТОРЫЕ НЕ ТОЛЬКО ПРОВОДИЛИ 
РЕШЕНИЯ ЦЕНТРА НА МЕСТАХ, НО И РАЗРАБАТЫВАЛИ ПЕРЕХОДНЫЕ ФОРМЫ УПРАВЛЕНИЯ, ВЫСТРАИВАЛИ РАЗНЫЕ УРОВНИ СОТРУДНИЧЕСТВА С ПРЕДСТАВИТЕЛЯМИ МЕСТНЫХ ЭЛИТ, СПОСОБСТВОВАЛИ ВКЛЮЧЕНИЮ ИХ В НОВУЮ АДМИНИСТРАТИВНУЮ СТРУКТУРУ 5 ПОСРЕДСТВОМ НАЗНАЧЕНИЯ ИХ НА СОЗДАВАЕМЫЕ ИМИ ДОЛЖНОСТИ И РАЗРАБОТКИ ОПРЕДЕЛЕННЫХ ГАРАНТИЙ ПО СОХРАНЕНИЮ ИХ ПРИВИЛЕГИРОВАННОГО ПОЛОЖЕНИЯ.

СЛОЖНОСТЬ ДЕЙСТВИЙ РОССИЙСКОЙ АДМИНИСТРАЦИИ В РЕГИОНАХ ОПРЕДЕЛЯЛАСЬ И ТЕМ, ЧТО НА ЕЕ ТЕРРИТОРИИ ПРОЖИВАЛО НАСЕЛЕНИЕ, В ЧАСТНОСТИ БАШКИРЫ (С СЕРЕДИНЫ XVI В.), ВОЛЖСКИЕ КАЛМЫКИ (С СЕРЕДИНЫ XVII В.), КАЗАХИ (30-Е ГОДЫ XVIII В.) КОТОРОЕ ОТЛИЧАЛОСЬ ХОЗЯЙСТВЕННО-КУЛЬТУРНЫМ ТИПОМ ОТ СЛАВЯНСКИХ, ФИННО-УГОРСКИХ И БОЛЬШЕЙ ЧАСТИ ТЮРКСКИХ (КАЗАНСКИЕ ТАТАРЫ, МИЩАРИ, ЧУВАШИ) НАРОДОВ ИМПЕРИИ. ЭТИ ОТЛИЧИЯ, В ПЕРВУЮ ОЧЕРЕДЬ, ЗАКЛЮЧАЛИСЬ В КОЧЕВОМ СКОТОВОДЧЕСКОМ ХОЗЯЙСТВЕ, КОТОРУЮ ВЕЛИ ЭТИ НАРОДЫ. И ДЛЯ РОССИЙСКОЙ АДМИНИСТРАЦИИ СЛОЖНЕЕ БЫЛО ВЫСТРОИТЬ ЛИНИЮ СОТРУДНИЧЕСТВА С ПРЕДСТАВИТЕЛЯМИ КОЧЕВОЙ КУЛЬТУРЫ, ЧЕЙ ОБРАЗ ЖИЗНИ ОПРЕДЕЛЯЛСЯ ТРАДИЦИЯМИ ПЛЕМЕННОГО (РОДОВОГО) СТРОЯ И ЗНАЧИТЕЛЬНО ОТЛИЧАЛСЯ ОТ ОСЕДЛОГО НАСЕЛЕНИЯ СООТВЕТСТВЕННО ЭТО НАВОДИТ НА РАЗМЫШЛЕНИЯ О ТОМ, КАКИЕ ПРИЕМЫ И МЕТОДЫ ИСПОЛЬЗОВАЛА РОССИЙСКАЯ ВЛАСТЬ В ПРОЦЕССЕ ФОРМИРОВАНИЯ НОВЫХ АДМИНИСТРАТИВНЫХ СВЯЗЕЙ С ПРЕДСТАВИТЕЛЯМИ РОДОВОЙ ЗНАТИ КОЧЕВЫХ НАРОДОВ, УНИФИКАЦИИ ИХ ТЕРРИТОРИЙ С ОСТАЛЬНОЙ ЧАСТЬЮ ГОСУДАРСТВА? ВЫЯСНЕНИЕ ДАННОГО ВОПРОСА ПОКАЗАЛО, ЧТО РАЗНЫЕ ОТПРАВНЫЕ ТОЧКИ ПРОЦЕССОВ ВКЛЮЧЕНИЯ КОЧЕВЫХ НАРОДОВ В ПОЛИТИЧЕСКУЮ СИСТЕМУ РОССИЙСКОЙ ИМПЕРИИ СПОСОБСТВОВАЛИ ТОМУ, ЧТО ПРИНЦИПЫ ИМПЕРСКОЙ ПРАКТИКИ ПЕРВОНАЧАЛЬНО БЫЛИ АПРОБИРОВАНЫ НА БАШКИРАХ ${ }^{7}$, КАЛМЫКАХ ${ }^{8}$, А ЗАТЕМ НЕСКОЛЬКО В ПРЕОБРАЗОВАННОМ ВИДЕ СТАЛИ ВНЕДРЯТЬСЯ В СОЦИАЛЬНОЕ ПРОСТРАНСТВО КАЗАХСКОЙ СТЕПИ. ЕСЛИ ПО ОТНОШЕНИЮ К БАШКИРАМ, РОССИЙСКИЕ ВЛАСТИ ОТ ПРАКТИКИ ЖЕСТКОГО ПОДАВЛЕНИЯ РЕГИОНАЛЬНОГО СЕПАРАТИЗМА И УНИЧТОЖЕНИЯ РОДОПЛЕМЕННОЙ ВЕРХУШКИ ПЕРЕШЛИ К КОМПРОМИССНОЙ СТРАТЕГИИ (СОЗДАНИЕ БАШКИРСКО-МЕЩЕРЯКСКОГО ВОЙСКА) И ВКЛЮЧЕНИЮ БАШКИРСКОЙ МЕСТНОЙ ЭЛИТЫ (КАНТОННЫЕ НАЧАЛЬНИКИ, ЮРТОВЫЕ СТАРШИНЫ) В СОСТАВНУЮ ЧАСТЬ РОССИЙСКОГО ЧИНОВНИЧЕСТВА, ТО ПО ОТНОШЕНИЮ К КАЛМЫКАМ И КАЗАХАМ ПРАВИТЕЛЬСТВО ИСПОЛЬЗОВАЛО БОЛЕЕ ГИБКИЕ СПОСОБЫ АДАПТАЦИИ НАСЕЛЕНИЯ К ИЗМЕНИВШИМСЯ УСЛОВИЯМ. ПРАВИТЕЛЬСТВО, УЖЕ ПОЛУЧИВ ОПЫТ ВЗАИМОДЕЙСТВИЯ С РОДОВОЙ ЗНАТЬЮ КОЧЕВЫХ НАРОДОВ ПОНИМАЛО, ЧТО КОМПРОМИССНАЯ ТАКТИКА УПРАВЛЕНИЯ МОЖЕТ ИМЕТЬ БОЛЬШИЙ УСПЕХ В ПРОЦЕССЕ ИХ ИНТЕГРАЦИИ, ЧЕМ НАСИЛЬСТВЕННЫЕ МЕТОДЫ. НЕ СЛУЧАЙНО, ЕКАТЕРИНА II В 1784-1792 ГГ. В УКАЗАХ СИМБИРСКОМУ И УФИМСКОМУ НАМЕСТНИКУ О.А. ИГЕЛЬСТРОМУ ОБ УЧРЕЖДЕНИИ ПЕРВЫХ АДМИНИСТРАТИВНЫХ УЧРЕЖДЕНИЙ В СТЕПИ (ПОГРАНИЧНОГО СУДА, ПОГРАНИЧНЫХ РАСПРАВ) ${ }^{9}$ ПРЕДЛАГАЛА СПОСОБЫ К « ДОБРОВОЛЬНОМУ СКЛОНЕНИЮ» ПРЕДСТАВИТЕЛЕЙ КАЗАХСКОЙ ЭЛИТЫ «В СЛУЖБУ ЗДЕШНЮЮ», « ПРИЛАСКАНИЮ САМЫХ НЕДОВОЛЬНЫХ» И НАКОНЕЦ, ПРИВЯЗАНИЮ ИХ» К ИМПЕРИИ ПОСРЕДСТВОМ НАДЕЛЕНИЯ ИХ ЧИНАМИ И ОПРЕДЕЛЕНИЯ ИМ ДЕНЕЖНОГО ЖАЛОВАНИЯ. ${ }^{10}$ СОЦИАЛЬНЫЕ ИНСТИТУТЫ КАЗАХСКИХ ХАНОВ, СУЛТАНОВ, БИЕВ, СТАРШИН ОКАЗАЛИСЬ В СФЕРЕ ИНТЕРЕСОВ РОССИЙСКОЙ ВЛАСТИ, ТАК КАК ПРИВЛЕЧЕНИЕ ИХ НА СЛУЖБУ ГОСУДАРЮ И ПРАВЯЩЕЙ ДИНАСТИИ ДАВАЛО ПРЯМОЙ КАНАЛ ВОЗДЕЙСТВИЯ НА ОСТАЛЬНОЕ МЕСТНОЕ НАСЕЛЕНИЕ И В КОНЕЧНОМ ИТО-ГЕ - КОНТРОЛЬ НАД ТЕРРИТОРИЕЙ КАЗАХСКИХ КОЧЕВИЙ. РОССИЙСКОЕ ПРАВИТЕЛЬСТВО В ТЕЧЕНИЕ ПОЧТИ СТОЛЕТИЯ (30-Е ГОДЫ XVIII - 20-Е ГОДЫ ХІХ ВВ.) ПРОЯВЛЯЛО ПРАГМАТИЗМ И ПОЛИТИЧЕСКУЮ 
ТЕРПИМОСТЬ В СВОИХ ВЗАИМООТНОШЕНИЯХ С ПРАВЯЩЕЙ ЭЛИТОЙ КАЗАХОВ, ИЗБЕГАЛО ПРЯМОГО АДМИНИСТРАТИВНОГО ДАВЛЕНИЯ, КОНФРОНТАЦИИ И ИСПОЛЬЗОВАЛО УЖЕ ТЕ АПРОБИРОВАННЫЕ ФОРМЫ (ПРИЕМЫ, ПЕРЕПИСКА, НАГРАЖДЕНИЕ ЦЕННЫМИ ПОДАРКАМИ, ДЕНЕЖНЫМИ ЗНАКАМИ, ОРДЕНАМИ, МЕДАЛЯМИ И ЧИНАМИ), КОТОРЫЕ ИМЕЛИ РЕЗУЛЬТАТ В ДРУГИХ КОЧЕВЫХ ОБЩЕСТВАХ.

3 А С ДРУГОЙ СТОРОНЫ, ОБРАЩАЕТ НА СЕБЯ И ТАКОЙ ФАКТ, ЧТО РОССИЙСКИЕ ВЛАСТИ НЕ ПРЕДПРИНИМАЛИ ШАГОВ ПО ИСПОЛЬЗОВАНИЮ КАЗАХОВ В ВОЕННЫХ ЭКСПЕДИЦИЯХ ИЛИ ВОЕННОЙ СЛУЖБЕ, ХОТЯ ОСОБЕННОСТИ ИХ ЖИЗНИ И БЫТА, « НЕУТОМИМОСТЬ В СТЕПНЫХ ПОХОДАХ» БЫЛИ АНАЛОГИЧНЫ БАШКИРАМ ( ПЕРЕВЕДЕНЫ В ВОЕННОЕ СОСЛОВИЕ) И КАЛМЫКАМ.

4 В case study КАЗАХСКОЙ СТЕПИ РОССИЙСКИЕ ВЛАСТИ ПОШЛИ ДАЛЬШЕ ПО РАЗВИТИЮ КОМПРОМИССНОЙ СТРАТЕГИИ СОТРУДНИЧЕСТВА С КАЗАХСКИМ НАСЕЛЕНИЕМ. ОНИ ИСПОЛЬЗОВАЛИ ИСТОРИЧЕСКИЙ ОПЫТ ВЗАИМООБЩЕНИЯ КАЗАХОВ С СОСЕДНИМИ ТЮРКО-МУСУЛЬМАНСКИМИ НАРОДАМИ (ВОЛЖСКИЕ ТАТАРЫ, БАШКИРЫ, МИШАРИ) В КАЧЕСТВЕ ЕСТЕСТВЕННЫХ ПОСРЕДНИКОВ МЕЖДУ РОССИЙСКОЙ АДМИНИСТРАЦИЕЙ И СТЕПЬЮ С ПОСЛЕДНЕЙ ЧЕТВЕРТИ ХVIII - СЕРЕДИНЫ ХІХ ВВ. ${ }^{11}$ В РЕЗУЛЬТАТЕ ТАТАРСКИЕ ПЕРЕ-ВОДЧИКИ, ТОЛМАЧИ КАНЦЕЛЯРИИ РЕГИОНАЛЬНЫХ АДМИНИСТРАЦИЙ, ПИСЬМОВОДИТЕЛИ И МУЛЛЫ, СЛУЖАЩИЕ У КАЗАХСКИХ ХАНОВ, СУЛТАНОВ, СТАРШИН УЧАСТВОВАЛИ НА ПЕРЕГОВОРАХ ПРАВЯЩЕЙ КАЗАХСКОЙ ЭЛИТЫ С РОССИЙСКОЙ ВЛАСТЬЮ. КРОМЕ ТОГО, ОНИ, КАК ДОЛЖНОСТНЫЕ ЛИЦА НЕОДНОКРАТНО ВЫЕЗЖАЛИ В КАЗАХСКИЕ КОЧЕВЬЯ, УЧАСТВОВАЛИ В РАЗРЕШЕНИИ КОНФЛИКТНЫХ СИТУАЦИЙ МЕЖДУ КАЗАХАМИ И ПРИЛИНЕЙНЫМИ ЖИТЕЛЯМИ, ДАВАЛИ «НАСТАВЛЕНИЯ» И ЗНАКОМИЛИ МЕСТНОЕ НАСЕЛЕНИЕ С НОВОЙ ПОЛИТИЧЕСКОЙ КУЛЬТУРОЙ ИМПЕРИИ. ${ }^{12}$ В СВОЮ ОЧЕРЕДЬ, КАЗАХСКАЯ ЗНАТЬ В ПРОЦЕССЕ ОБЩЕНИЯ И СОТРУДНИЧЕСТВА СО СВОИМИ ЕДИНОВЕРЦАМИ-ЧИНОВНИКАМИ РОССИЙСКОЙ ИМПЕРИИ УВИДЕЛИ МОДЕЛЬ, ДАЮЩУЮ ВОЗМОЖНОСТЬ НЕ ТОЛЬКО СОХРАНЕНИЯ СВОЕГО ВЛИЯНИЯ У СОРОДИЧЕЙ, СТАТУСА В ОБЩЕСТВЕ, НО И СПОСОБ ПОЛУЧЕНИЯ ПРИЗНАНИЯ И ПРИВИЛЕГИЙ УЖЕ ОТ НОВЫХ ВЛАСТНЫХ СТРУКТУР, А ИМЕННО РОССИЙСКОЙ АДМИНИСТРАЦИИ. ИМЕННО КАЗАХСКАЯ ПРАВЯЩАЯ ЭЛИТА СТАЛИ СВИДЕТЕЛЯМИ ПРОДВИЖЕНИЯ ТАТАРСКИХ ПЕРЕВОДЧИКОВ И ТОЛМАЧЕЙ ПО СЛУЖЕБНОЙ ЛЕСТНИЦЕ, НАГРАЖДЕНИЯ ИХ, КАК РОССИЙСКИХ ЧИНОВНИКОВ, ОРДЕНАМИ И МЕДАЛЯМИ СООТВЕТСТВЕННО «ТАБЕЛЮ О РАНГАХ» ${ }^{13}$ И ВХОЖДЕНИЯ ИХ В ВЫСШЕЕ СОСЛОВИЕ РОССИЙСКОЙ ИМПЕРИИ - ПОТОМСТВЕННОЕ И ЛИЧНОЕ ДВОРЯНСТВО. ${ }^{14}$

5 КАК МЫ ВИДИМ, ПРОЦЕСС И ФОРМЫ СОТРУДНИЧЕСТВА РОССИЙСКОЙ АДМИНИСТРАЦИИ С КАЗАХСКОЙ ЭЛИТОЙ ЯВЛЯЛОСЬ, С ОДНОЙ СТОРОНЫ, ЧАСТЬЮ ОБЩЕГО ВОПРОСА ИНТЕГРАЦИИ НЕРУССКОГО НАСЕЛЕНИЯ В ГОСУДАРСТВЕННУЮ СИСТЕМУ МНОГОНАЦИОНАЛЬНОЙ ИМПЕРИИ, А С ДРУГОЙ СТОРОНЫ - ИМЕЛО СВОИ ОТЛИЧИЯ, ЗАКЛЮЧАВШИЕСЯ В СОЗДАНИИ СЕТИ НОВЫХ ДОЛЖНОСТЕЙ В АДМИНИСТРАТИВНОЙ СИСТЕМЕ УПРАВЛЕНИЯ, УСТАНОВЛЕНИИ АТРИБУТОВ КАЗАХСКОГО ЧИНОВНИКА РОССИЙСКОЙ СЛУЖБЫ: КАЗЕННОЕ ЖАЛОВАНИЕ, ОФИЦЕРСКИЙ ЧИН, ПРАВО НОШЕНИЯ МУНДИРА И ЗНАКОВ ОТЛИЧИЯ, НАГРАДЫ. ЭТИ ОТЛИЧИЯ ОТРАЖАЮТ ХАРАКТЕР СОЦИАЛЬНОЙ АДАПТАЦИИ КАЗАХСКОГО КОЧЕВОГО ОБЩЕСТВА К НОВЫМ ИЗМЕНИВШИМСЯ УСЛОВИЯМ НА ПРОТЯЖЕНИИ ХІХ В. НЕСМОТРЯ НА ТО, ЧТО В КАЗАХСТАНСКОЙ ИСТОРИОГРАФИИ ДОСТАТОЧНО ПОЛНО РАЗРАБОТАНА СТРУКТУРА АДМИНИСТРАТИВНОГО УСТРОЙСТВА КАЗАХСКОЙ СТЕПИ В ХІХ В. ${ }^{15}$, ВОПРОС КООПТАЦИИ ПРЕДСТАВИТЕЛЕЙ 
КАЗАХСКОГО НАСЕЛЕНИЯ В СОСТАВ РОССИЙСКОГО ЧИНОВНИЧЕСТВА, ФОРМИРОВАНИЕ КАДРОВОЙ ПОЛИТИКИ РЕГИОНАЛЬНЫХ И ЦЕНТРАЛЬНЫХ ВЛАСТЕЙ В ПРОЦЕССЕ ИНТЕГРИРОВАНИЯ КАЗАХСКОГО КОЧЕВОГО ОБЩЕСТВА В ЕДИНОЕ АДМИНИСТРАТИВНО -ПРАВОВОЕ ПРОСТРАНСТВО ИМПЕРИИ ПРАКТИЧЕСКИ ОСТАЛСЯ ВНЕ ВНИМАНИЯ. В КАЗАХСТАНСКОЙ ИСТОРИОГРАФИИ БОЛЬШЕ УДЕЛЯЛОСЬ ВНИМАНИЕ ПРОЦЕССУ РАСПРОСТРАНЕНИЯ СВЕТСКОГО ОБРАЗОВАНИЯ И ФОРМИРОВАНИЯ КАЗАХСКОЙ ИНТЕЛЛИГЕНЦИИ ${ }^{16}$, ИХ НАУЧНОЙ И ОБЩЕСТВЕННО-ПОЛИТИЧЕСКОЙ ДЕЯТЕЛЬНОСТИ ${ }^{17}$, ХОТЯ МНОГИЕ ИЗ НИХ НАХОДИЛИСЬ НА СЛУЖБЕ В РЕГИОНАЛЬНЫХ ОРГАНАХ УПРАВЛЕНИЯ (ОРЕНБУРГСКОЕ, ЗАПАДНО-СИБИРСКОЕ И ТУРКЕСТАНСКОЕ ГЕНЕРАЛ-ГУБЕРНАТОРСТВА). ЛИШЬ В ПОСЛЕДНИЕ ДЕСЯТИЛЕТИЯ ПОЯВИЛИСЬ РАБОТЫ ПО ФОРМИРОВАНИЮ КАЗАХСКОГО ЧИНОВНИЧЕСТВА ОРЕНБУРГСКОГО ВЕДОМСТВА ${ }^{18}$, МЕСТНОГО САМОУПРАВЛЕНИЯ В ТУРКЕСТАНСКОМ РЕГИОНЕ ${ }^{19}$, КОГДА ЛЕГИТИМНОСТЬ ВЛАСТИ КАЗАХСКОЙ ЭЛИТЫ СТАЛА ОПРЕДЕЛЯТЬСЯ РОССИЙСКИМИ ВЛАСТЯМИ, А НЕ ТРАДИЦИЯМИ ОБЩИННОГО САМОУПРАВЛЕНИЯ.

ОПРЕДЕЛЕННЫЙ ВКЛАД В ИЗУЧЕНИЕ КАЗАХСКОГО ЧИНОВНИЧЕСТВА РОССИЙСКОЙ ИМПЕРИИ ВНОСИТ СБОРНИК ДОКУМЕНТОВ «О ПОЧЕТНЕЙШИХ И ВЛИЯТЕЛЬНЕЙШИХ ОРДЫНЦАХ», АККУМУЛИРОВАВШИЙ ПОСЛУЖНЫЕ И ФОРМУЛЯРНЫЕ СПИСКИ КАЗАХОВ ОРЕНБУРГСКОГО, СИБИРСКОГО ВЕДОМСТВ, СТЕПНОГО ГЕНЕРАЛ-ГУБЕРНАТОРСТВА ИЗ ФОНДОВ ЦЕНТРАЛЬНОГО ГОСУДАРСТВЕННОГО АРХИВА РЕСПУБЛИКИ КАЗАХСТАН ${ }^{20}$. ОПУБЛИКОВАННЫЕ ФОРМУЛЯРНЫЕ СПИСКИ СВИДЕТЕЛЬСТВОВАЛИ О ТОМ, ЧТО НА КАЗАХСКИХ ЧИНОВНИКОВ БЫЛИ РАСПРОСТРАНЕНЫ ОБЩЕРОССИЙСКИЕ СТАНДАРТЫ ДЕЛОПРОИЗВОДСТВА. ЭТИ ДОКУМЕНТЫ ПОЗВОЛИЛИ УВИДЕТЬ УЧАСТИЕ СУЛТАНОВ, СТАРШИН, БИЕВ В ВАЖНЫХ МЕРОПРИЯТИЯХ ОБЩЕРОССИЙСКОГО И МЕСТНОГО МАСШТАБА В ПРОЦЕССЕ РЕФОРМИРОВАНИЯ СТЕПИ И ВЫПОЛНЕНИЯ ИМИ РАЗНЫХ ПОРУЧЕНИЙ РЕГИОНАЛЬНОЙ АДМИНИСТРАЦИИ, ПРОЦЕСС НАГРАЖДЕНИЯ ОРДЕНАМИ, МЕДАЛЯМИ, ДЕНЕЖНЫМИ ПОСОБИЯМИ ЗА ИСПОЛНЕНИЕ ИМИ ДОЛЖНОСТНЫХ ОБЯЗАННОСТЕЙ. СОВОКУПНОСТЬ ДОКУМЕНТОВ (МАТЕРИАЛЫ ОФИЦИАЛЬНОГО ДЕЛОПРОИЗВОДСТВА, ДОКУМЕНТЫ ЛИЧНОГО ПРОИСХОЖДЕНИЯ, МАТЕРИАЛЫ ПЕРИОДИЧЕСКОЙ ПЕЧАТИ И ДР.), ЗАФИКСИРОВАВШИЕ АДМИНИСТРАТИВНЫЙ ОПЫТ КАЗАХОВ, НАХОДИВШИХСЯ НА ДОЛЖНОСТЯХ В СИСТЕМЕ ПОГРАНИЧНОГО ИЛИ МЕСТНОГО УПРАВЛЕНИЯ, БЫЛИ СОБРАНЫ В СБОРНИКЕ « КАЗАХСКИЕ ЧИНОВНИКИ НА СЛУЖБЕ РОССИЙСКОЙ ИМПЕРИИ» ${ }^{21}$.

7 НА ОСНОВЕ СИНТЕЗА ИСТОРИЧЕСКОЙ ЛИТЕРАТУРЫ И ДОКУМЕНТАЛЬНЫХ МАТЕРИАЛОВ МНОЮ ПРЕДПРИНЯТ АНАЛИЗ МЕХАНИЗМА КООПТАЦИИ КАЗАХСКОЙ ЭЛИТЫ НА ГОСУДАРСТВЕННУЮ СЛУЖБУ В ХІХ В., ПОСТЕПЕННОЙ СМЕНЫ ПРИОРИТЕТОВ ПОЛИТИКИ РОССИЙСКОГО ПРАВИТЕЛЬСТВА В СОЦИО-КУЛЬТУРНОЙ ЖИЗНИ КАЗАХСКОГО КОЧЕВОГО ОБЩЕСТВА, ПРЕДСТАВЛЯВШЕЕ СОБОЙ НЕ ЕДИНОЕ ПРОСТРАНСТВО, А ТРИ ЧАСТИ: МЛАДШИЙ, СРЕДНИЙ И СТАРШИЙ ЖУЗЫ, КАЖДОЕ ИЗ КОТОРЫХ УПРАВЛЯЛОСЬ ЧЕРЕЗ ХАНА, ИЗБИРАЕМОГО В ДАННОМ ЖУЗЕ, СУЛТАНОВ, БИЕВ И СТАРШИН ВО ГЛАВЕ РОДО-ПЛЕМЕННЫХ ОБЪЕДИНЕНИЙ. РОССИЙСКИЕ ВЛАСТИ ДОЛЖНЫ БЫЛИ ВЫСТРАИВАТЬ СВОИ ПРАКТИКИ И ИНСТРУМЕНТЫ УПРАВЛЕНИЯ ИСХОДЯ ИЗ СПЕЦИФИКИ КАЖДОГО РЕГИОНА СТЕПИ. ОТКРЫТЫМ ОСТАЕТСЯ И ВОПРОС О ТОМ, КАК ВОСПРИНИМАЛИ СВОИ ДОЛЖНОСТИ, НОВЫЕ АТРИБУТЫ РОССИЙСКОЙ ВЛАСТИ КАЗАХСКИЕ ЧИНОВНИКИ, КАК ПРОТИВОРЕЧИВО РАЗВИВАЛИСЬ ИХ ПРЕДСТАВЛЕНИЯ В ПОПЫТКЕ СОХРАНЕНИЯ ИМИ АДМИНИСТРАТИВНЫХ РЕСУРСОВ ВЛИЯНИЯ НА СВОИХ СОРОДИЧЕЙ И ПРИВИЛЕГИРОВАННОГО ПОЛОЖЕНИЯ В КОЧЕВОМ ОБЩЕСТВЕ. 


\section{Должности, жалование казахских чиновников}

РЕФОРМИРОВАНИЕ РОССИЙСКИМ ПРАВИТЕЛЬСТВОМ ВСЕХ ИНСТИТУТОВ ВЛАСТИ В КАЗАХСКОЙ СТЕПИ, ПРЕДПРИНЯТОЕ В 20-Х ГОДАХ ХІХ В., ПОСЛУЖИЛО НАЧАЛОМ ФОРМИРОВАНИЮ ШТАТНЫХ ДОЛЖНОСТЕЙ В СИСТЕМЕ МЕСТНОГО УПРАВЛЕНИЯ, ОПРЕДЕЛЕНИЮ ИХ ПОЛНОМОЧИЙ, РАЗМЕРА КАЗЕННОГО ЖАЛОВАНИЯ. КЛЮЧЕВЫМ МОМЕНТОМ В ПРОВОДИМОЙ РОССИЙСКИМ ПРАВИТЕЛЬСТВОМ ПОЛИТИКЕ РЕФОРМ В СТЕПИ СТАЛО УПРАЗДНЕНИЕ ХАНСКОЙ ВЛАСТИ, ПЕРВОНАЧАЛЬНО В СРЕДНЕМ ЖУЗЕ (1822)22, А ЧЕРЕЗ ДВА ГОДА В МЛАДШЕМ (1824). СОЦИАЛЬНОЙ ОПОРОЙ ПРИ СОЗДАНИИ ПЕРЕХОДНОЙ ФОРМЫ УПРАВЛЕНИЯ КАЗАХАМИ РОССИЙСКИЕ ВЛАСТИ ОПРЕДЕЛИЛИ СУЛТАНОВ, КАК ПРЕДСТАВИТЕЛЕЙ «ВЫСШЕГО НАСЛЕДСТВЕННОГО СОСЛОВИЯ» НА ПРОТЯЖЕНИИ СТОЛЕТИЙ В КАЗАХСКОМ КОЧЕВОМ ОБЩЕСТВЕ. ЗНАКОВЫМ В ПОЛИТИКЕ РОССИЙСКОЙ ВЛАСТИ ЯВИЛАСЬ И ПОПЫТКА ОПРЕДЕЛИТЬ ПОЛОЖЕНИЕ КАЗАХСКИХ СУЛТАНОВ ${ }^{23}$ В СОСЛОВНОЙ СИСТЕМЕ РОССИЙСКОЙ ИМПЕРИИ ЕЩЕ В ПОСЛЕДНЕЙ ЧЕТВЕРТИ ХVIIІВ. ТАК, ЕКАТЕРИНА II СЧИТАЛА, ЧТО КАЗАХСКИЕ СУЛТАНЫ МОГЛИ БЫТЬ ПОЧИТАЕМЫ ЗА КНЯЗЕЙ» (УКАЗ ОТ 14 МАРТА 1776 Г.). ${ }^{24}$ В РЕЗУЛЬТАТЕ В 20-Х ГОДАХ ХІХВ. ДЛЯ КАЗАХСКИХ СУЛТАНОВ В СТРУКТУРЕ СРЕДНЕГО ЗВЕНА МЕСТНОГО УПРАВЛЕНИЯ БЫЛИ СОЗДАНЫ ДОЛЖНОСТИ « СТАРШЕГО СУЛТАНА» (СРЕДНИЙ ЖУЗ) И « СУЛТАНА-ПРАВИТЕЛЯ» (МЛАДШИЙ ЖУЗ). БОЛЕЕ ТОГО, В ПАРАГРАФЕ 16, ГЛАВЫ 2 УСТАВА О СИБИРСКИХ КАЗАХАХ (1822) БЫЛО ОБОЗНАЧЕНО, ЧТО ВОЛОСТИ УПРАВЛЯЮТСЯ ТОЛЬКО СУЛТАНАМИ ${ }^{25}$. ПРАВО НА ДОЛЖНОСТЬ СТАРШЕГО СУЛТАНА В ПЕРВУЮ ОЧЕРЕДЬ БЫЛО ДАНО ПОТОМКАМ ХАНСКИХ ДИНАСТИЙ - АБЫЛАЯ И БУКЕЯ, А НА ДОЛЖНОСТЬ СУЛТАНА-ПРАВИТЕЛЯ - ПОТОМКАМ ФАМИЛИИ ХАНА МЛАДШЕГО ЖУЗА АБУЛХАИРА. СВИДЕТЕЛЬСТВОМ СОХРАНЕНИЯ ВНЕШНИХ ФОРМ ТРАДИЦИОННОЙ СИСТЕМЫ ВЛАСТИ В СТЕПИ СТАЛ И СПЕЦИАЛЬНЫЙ ЦЕРЕМОНИАЛ, УТВЕРЖДАЕМЫЙ ГЕНЕРАЛ-ГУБЕРНАТОРАМИ И РАЗРАБОТАННЫЙ ПО АНАЛОГИИ С ПРОЦЕДУРОЙ ИЗБРАНИЯ КАЗАХСКИХ ХАНОВ, НО ПРОВОДИМЫЙ ПРИ ВОЗВЕДЕНИИ НА ДОЛЖНОСТЬ СУЛТАНА ПРАВИТЕЛЯ ${ }^{26}$. ЭТИМ САМЫМ РОССИЙСКОЕ ПРАВИТЕЛЬСТВО ИСПОЛЬЗОВАЛО ТРАДИЦИОННОЕ УВАЖЕНИЕ КОЧЕВОГО ОБЩЕСТВА К ПОТОМКАМ ХАНСКИХ ДИНАСТИЙ, НО В ДЕЙСТВИТЕЛЬНОСТИ СТАРШИЕ СУЛТАНЫ, СУЛТАНЫ-ПРАВИТЕЛИ СТАНОВИЛИСЬ УЖЕ «МЕСТНЫМИ ЧИНОВНИКАМИ, ДЛЯ УПРАВЛЕНИЯ НАРОДОВ ПОСТАВЛЕННЫЕ», КОТОРЫЕ УТВЕРЖДАЛИСЬ В ДОЛЖНОСТИ ЗАПАДНО-СИБИРСКИМ И ОРЕНБУРГСКИМ ГЕНЕРАЛ-ГУБЕРНАТОРАМИ. С ЭТОГО ВРЕМЕНИ ВЫСШЕЕ ЗВЕНО В УПРАВЛЕНИИ КАЗАХСКИМ НАСЕЛЕНИЕМ СТАЛО ПРИНАДЛЕЖАТЬ РОССИЙСКОМУ ГОСУДАРСТВЕННОМУ АППАРАТУ В ЛИЦЕ ГЕНЕРАЛ-ГУБЕРНАТОРОВ, НАЗНАЧАЕМЫХ РОССИЙСКИМ ИМПЕРАТОРОМ. КАЗАХИ МЛАДШЕГО ЖУЗА БЫЛИ ОТНЕСЕНЫ К КОМПЕТЕНЦИИ ОРЕНБУРГСКОГО ГЕНЕРАЛ-ГУБЕРНАТОРА И ПРЕДСЕДАТЕЛЯ ОРЕНБУРГСКОЙ ПОГРАНИЧНОЙ КОМИССИИ ${ }^{27}$, А НАСЕЛЕНИЕ СРЕДНЕГО ЖУЗА В ВЕДЕНИИ ЗАПАДНО-СИБИРСКОГО ГЕНЕРАЛ-ГУБЕРНАТОРА И НАЧАЛЬНИКА ОМСКОЙ ОБЛАСТИ (В 1822-1838), А, ПОЗДНЕЕ, - НАЧАЛЬНИКА ПОГРАНИЧНОГО УПРАВЛЕНИЯ СИБИРСКИМИ КАЗАХАМИ (В 1838-1868). ${ }^{28}$

ВМЕСТЕ С ТЕМ ИДЕЯ РОССИЙСКОГО ПРАВИТЕЛЬСТВА ОПИРАТЬСЯ ТОЛЬКО НА СУЛТАНСКОЕ СОСЛОВИЕ В ДЕЙСТВИТЕЛЬНОСТИ НЕ БЫЛА РЕАЛИЗОВАНА. ТАК, ЗА 1824-1868 ГГ. НА ДОЛЖНОСТИ СТАРШИХ СУЛТАНОВ КАЗАХОВ ЗАПАДНО-СИБИРСКОГО ВЕДОМСТВА НАХОДИЛОСЬ 43 ЧЕЛОВЕКА, ИЗ НИХ 16 БЫЛИ НЕ СУЛТАНСКОГО ПРОИСХОЖДЕНИЯ. К ПРИМЕРУ, ЗА 1832-1868 ГГ. ИЗ 9 ИЗБРАННЫХ СТАРШИХ СУЛТАНОВ БАЯН-АУЛЬСКОГО 
ВНЕШНЕГО ОКРУГА 5 ВЛИЯТЕЛЬНЫХ БИЕВ И СТАРШИН (ШОН ЕДИГИН, ШОРМАН КУЧУКОВ, БЕРДАЛЫ КАЗАНГАПОВ, КАЗАНГАП САТЫБАЛДИН, МУСА ЧОРМАНОВ) БЫЛИ УТВЕРЖДЕНЫ В ДОЛЖНОСТИ, НЕСМОТРЯ НА ТО, ЧТО НЕ ИМЕЛИ СУЛТАНСКОГО ТИТУЛА. ЯРКИМ ПРИМЕРОМ МОЖЕТ БЫТЬ И КАРЬЕРА СТАРШИНЫ ДЖИЛГАРА БАЙТОКИНА, СТАРШЕГО СУЛТАНА КОКЧЕТАВСКОГО ОКРУЖНОГО ПРИКАЗА (1839-1841), ПОЛУЧИВШЕГО ЗВАНИЕ ПОТОМСТВЕННОГО ДВОРЯНИНА РОССИЙСКОЙ ИМПЕРИИ В 1849 Г. 29 ЭТА СИСТЕМА НЕ СОБЛЮДАЛАСЬ И НА НИЗОВОМ ЗВЕНЕ УПРАВЛЕНИЯ (ВОЛОСТИ). ТАК, В 1839 Г. ИЗ 16 ВОЛОСТНЫХ УПРАВИТЕЛЕЙ АКМОЛИНСКОГО ВНЕШНЕГО ОКРУГА БЫЛО ТОЛЬКО 4 СУЛТАНА, А В КОКЧЕТАВСКОМ ОКРУГЕ ИЗ 9 УПРАВИТЕЛЕЙ ТОЛЬКО ТРОЕ ОТНОСИЛИСЬ К СУЛТАНСКОМУ СОСЛОВИЮ. ${ }^{30}$ К 1860 ГОДАМ, ПО ДАННЫМ СОВЕТА ОБЛАСТНОГО УПРАВЛЕНИЯ СИБИРСКИМИ КАЗАХАМИ, ИЗ 77 ВОЛОСТНЫХ УПРАВИТЕЛЕЙ ТОЛЬКО 11 БЫЛИ СУЛТАНАМИ ${ }^{31}$.

В ТО ЖЕ ВРЕМЯ СУЛТАНЫ НА ТЕРРИТОРИИ ОБЛАСТИ ОРЕНБУРГСКИХ КАЗАХОВ ИМЕЛИ БОЛЕЕ СИЛЬНЫЕ ПОЗИЦИИ. ЗА 1824-1869 ГГ. НА ДОЛЖНОСТИ СУЛТАНА-ПРАВИТЕЛЕЙ ЧАСТЕЙ КАЗАХОВ ОРЕНБУРГСКОГО ВЕДОМСТВА НАХОДИЛИСЬ 16 ЧЕЛОВЕК, ВСЕ ОТНОСИЛИСЬ К СУЛТАНСКОМУ СОСЛОВИЮ. АНАЛИЗ ПОСЛУЖНЫХ СПИСКОВ ДИСТАНОЧНЫХ НАЧАЛЬНИКОВ ${ }^{32}$ ОРЕНБУРГСКОГО ВЕДОМСТВА (НИЗОВОЕ ЗВЕНО УПРАВЛЕНИЯ) ПОЗВОЛИЛ ОПРЕДЕЛИТЬ, ЧТО ЗА 1831-1869 ИЗ 52-Х НАЗНАЧЕННЫХ НА ДОЛЖНОСТЬ ДИСТАНОЧНЫХ НАЧАЛЬНИКОВ ОРЕНБУРГСКОГО ВЕДОМСТВА 25 ОТНОСИЛИСЬ К СУЛТАНСКОМУ СОСЛОВИЮ. В ОСНОВНОМ ВСЕ ОНИ ЯВЛЯЛИСЬ ПРЕДСТАВИТЕЛЯМИ ДИНАСТИИ ХАНОВ МЛАДШЕГО ЖУЗА НУРАЛЫ (ПРАВИЛ В 1748-1786), АЙШУАКА (1797-1805), СЕРГАЗЫ (1812-1824). ЭТИ ДАННЫЕ СВИДЕТЕЛЬСТВУЮТ О ТОМ, ЧТО СУЛТАНЫ НА ТЕРРИТОРИИ МЛАДШЕГО ЖУЗА ИГРАЛИ ЗНАЧИТЕЛЬНУЮ РОЛЬ В ЖИЗНИ КАЗАХОВ. ПРИЧИНА СЛОЖИВШЕЙСЯ СИТУАЦИИ КРЫЛАСЬ КАК В СОЗДАНИИ РАЗЛИЧНЫХ ФОРМ УПРАВЛЕНИЯ НА ТЕРРИТОРИИ МЛАДШЕГО ( РАЗДЕЛЕНИЕ НА ТРИ ЧАСТИ) И СРЕДНЕГО ЖУЗА (РАЗДЕЛЕНИЕ НА ВОСЕМЬ ВНЕШНИХ ОКРУГОВ), ТАК И В НЕОДИНАКОВЫХ ПРИНЦИПАХ НАЗНАЧЕНИЯ ДОЛЖНОСТНЫХ ЛИЦ. НА ТЕРРИТОРИИ СРЕДНЕГО ЖУЗА ВВОДИЛАСЬ СИСТЕМА ВЫБОРНОСТИ ДОЛЖНОСТНЫХ ЛИЦ. СТАРШИЙ СУЛТАН, УПРАВИТЕЛЬ ВОЛОСТИ ИЗБИРАЛИСЬ НА ТРИ ГОДА, НО ЗА НИМИ СОХРАНЯЛОСЬ ПРАВО ПЕРЕИЗБРАНИЯ НА ВТОРОЙ И СЛЕДУЮЩИЕ СРОКИ. НА ТЕРРИТОРИИ ОБЛАСТИ ОРЕНБУРГСКИХ КАЗАХОВ ТАКЖЕ ЮРИДИЧЕСКИ БЫЛА ЗАКРЕПЛЕНА ВЫБОРНОСТЬ ДОЛЖНОСТЕЙ, НО РЕАЛЬНО СЛОЖИЛАСЬ СИСТЕМА НАЗНАЧЕНИЯ НА ДОЛЖНОСТЬ СУЛТАНОВ-ПРАВИТЕЛЕЙ. В 1824 Г. ПРИ ОБСУЖДЕНИИ ВОПРОСА ВНЕДРЕНИЯ «УТВЕРЖДЕННОГО МНЕНИЯ КОМИТЕТА АЗИАТСКИХ ДЕЛ ОТНОСИТЕЛЬНО ПРЕОБРАЗОВАНИЯ УПРАВЛЕНИЯ ОРЕНБУРГСКИМ КРАЕМ» АЗИАТСКИЙ КОМИТЕТ ПРИЗНАЛ, ЧТО А ПО « ПО РАССТРОЕННОМУ СОСТОЯНИЮ ОРДЫ» ВЫБОРНАЯ СИСТЕМА НА ТЕРРИТОРИИ МЛАДШЕГО ЖУЗ МЕРА «НЕУДОБНАЯ» И ПРЕДЛОЖИЛ «ОПРЕДЕЛЯТЬ ИХ [СУЛТАНОВ-ПРАВИТЕЛЕЙ -Г.С.] ОТ ПРАВИТЕЛЬСТВА, НАЗНАЧИВ ИМЕННО ДОСТОЙНЕЙШИХ॥ ${ }^{33}$. ПО СУТИ, В ОБЛАСТИ КАЗАХОВ ОРЕНБУРГСКОГО ВЕДОМСТВА ИСПОЛЬЗОВАЛАСЬ ПРАКТИКА НАЗНАЧЕНИЯ НЕ ТОЛЬКО СУЛТАНОВ ПРАВИТЕЛЕЙ ВОСТОЧНОЙ, СРЕДНЕЙ И ЗАПАДНОЙ ЧАСТЕЙ, НО И ДИСТАНОЧНЫХ И МЕСТНЫХ НАЧАЛЬНИКОВ. СЛЕДУЮЩЕЕ ОТЛИЧИЕ ЗАКЛЮЧАЛОСЬ В ТОМ, ЧТО ВЛАСТЬ ПРАВИТЕЛЕЙ ЧАСТЕЙ КАЗАХОВ ОРЕНБУРГСКОГО ВЕДОМСТВА В ОТЛИЧИЕ ОТ СТАРШИХ СУЛТАНОВ ОКРУЖНЫХ ПРИКАЗОВ, НЕ БЫЛА ОГРАНИЧЕНА ВРЕМЕННЫМИ РАМКАМИ. К ПРИМЕРУ, БАЙМУХАМЕД АЙЧУВАКОВ УПРАВЛЯЛ ЗАПАДНОЙ ЧАСТЬЮ КАЗАХОВ ОРЕНБУРГСКОГО ВЕДОМСТВА 17 ЛЕТ (1830-1847), А МУХАММЕТГАЛИ ТАУКИН - 20 ЛЕТ (1847-1867). 
СУЛТАНА, КАК ПРЕДСЕДАТЕЛЯ КОРРЕЛИРОВАЛАСЬ ЧЕТЫРЬМЯ ЗАСЕДАТЕЛЯМИ (ДВА РУССКИХ ЧИНОВНИКА И ДВА ПРЕДСТАВИТЕЛЯ ОТ « ПОЧЕТНЫХ КАЗАХОВ» СРЕДНЕГО ЖУЗА) $)^{34}$. ПРИ ЭТОМ, КАЗАХСКИЕ ЗАСЕДАТЕЛИ ОКРУЖНЫХ ПРИКАЗОВ МОГЛИ В ЭКСТРЕННЫХ СЛУЧАЯХ ИСПОЛНЯТЬ ОБЯЗАННОСТИ СТАРШЕГО СУЛТАНА ${ }^{35}$. СУЩЕСТВОВАВШИЙ ПРИНЦИП КОЛЛЕГИАЛЬНОСТИ В СИСТЕМЕ УПРАВЛЕНИЯ СИБИРСКИМИ КАЗАХАМИ ВНОСИЛ ЗАМЕТНЫЕ ОТЛИЧИЯ В ХАРАКТЕР ДЕЯТЕЛЬНОСТИ СТАРШЕГО СУЛТАНА, ИБО ОН УЖЕ НЕ МОГ САМОСТОЯТЕЛЬНО УТВЕРЖДАТЬ ИЛИ ОТСТРАНЯТЬ ОТ ДОЛЖНОСТИ ВОЛОСТНЫХ УПРАВИТЕЛЕЙ В СВОЕМ ОКРУГЕ.

12 В ТО ЖЕ ВРЕМЯ ПРАВИТЕЛЬ ЧАСТЕЙ КАЗАХОВ ОРЕНБУРГСКОГО ВЕДОМСТВА ПРИНИМАЛ ЕДИНОЛИЧНЫЕ РЕШЕНИЯ, ПО ЕГО ЛИЧНЫМ РЕКОМЕНДАЦИЯМ НАЗНАЧАЛИСЬ ДИСТАНОЧНЫЕ И МЕСТНЫЕ НАЧАЛЬНИКИ, ЧТО СТАВИЛО ПОСЛЕДНИХ В ЗАВИСИМОЕ ПОЛОЖЕНИЕ ОТ ЕГО РЕШЕНИЯ. ПРИ СУЛТАНЕ-ПРАВИТЕЛЕ ИМЕЛАСЬ ДОЛЖНОСТЬ ПОМОЩНИКА, КОТОРУЮ ЗАНИМАЛИ В ОСНОВНОМ ПРЕДСТАВИТЕЛИ СУЛТАНСКОГО СОСЛОВИЯ, НО ОНИ НЕ ИМЕЛИ ПРАВО ГОЛОСА ПРИ ПРИНЯТИИ ТЕХ ИЛИ ИНЫХ РЕШЕНИЙ. ДОЛЖНОСТЬ ПОМОЩНИКА СУЛТАНА-ПРАВИТЕЛЯ БЫЛА БОЛЬШЕ СТАРТОВОЙ ПЛОЩАДКОЙ ДЛЯ ЗАНЯТИЯ В ПОСЛЕДУЮЩЕМ ДОЛЖНОСТИ ПРАВИТЕЛЯ ЧАСТИ ${ }^{36}$.

ДАЛЕЕ, «ПРИКАЗНАЯ» СИСТЕМА 1822 ГОДА ОХВАТИЛА АДМИНИСТРАТИВНЫМ УПРАВЛЕНИЕМ ВСЮ ТЕРРИТОРИЮ СРЕДНЕГО ЖУЗА, ВКЛЮЧАЯ АУЛЬНЫЕ И РОДОВЫЕ ЗВЕНЬЯ : СТАРШИЕ СУЛТАНЫ - В ОКРУГАХ, СУЛТАНЫ - В ВОЛОСТЯХ, СТАРШИНЫ ${ }^{37}$ - В АУЛАХ. ПРИ ЭТОМ ФОРМИРОВАНИЕ НОВЫХ ТЕРРИТОРИАЛЬНО-АДМИНИСТРАТИВНЫХ СТРУКТУР ПРОИСХОДИЛО ПОСТЕПЕННО НА ПРОТЯЖЕНИИ БОЛЕЕ 20 ЛЕТ (С 1824 ПО 1844 ГГ. $)^{38}$. ПРОНИЗЫВАНИЕ ВСЕЙ СТРУКТУРЫ СРЕДНЕГО ЖУЗА НОВЫМ УПРАВЛЕНИЕМ ОБУСЛОВИЛО ВЫБОР АДМИНИСТРАТИВНОГО ЦЕНТРА СОЗДАВАЕМЫХ ОКРУЖНЫХ ПРИКАЗОВ В ГЛУБИ СТЕПИ, В ЧАСТНОСТИ НА УРОЧИЩАХ КАРКАРАЛЫ, КАРАУТКОЛ, КОКБЕКТЫ И ДР. ${ }^{39}$ ЭТИМ САМЫМ РОССИЙСКИЕ ВЛАСТИ ФОРМИРОВАЛИ БАЗОВЫЕ ПУНКТЫ В ЦЕНТРЕ КАЗАХСКИХ КОЧЕВИЙ, ГДЕ СТАРШИЙ СУЛТАН ДОЛЖЕН БЫЛ СПОСОБСТВОВАТЬ « СОХРАНЕНИЮ ТИШИНЫ И ПОРЯДКА» СРЕДИ ПОДВЕДОМСТВЕННЫХ ЕМУ ЛЮДЕЙ. КРОМЕ ТОГО, ВЫБОР ЦЕНТРОВ ОКРУЖНЫХ ПРИКАЗОВ ПОЛОЖИЛ НАЧАЛО СОЗДАНИЮ СТАЦИОНАРНЫХ МЕСТ В КАЗАХСКИХ КОЧЕВЬЯХ, ГДЕ СОСРЕДОТОЧИВАЛИСЬ ТАКИЕ ОБЩЕСТВЕННО ЗНАЧИМЫЕ ОБЪЕКТЫ, КАК ДОМА ДЛЯ ОКРУЖНЫХ ПРИКАЗОВ, ПОЧТОВЫЕ СТАНЦИИ.

14 РАЗДЕЛЕНИЕ ЖЕ ТЕРРИТОРИИ МЛАДШЕГО ЖУЗА НА НОВЫЕ АДМИНИСТРАТИВНЫЕ ЧАСТИ ПРОИЗОШЛО ЕДИНОВРЕМЕННО И УТВЕРДИВШАЯСЯ «ПОГРАНИЧНАЯ» СИСТЕМА УПРАВЛЕНИЯ ПРОЯВИЛАСЬ В ТОМ, ЧТО АДМИНИСТРАТИВНЫЕ СТАВКИ СУЛТАНОВ-ПРАВИТЕЛЕЙ НАХОДИЛИСЬ ВДОЛЬ ПОГРАНИЧНОЙ ЛИНИИ, РЯДОМ С КРЕПОСТЯМИ И КАЗАЧЬИМИ СЕЛЕНИЯМИ. ТАК, СТАВКА СУЛТАНА-ПРАВИТЕЛЯ ВОСТОЧНОЙ ЧАСТИ РАСПОЛАГАЛАСЬ ПРОТИВ УСТ-УЙСКОЙ СТАНИЦЫ, СТАВКА ПРАВИТЕЛЯ ЗАПАДНОЙ ЧАСТИ МЕЖДУ СУХОРЕЧЕНСКИМ И ЗАТОННЫМ ФОРПОСТАМИ, СТАВКА ПРАВИТЕЛЯ СРЕДНЕЙ ЧАСТИ В ИЛЕЦКОЙ ЗАЩИТЕ ${ }^{40}$. И ТОЛЬКО СПУСТЯ СЕМЬ ЛЕТ (1831) НА ТЕРРИТОРИИ МЛАДШЕГО ЖУЗА БЫЛИ СОЗДАНЫ ДРОБНЫЕ АДМИНИСТРАТИВНО-ТЕРРИТОРИАЛЬНЫЕ ЕДИНИЦЫ - ЛИНЕЙНЫЕ И СТЕПНЫЕ ДИСТАНЦИИ ${ }^{41}$, АДМИНИСТРАТИВНЫЕ АУЛЫ ВО ГЛАВЕ С МЕСТНЫМИ НАЧАЛЬНИКАМИ ${ }^{42}$.

15 СТАРШИЕ СУЛТАНЫ В СРЕДНЕМ ЖУЗЕ И СУЛТАНЫ-ПРАВИТЕЛИ В МЛАДШЕМ ЖУЗЕ, ПОСТАВЛЕННЫЕ ВО ГЛАВЕ МЕСТНОГО УПРАВЛЕНИЯ, БЫЛИ НАДЕЛЕНЫ ИСПОЛНИТЕЛЬНОЙ

Cahiers du monde russe, 56/4 | 2015 
ВЛАСТЬЮ ОТ РУССКОГО ПРАВИТЕЛЬСТВА И СИМВОЛИЧЕСКИМИ ЗНАКАМИ ИМПЕРИИ ЗНАМЕНАМИ, ЗОЛОТЫМИ САБЛЯМИ И ГРАМОТОЙ « ДАБЫ ПРИДАТЬ ИМ ВЕСУ» В ГЛАЗАХ СОПЛЕМЕННИКОВ ${ }^{43}$. ИМ, КАК РОССИЙСКИМ ЧИНОВНИКАМ, ВЫПЛАЧИВАЛОСЬ ЖАЛОВАНИЕ В РАЗМЕРЕ 1200 РУБЛЕЙ СЕРЕБРОМ В ГОД, ДОПОЛНИТЕЛЬНО 60 ЧЕТВЕРТЕЙ РЖАНОЙ МУКИ. СТАРШИЕ СУЛТАНЫ И СУЛТАНЫ-ПРАВИТЕЛИ ПРИ ВСТУПЛЕНИИ В ДОЛЖНОСТЬ ПОЛУЧАЛИ ЧИН МАЙОРА РОССИЙСКОЙ СЛУЖБЫ И «НАРЯДУ С РОССИЙСКИМИ ДВОРЯНАМИ» ИМ БЫЛО ПРИСВОЕНО ПОЧЕТНОЕ ОБРАЩЕНИЕ «СТЕПЕНСТВО» ${ }^{44}$. И САМОЕ ГЛАВНОЕ, ПО ИСТЕЧЕНИИ ТРЕХ СРОКОВ СЛУЖБЫ ИМЕЛИ ПРАВО ПРОСИТЬ ДИПЛОМ НА ДВОРЯНСКОЕ ДОСТОИНСТВО РОССИЙСКОЙ ИМПЕРИИ. ОДНИМИ ИЗ ПЕРВЫХ ПОЛУЧИЛИ ДИПЛОМ НА ДВОРЯНСКОЕ ДОСТОИНСТВО СТАРШИЕ СУЛТАНЫ ЗАПАДНО-СИБИРСКОГО ГЕНЕРАЛ-ГУБЕРНАТОРСТВА ТУРСУН ЧИНГИЗОВ (КАРКАРАЛИНСКИЙ ОКРУЖНОЙ ПРИКАЗ), КОНЫР КУЛЬДЖА ХУДАЙМЕНДИН (АКМОЛИНСКИЙ ОКРУЖНОЙ ПРИКАЗ), ДЖИЛГАРЫ БАЙТОКИН (КОКЧЕТАВСКИЙ ОКРУЖНОЙ ПРИКАЗ). СРЕДИ СУЛТАНОВ-ПРАВИТЕЛЕЙ КАЗАХОВ ОРЕНБУРГСКОГО ВЕДОМСТВА ПЕРВЫМИ ВОШЛИ В СОСТАВ РОССИЙСКОГО ДВОРЯНСТВА БАЙМУХАМЕД АЙЧУВАКОВ (ЗАПАДНАЯ ЧАСТЬ ОРДЫ, 1837-1847) И МУХАМЕДЖАН БАЙМУХАМЕДОВ (СРЕДНЯЯ ЧАСТЬ ОРДЫ, 1855-1869), МУХАММЕД- ГАЛИ ТАУКИН (ЗАПАДНАЯ ЧАСТЬ ОРДЫ, 1847-1867) ${ }^{45}$.

НА ТЕРРИТОРИИ ВНУТРЕННЕЙ ОРДЫ ДОЛЖНОСТЬ СУЛТАНА-ПРАВИТЕЛЯ БЫЛА ВВЕДЕНА В 1855 Г., КОГДА БЫЛИ СОЗДАНЫ НОВЫЕ ТЕРРИТОРИАЛЬНО-АДМИНИСТРАТИВНЫЕ СТРУКТУРЫ, А ИМЕННО І-Й И ІІ-Й ПРИКАСПИЙСКИЕ ОКРУГА, ЗАНЯВШИЕ ПРОСТРАНСТВО НА ПОБЕРЕЖЬЕ КАСПИЙСКОГО МОРЯ, А ЧЕРЕЗ ПЯТЬ ЛЕТ К СЕВЕРУ ОТ ОКРУГОВ - ЧАСТИ : КАЛМЫЦКАЯ, ТОРГУНСКАЯ, ТАЛОВСКАЯ, КАМЫШ-САМАРСКАЯ, НАРЫНСКАЯ. ОКРУГА И ЧАСТИ ВОЗГЛАВЛЯЛ СУЛТАН-ПРАВИТЕЛЬ, УТВЕРЖДАВШИЙСЯ В ДОЛЖНОСТИ ПО РЕКОМЕНДАЦИИ ВРЕМЕННОГО СОВЕТА ОРЕНБУРГСКИМ ГЕНЕРАЛ-ГУБЕРНАТОРОМ. ВО ГЛАВЕ ЧАСТЕЙ В ОСНОВНОМ НАХОДИЛИСЬ СУЛТАНЫ ИЗ ДОМА БУКЕЙ-ХАНА. В ШТАТ ПРАВИТЕЛЯ ЧАСТИ ВХОДИЛИ ПОМОЩНИК, ДВА ВЕСТОВЫХ ${ }^{46}$.

В НИЗОВОМ ЗВЕНЕ МЕСТНОГО УПРАВЛЕНИЯ БЫЛИ СОЗДАНЫ СЛЕДУЮЩИЕ ДОЛЖНОСТИ : ВОЛОСТНЫЕ УПРАВИТЕЛИ (ОБЛАСТЬ СИБИРСКИХ КАЗАХОВ), ДИСТАНОЧНЫЕ НАЧАЛЬНИКИ (КАЗАХИ ОРЕНБУРГСКОГО ВЕДОМСТВА), АУЛЬНЫЕ СТАРШИНЫ (ОБЛАСТЬ СИБИРСКИХ КАЗАХОВ, ВНУТРЕННЯЯ ОРДА) И МЕСТНЫЕ НАЧАЛЬНИКИ (КАЗАХИ ОРЕНБУРГСКОГО ВЕДОМСТВА). ВСЕ ОНИ НАХОДИЛИСЬ В ПОДЧИНЕНИИ СООТВЕТСТВУЮЩЕМУ СТАРШЕМУ СУЛТАНУ ИЛИ СУЛТАНУ ПРАВИТЕЛЮ. В ОСНОВНОМ ЭТИ ДОЛЖНОСТИ ЗАНИМАЛИ ПРЕДСТАВИТЕЛИ РОДОВОЙ ЗНАТИ. ИСКЛЮЧЕНИЕ ДОЛЖНЫ БЫЛИ СОСТАВЛЯТЬ ВОЛОСТНЫЕ УПРАВИТЕЛИ НА ТЕРРИТОРИИ ОБЛАСТИ СИБИРСКИХ КАЗАХОВ, ГДЕ СОГЛАСНО § 16 УСТАВА О СИБИРСКИХ КАЗАХАХ ВОЛОСТЬЮ ДОЛЖНЫ БЫЛИ УПРАВЛЯТЬ СУЛТАНЫ, КОТОРЫЕ НА ОСНОВАНИИ § Б2ПОЛУЧАЛИ ЗВАНИЕ ЧИНОВНИКА 12 -ГО КЛАССА ${ }^{47}$. ДИСТАНОЧНЫМ И МЕСТНЫМ НАЧАЛЬНИКАМ ПРИСВАИВАЛСЯ ОРЕНБУРГСКИМ ГЕНЕРАЛ-ГУБЕРНАТОРОМ ЧИН ЗАУРЯДА, ЧТОБЫ « ПРИ ЗАНЯТИИ ДОЛЖНОСТИ ДАТЬ ИМ ОЧЕВИДНЫЕ ПРЕИМУЩЕСТВА ПРЕД ДРУГИМИ И ОСОБЕННОСТИ ДЛЯ ВНУШЕНИЯ КАЗАКАМ» 48. ЖАЛОВАНИЕ ИХ СОСТАВЛЯЛО ОТ 150 РУБЛЕЙ (ВОЛОСТНЫЕ) ДО 75-50 РУБЛЕЙ (ДИСТАНОЧНЫЕ НАЧАЛЬНИКИ) В ГОД ${ }^{49}$.

В ПЕРВОЙ ПОЛОВИНЕ ХІХ В. ДОЛЖНОСТИ ДЛЯ ПРЕДСТАВИТЕЛЕЙ КАЗАХСКОГО НАСЕЛЕНИЯ БЫЛИ ПРЕДСТАВЛЕНЫ И В СИСТЕМЕ ПОГРАНИЧНОГО УПРАВЛЕНИЯ. В ШТАТ ОРЕНБУРГСКОЙ ПОГРАНИЧНОЙ КОМИССИИ НАРЯДУ С РУССКИМИ ЧИНОВНИКАМИ БЫЛИ ВКЛЮЧЕНЫ И ЗАСЕДАТЕЛИ (ОДИН СУЛТАН И ДВОЕ СТАРШИН) ОТ ТРЕХ ПЛЕМЕННЫХ ОБЪЕДИНЕНИЙ 
МЛАДШЕГО ЖУЗА, КОТОРЫЕ ДОЛЖНЫ БЫЛИ ПРИНИМАТЬ «ПОЛНОЕ УЧАСТИЕ В РАЗБИРАТЕЛЬСТВЕ ДЕЛ» КАСАЮЩИХСЯ КАЗАХСКОГО НАСЕЛЕНИЯ ${ }^{50}$. ДОЛЖНОСТЬ КАЗАХСКИХ ЗАСЕДАТЕЛЕЙ ПОГРАНИЧНОЙ КОМИССИИ БЫЛА ВЫБОРНАЯ И ОПРЕДЕЛЕНА СРОКОМ НА ТРИ ГОДА, ХОТЯ ЭТИ УСЛОВИЯ НЕ СОБЛЮДАЛИСЬ, ЧАЩЕ ЗАСЕДАТЕЛИ ОСТАВАЛИСЬ НА СЛУЖБЕ ДОЛЬШЕ. ТАК, СУЛТАН ТАУКЕ АЙШУАКОВ, НАЗНАЧЕННЫЙ НА ДОЛЖНОСТЬ ЗАСЕДАТЕЛЯ В 1800 Г., А СУЛТАН НУРМУХАММЕТ АБЗЕЛИЛОВ В 1802 Г. ПРОСЛУЖИЛИ В ОБЩЕЙ СЛОЖНОСТИ В КОМИССИИ БОЛЕЕ 18 ЛЕТ. С ВВЕДЕНИЕМ НОВОГО ПОРЯДКА УПРАВЛЕНИЯ В КАЗАХСКИХ ЗЕМЛЯХ МЛАДШЕГО ЖУЗА (1824) ЗАСЕДАТЕЛЕЙ ОТ КАЗАХОВ СТАЛИ ОПРЕДЕЛЯТЬ НЕ ОТ ПОКОЛЕНИЙ, А ОТ ЧАСТЕЙ : ВОСТОЧНАЯ, СРЕДНЯЯ, ЗАПАДНАЯ. СОГЛАСНО РАСПОРЯЖЕНИЮ ОРЕНБУРГСКОГО ГУБЕРНАТОРА ОТ 25 ИЮЛЯ 1825 Г. №611 ЗАСЕДАТЕЛЯМИ МОГЛИ НАЗНАЧАТЬ ТЕПЕРЬ ТОЛЬКО СУЛТАНОВ ${ }^{51}$. ВТОРАЯ ОСОБЕННОСТЬ ЭТОГО ПЕРИОДА ЗАКЛЮЧАЛАСЬ В РАСШИРЕНИИ ДОЛЖНОСТНЫХ ФУНКЦИЙ КАЗАХСКИХ ЗАСЕДАТЕЛЕЙ КОМИССИИ. ТЕПЕРЬ, ОНИ НЕ ПРОСТО УЧАСТВОВАЛИ В РАССМОТРЕНИИ ДЕЛ КАЗАХОВ НА ЗАСЕДАНИЯХ КОМИССИИ, НО И КОМАНДИРОВАЛИСЬ НЕОДНОКРАТНО В КАЗАХСКИЕ КОЧЕВЬЯ ДЛЯ СБОРА КИБИТОЧНОЙ ПОДАТИ, ПРОВЕРКИ ДОСТОВЕРНОСТИ СВЕДЕНИЙ О КОЛИЧЕСТВЕ КИБИТОК, СКОТА, ПРЕДСТАВЛЯЕМЫХ ОТ СУЛТАНОВ-ПРАВИТЕЛЕЙ И ДИСТАНОЧНЫХ НАЧАЛЬНИКОВ, УТОЧНЯЛИ МЕСТА ДИСЛОКАЦИЙ ЗИМНИХ И ЛЕТНИХ ПАСТБИЩ, КОЧЕВЫЕ МАРШРУТЫ КАЗАХСКИХ РОДОВ. СООТВЕТСТВЕННО ИЗМЕНИЛОСЬ И ЖАЛОВАНИЕ КАЗАХСКИХ ЗАСЕДАТЕЛЕЙ, КОТОРОЕ ВЫРОСЛО ОТ 200 ДО 600 РУБЛЕЙ В ГОД И ВКЛЮЧАЛО ДОПОЛНИТЕЛЬНО ШЕСТЬ ЧЕТВЕРТЕЙ РЖАНОЙ МУКИ ${ }^{52}$.

19 В ШТАТЕ ПОГРАНИЧНОГО УПРАВЛЕНИЯ СИБИРСКИМИ КАЗАХАМИ (1838-1854) ПРЕДУСМАТРИВАЛОСЬ ЧЕТЫРЕ СОВЕТНИКА, ОДНУ ИЗ КОТОРЫХ ДОЛЖЕН БЫЛ ЗАНЯТЬ ПРЕДСТАВИТЕЛЬ ОТ КАЗАХСКОГО НАСЕЛЕНИЯ СРЕДНЕГО ЖУЗА, ИМЕВШИЙ УЖЕ ОПЫТ СЛУЖБЫ В КАЧЕСТВЕ ВОЛОСТНОГО УПРАВИТЕЛЯ ИЛИ СТАРШЕГО СУЛТАНА ОКРУЖНОГО ПРИКАЗА. ФУНКЦИИ СОВЕТНИКА БЫЛИ ТЕ ЖЕ, ЧТО И КАЗАХСКИХ ЗАСЕДАТЕЛЕЙ ОРЕНБУРГСКОЙ ПОГРАНИЧНОЙ КОМИССИИ ${ }^{53}$. НО, В ОТЛИЧИЕ ОТ КАЗАХСКИХ ЗАСЕДАТЕЛЕЙ ОРЕНБУРГСКОЙ ПОГРАНИЧНОЙ КОМИССИИ, СОВЕТНИКИ ОТ КАЗАХОВ СИБИРСКОГО ВЕДОМСТВА НЕ ВСЕГДА УЧАСТВОВАЛИ В ЗАСЕДАНИЯХ ПОГРАНИЧНОГО УПРАВЛЕНИЯ, ТАК КАК ЗАЧАСТУЮ ДОЛЖНОСТЬ ОСТАВАЛАСЬ ВАКАНТНОЙ. ЭТОТ ФАКТ ВЫЗВАЛ НЕГОДОВАНИЕ ЗАПАДНО-СИБИРСКОГО ГЕНЕРАЛ-ГУБЕРНАТОРА Г. ГАСФОРТА (1850-1861), ПРЕДЛАГАВШЕГО ПОГРАНИЧНОМУ УПРАВЛЕНИЮ УЛУЧШИТЬ РАБОТУ ПО ВЫБОРУ КАНДИДАТОВ НА ДОЛЖНОСТЬ СОВЕТНИКА « ИЗ ПОЧЕТНЫХ КАЗАХОВ, ИМЕЮЩИХ ЧИНЫ ${ }^{54}$. ДОЛЖНОСТЬ СОВЕТНИКА БЫЛА ВНЕДРЕНА С 1845 Г. И В ШТАТ ВРЕМЕННОГО СОВЕТА ПО УПРАВЛЕНИЮ ВНУТРЕННЕЙ ОРДОЙ. НА ЭТУ ДОЛЖНОСТЬ БЫЛИ НАЗНАЧЕНЫ СУЛТАНЫ ЧУКА НУРАЛИХАНОВ И МЕНГЛИ-ГИРЕЙ БУКЕЙХАНОВ ${ }^{55}$.

ОСОБЕННОСТЬ ТРАНСГРАНИЧНОГО ПОЛОЖЕНИЯ ВНУТРЕННЕЙ ОРДЫ (ГРАНИЧАЛА С ЦАРЕВСКИМ, ЕНОТАЕВСКИМ И КРАСНОЯРСКИМ УЕЗДАМИ АСТРАХАНСКОЙ ГУБЕРНИИ, НОВОУЗЕНСКИМ УЕЗДОМ САРАТОВСКОЙ ГУБЕРНИИ) ОБУСЛОВИЛА ВВЕДЕНИЕ ТАК НАЗЫВАЕМОЙ ДОЛЖНОСТИ « ДЕПУТАТА», КОТОРЫЕ КАК ПРЕДСТАВИТЕЛЬ КАЗАХСКОГО НАСЕЛЕНИЯ ПОГРАНИЧНЫХ УЕЗДОВ, ДОЛЖЕН БЫЛ РАЗРЕШАТЬ СПОРНЫЕ ВОПРОСЫ МЕЖДУ КАЗАХАМИ И РУССКИМ НАСЕЛЕНИЕМ, ЗАЩИЩАТЬ ИНТЕРЕСЫ КОЧЕВНИКОВ. ЭТА ДОЛЖНОСТЬ БЫЛА ВВЕДЕНА ЕЩЕ ПРИ УПРАВЛЕНИИ ХАНа ДЖАНГИРА (1823-1845), НО С СЕРЕДИНЫ 40-Х ГОДОВ ХІХ В. « ДЕПУТАТЫ» НАХОДИЛИСЬ В ПОДЧИНЕНИИ ПРАВИТЕЛЯ 
ЧАСТИ ИЛИ ОКРУГА И УТВЕРЖДАЛИСЬ В ДОЛЖНОСТИ ВРЕМЕННЫМ СОВЕТОМ ПО УПРАВЛЕНИЮ ВНУТРЕННЕЙ ОРДОЙ.

РОССИЙСКИЕ ВЛАСТИ НАРЯДУ С ПРОЦЕССОМ СОЗДАНИЯ ДОЛЖНОСТЕЙ В СТЕПИ РАЗРАБАТЫВАЛИ ЦЕЛЫЙ КОМПЛЕКС ДОКУМЕНТОВ, РЕГЛАМЕНТИРУЮЩИЙ ОТВЕТСТВЕННОСТЬ ДОЛЖНОСТНЫХ ЛИЦ - КАЗАХОВ ПРИ ИСПОЛНЕНИИ ИМИ СВОИХ ОБЯЗАННОСТЕЙ. ТАК, ПАРАГРАФЫ ГЛАВЫ 3 УСТАВА О СИБИРСКИХ КАЗАХАХ, « ПРАВИЛА», СОСТАВЛЕННЫЕ ПРЕДСЕДАТЕЛЕМ ПОГРАНИЧНОЙ КОМИССИИ Г.Ф.ГЕНСОМ ДЛЯ ДИСТАНОЧНЫХ НАЧАЛЬНИКОВ, АУЛЬНЫХ СТАРШИН И ПОМОЩНИКОВ СУЛТАНОВ-ПРАВИТЕЛЕЙ (1831 Г.), ПАРАГРАФЫ (46-47) ПОЛОЖЕНИЯ ОБ УПРАВЛЕНИИ ОРЕНБУРГСКИМИ КАЗАХАМИ ОТ 14 ИЮНЯ 1844 Г. ОПРЕДЕЛЯЛИ КРУГ ПОЛНОМОЧИЙ МЕСТНЫХ ЧИНОВНИКОВ ${ }^{56}$. ОСНОВНОЕ СОДЕРЖАНИЕ ФУНКЦИЙ КАЗАХОВ, НАХОДИВШИХСЯ НА ДОЛЖНОСТЯХ В ПЕРВОЙ ПОЛОВИНР ХІХ В. БЫЛО ПРАКТИЧЕСКИ ОДНОРОДНЫМ И ВКЛЮЧАЛО СЛЕДУЮЩИЕ НАПРАВЛЕНИЯ ИХ ДЕЯТЕЛЬНОСТИ: ТЩАТЕЛЬНОЕ ОТСЛЕЖИВАНИЕ ПОВЕДЕНИЯ КАЗАХСКОГО НАСЕЛЕНИЯ И ВНУШЕНИЕ ИМ « ... ВСЕГДАШНЕЙ ВЕРНОСТИ И ПОСЛУШАНИЯ ПРАВИТЕЛЬСТВУ»; СБОР «ВЕРНЕЙШИХ СВЕДЕНИЙ» О ЧИСЛЕННОСТИ НАСЕЛЕНИЯ, КИБИТОК И СКОТА ВО ВВЕРЕННОЙ ИМ ЧАСТИ ; СВОЕВРЕМЕННОЕ ИСПОЛНЕНИЕ ПОРУЧЕНИЙ РЕГИОНАЛЬНОЙ АДМИНИСТРАЦИИ КАК « ПРИ СБОРЕ ДЕНЕГ, ТАК И В ДРУГИХ СЛУЧАЯХ, ТРЕБУЮЩИХ ОСОБОЙ ПОСПЕШНОСТИ И ОТЧЕТЛИВОСТИ» ${ }^{57}$. ОСОБОЕ ВНИМАНИЕ КАЗАХСКИХ ЧИНОВНИКОВ ОБРАЩАЛОСЬ НА ВАЖНОСТЬ ПРАВИЛЬНОЙ ОРГАНИЗАЦИИ ДЕЛОПРОИЗВОДСТВА, СВОЕВРЕМЕННОГО ПРЕДСТАВЛЕНИЯ ТРЕБУЕМОЙ ИНФОРМАЦИИ ДЛЯ РЕГИОНАЛЬНОЙ АДМИНИСТРАЦИИ. ОДНАКО, ПОГРАНИЧНЫЙ НАЧАЛЬНИК УПРАВЛЕНИЯ СИБИРСКИМИ КАЗАХАМИ НИКОЛАЙ ВИШНЕВСКИЙ, ПРОВОДЯ РЕВИЗИЮ ВНЕШНИХ ОКРУЖНЫХ ПРИКАЗОВ, КОНСТАТИРОВАЛ, ЧТО СТАРШИЕ СУЛТАНЫ И ВОЛОСТНЫЕ УПРАВИТЕЛИ «НЕ ЗНАЮТ НАСТОЯЩИХ СВОИХ ОБЯЗАННОСТЕЙ, КОИ НА НИХ ВОЗЛАГАЮТСЯ» И, САМОЕ ГЛАВНОЕ, «САМОЙ ОТВЕТСТВЕННОСТИ НА НИХ ЛЕЖАЩЕЙ ${ }^{58}$. В 1846 ГОДУ ЧИНОВНИК МИНИСТЕРСТВА ИНОСТРАННЫХ ДЕЛ Н. ЛЮБИМОВ, ИЗУЧАВШИЙ СОСТОЯНИЕ УПРАВЛЕНИЯ У КАЗАХОВ ОРЕНБУРГСКОГО ВЕДОМСТВА, ТАКЖЕ ЗАФИКСИРОВАЛ ТОТ ФАКТ, ЧТО ДИСТАНОЧНЫЕ И МЕСТНЫЕ НАЧАЛЬНИКИ ЗАЧАСТУЮ « УКЛОНЯЮТСЯ ОТ ИСПРАВЛЕНИЯ ВОЗЛОЖЕННЫХ НА НИХ ДОЛЖНОСТЕЙ ${ }^{59}$. ИСХОДЯ ИЗ СЛОЖИВШЕЙСЯ СИТУАЦИИ, РЕГИОНАЛЬНЫЕ ВЛАСТИ СТАЛИ РАЗРАБАТЫВАТЬ МЕРЫ ПО ПОДДЕРЖАНИЮ « ИСПОЛНИТЕЛЬНОСТИ» КАЗАХСКИХ ЧИНОВНИКОВ : А ИМЕННО : ОТСТРАНЕНИЕ ОТ ДОЛЖНОСТИ ${ }^{60}$, ЛИШЕНИЕ ЧИНА ${ }^{61}$, ПРЕКРАЩЕНИЕ ВЫДАЧИ ЖАЛОВАНИЯ ${ }^{62}$, АРЕСТ ОТ 3-15 СУТОК ${ }^{63}$, ШТРАФЫ И ДАЖЕ ССЫЛКА НА КАТОРГУ. ОРЕНБУРГСКИЙ ГУБЕРНАТОР В. ПЕРОВСКИЙ СЧИТАЛ, ЧТО НЕДОСТАТОЧНО «ВПОЛНЕ СПОСОБНЫХ И БЛАГОНАДЕЖНЫХ ОРДЫНЦЕВ» ДЛЯ КООПТАЦИИ ИХ НА ГОСУДАРСТВЕННУЮ СЛУЖБУ. ИСХОДЯ ИЗ ЭТОГО ФАКТА, ПРЕДЛАГАЛ, ЧТО ТЕХ КАЗАХОВ, КОТОРЫЕ НАХОДЯТСЯ НА СЛУЖБЕ, МОЖНО «ЛИШЬ В СЛУЧАЕ ОСОБОЙ ВАЖНОСТИ» ПОДВЕРГАТЬ СЛЕДСТВИЮ И СУДУ ЗА НЕИСПОЛНЕНИЕ ВОЗЛОЖЕННЫХ НА НИХ ОБЯЗАННОСТЕЙ. И ЕСЛИ, ВСЕ ЖЕ ПРОИСХОДИЛИ « УПУЩЕНИЯ ПО СЛУЖБЕ», СКОРЕЕ ВСЕГО ОТ « ЛЕНОСТИ ИЛИ «КИРГИЗСКИХ [КАЗАХСКИХ - Г.С.] ПОНЯТИЙ О ВЕЩАХ», ТО ГУБЕРНАТОР РЕКОМЕНДОВАЛ « НАКАЗЫВАТЬ НЕМЕДЛЕННО», А ИМЕННО « ЗАКЛЮЧЕНИЕМ ПОД СТРАЖУ ПО МЕРЕ ВИНЫ, НА БОЛЕЕ ИЛИ МЕНЕЕ ДОЛГОВРЕМЕННЫЕ СРОКИ», НО ННЕ УДАЛЯя ОТ ДОЛЖНОСТИ» ${ }^{64}$.

ОДНОВРЕМЕННО РОССИЙСКИЕ ВЛАСТИ ДЛЯ ПОВЫШЕНИЯ ИСПОЛНИТЕЛЬНОСТИ ДОЛЖНОСТНЫХ ЛИЦ В СТЕПИ, ВОЗМОЖНОСТИ ПРИВЛЕЧЕНИЯ НА СЛУЖБУ БОЛЕЕ ШИРОКОГО КРУГА ЛИЦ, СПОСОБНЫХ АККУРАТНО И СВОЕВРЕМЕННО ВЫПОЛНЯТЬ СВОИ 
ОБЯЗАННОСТИ И СОЗДАНИЯ КОНКУРЕНТНОЙ СРЕДЫ СРЕДИ НИХ СТАЛИ РАЗРАБАТЫВАТЬ МЕРЫ ПО СУЩЕСТВЕННОМУ ОГРАНИЧЕНИЮ ТРАДИЦИОННЫХ ПРАВ НАСЛЕДСТВЕННОЙ АРИСТОКРАТИИ (СУЛТАНОВ) НА ВЛАСТЬ В КОЧЕВОМ ОБЩЕСТВЕ И ЗАКОНОДАТЕЛЬНОМУ ОБЕСПЕЧЕНИЮ ПО КООПТАЦИИ НЕПРИВИЛЕГИРОВАННЫХ СОСЛОВНЫХ ГРУПП (КАЗАХСКИХ БИЕВ, СТАРШИН) В СОСТАВ РОССИЙСКОГО АДМИНИСТРАТИВНО-УПРАВЛЕНЧЕСКОГО АППАРАТА. ОРЕНБУРГСКИЙ ГУБЕРНАТОР В. ПЕРОВСКИЙ СЕТОВАЛ, ЧТО НАЗНАЧЕНИЕ ОДНИХ СУЛТАНОВ НА ДОЛЖНОСТИ «ПОЧЕМУ ТО ВОШЛО В ОБЫЧАЙ», ХОТЯ СТАРШИНЫ ТОЖЕ ЗАСЛУЖИВАЛИ ЭТОГО «ЧЕСТНОСТЬЮ СВОЕЮ, ПОНЯТЛИВОСТЬЮ К ДЕЛАМ» И ИХ НАЗНАЧЕНИЕ НА ДОЛЖНОСТИ В СТЕПИ, ПО ЕГО МНЕНИЮ, СОВЕРШЕННО С СОГЛАСОВАЛОСЬ БЫ С КОРЕННЫМИ ЗАКОНАМИ ИМПЕРИИ, ОТКРЫВАЮЩИМ ПОПРИЩЕ ГОСУДАРСТВЕННОЙ слУжБЫ ВсякОМУ ТОМУ дОстоИнстВУ» ${ }^{65}$. С ДРУГОЙ СТОРОНЫ, СЛОЖИВШАЯСЯ СИТУАЦИЯ В ОКРУЖНЫХ ПРИКАЗАХ, ГДЕ НА ДОЛЖНОСТИ СТАРШЕГО СУЛТАНА ИЗБИРАЛИСЬ ВЛИЯТЕЛЬНЫЕ ПРЕДСТАВИТЕЛИ СТЕПНОЙ ЗНАТИ ВЫНУДИЛО РОССИЙСКОЕ ПРАВИТЕЛЬСТВО ПРИЗНАТЬ РОЛЬ И ВЛИЯНИЕ СТАРШИН И БИЕВ В КОЧЕВОМ ОБЩЕСТВЕ И ПРОВЕСТИ СУЩЕСТВЕННЫЕ РЕВИЗИИ. ИТОГОМ ОБСУЖДЕНИЯ ЭТИХ ВОПРОСОВ СТАЛ НОВЫЙ ЗАКОНОДАТЕЛЬНЫЙ ДОКУМЕНТ « О ПОРЯДКЕ ИЗБРАНИЯ ПО КИРГИЗСКОЙ [КАЗАХСКОЙ] СТЕПИ В СТАРШИЕ СУЛТАНЫ», УТВЕРЖДЕННОЕ ИМПЕРАТОРОМ 23 ФЕВРАЛЯ 1855 ГОДА, ГДЕ ДОПУСКАЛОСЬ ИЗБРАНИЕ НА ДОЛЖНОСТЬ СТАРШЕГО СУЛТАНА, НАРЯДУ С ЧИНГИЗИДАМИ И ВЛИЯТЕЛЬНЫХ КАЗАХОВ НЕ СУЛТАНСКОГО ПРОИСХОЖДЕНИЯ. ПРЕДЛАГАЛАСЬ ДВЕ КАТЕГОРИИ ЛИЦ. ПЕРВАЯ ПОЧЕТНЫЕ КАЗАХИ, ПРОСЛУЖИВШИЕ НА ДОЛЖНОСТЯХ В ТЕЧЕНИЕ ТРЕХ ЛЕТ В КАЧЕСТВЕ ЗАСЕДАТЕЛЕЙ ОКРУЖНЫХ ПРИКАЗОВ ИЛИ ВОЛОСТНЫМИ УПРАВИТЕЛЯМИ И УЖЕ « ПОЖАЛОВАННЫЕ ОФИЦЕРСКИМИ ЧИНАМИ». ВТОРАЯ ГРУППА ЛИЦ - ПОЧЕТНЫЕ КАЗАХИ, КОТОРЫЕ ПРОСЛУЖИЛИ НА ДОЛЖНОСТЯХ В ТЕЧЕНИЕ ДЕВЯТИ ЛЕТ, НО НЕ ИМЕЛИ « ОФИЦЕРСКИХ ЧИНОВ» ${ }^{66} .4$ АПРЕЛЯ 1861 ГОДА УКАЗ ИМПЕРАТОРА АЛЕКСАНДРА ІІ ВНЕС СУЩЕСТВЕННЫЕ ПОПРАВКИ И О ПОРЯДКЕ ВЫБОРА ВОЛОСТНЫХ УПРАВИТЕЛЕЙ. СОГЛАСНО ДАННОМУ ЗАКОНУ, К УПРАВЛЕНИЮ ВОЛОСТЯМИ ДОПУСКАЛИСЬ ЛИЦА НЕ СУЛТАНСКОГО ПРОИСХОЖДЕНИЯ, А ИМЕННО КАЗАХИ, ИМЕВШИЕ ОФИЦЕРСКИЕ ЧИНЫ, ВОЕННЫЕ ОРДЕНА, МЕДАЛИ ИЛИ «ПОЧЕТНЫЕ КАФТАНЫ», ПОЖАЛОВАННЫЕ ГЕНЕРАЛ-ГУБЕРНАТОРАМИ. В СЛУЧАЕ ЖЕ ИЗБРАНИЯ НА ДОЛЖНОСТЬ УПРАВИТЕЛЯ ВЛИЯТЕЛЬНОГО И УВАЖАЕМОГО КАЗАХА, НЕ ИМЕВШЕГО НИ ОДНОГО ИЗ ПЕРЕЧИСЛЕННЫХ ОТЛИЧИЙ», ОН ОПРЕДЕЛЯЛСЯ КАК ИСПОЛНЯЮЩИЙ ДОЛЖНОСТЬ, ДО ПОЛУЧЕНИЯ ПО СЛУЖБЕ ЧИНА ИЛИ МЕДАЛИ ${ }^{67}$ НОВОВВЕДЕНИЯ СТАЛИ ОТРАЖЕНИЕМ СМЕЩЕНИЯ АКЦЕНТОВ РОССИЙСКОГО ПРАВИТЕЛЬСТВА ПРИ НАЗНАЧЕНИИ НА ДОЛЖНОСТИ В СТЕПИ. С ОДНОЙ СТОРОНЫ « ПРИ ПОМОЩИ ТАБЕЛИ О РАНГАХ ПРОИЗВОДИЛСЯ КАК БЫ, ПОСТОЯННЫЙ ОТБОР ЛУЧШИХ ЭЛЕМЕНТОВ ${ }^{68}$, А, С ДРУГОЙ СТОРОНЫ, УКАЗАННЫЕ ПОСТЫ СТАЛИ ЗАНИМАТЬ ВЫХОДЦЫ ИЗ СТЕПНОЙ ЭЛИТЫ (БИИ, СТАРШИНЫ). К 60-М ГОДАМ ХІХ В. НА ПОВЕСТКУ СТАЛ ВОПРОС О НЕОБХОДИМОСТИ УНИФИКАЦИИ СИСТЕМЫ АДМИНИСТРАТИВНОГО УПРАВЛЕНИЯ НА ВСЕЙ ТЕРРИТОРИИ КАЗАХСКОЙ СТЕПИ И, СООТВЕТСТВЕННО, СОЗДАНИЕ ЕДИНООБРАЗИЯ В СИСТЕМЕ ДОЛЖНОСТЕЙ ДЛЯ ПРЕДСТАВИТЕЛЕЙ КАЗАХСКОГО НАСЕЛЕНИЯ. В ИЮЛЕ 1867 Г. АЛЕКСАНДР ІІ ОПУБЛИКОВАЛ УКАЗ ОБ УЧРЕЖДЕНИИ ТУРКЕСТАНСКОГО ГЕНЕРАЛ-ГУБЕРНАТОРСТВА, КУДА ВОШЛИ СОЗДАННЫЕ СЕМИРЕЧЕНСКАЯ И СЫР-ДАРЬИНСКАЯ ОБЛАСТИ, А 21 ОКТЯБРЯ 1868 Г. НА ОСНОВАНИИ «ВРЕМЕННОГО ПОЛОЖЕНИЯ ОБ УПРАВЛЕНИИ СТЕПНЫХ ОБЛАСТЕЙ ОРЕНБУРГСКОГО И ЗАПАДНО-СИБИРСКОГО ГЕНЕРАЛ-ГУБЕРНАТОРСТВА» БЫЛИ СОЗДАНЫ УРАЛЬСКАЯ И ТУРГАЙСКАЯ, АКМОЛИНСКАЯ И СЕМИПАЛАТИНСКАЯ ОБЛАСТИ. НА 
ОСНОВАНИИ ЭТИХ ЗАКОНОДАТЕЛЬНЫХ ДОКУМЕНТОВ С 1 ЯНВАРЯ 1869 Г. ДОЛЖНОСТИ СТАРШЕГО СУЛТАНА И СУЛТАНА-ПРАВИТЕЛЯ БЫЛИ УПРАЗДНЕНЫ. КАЗАХИ ТЕПЕРЬ МОГЛИ БЫТЬ ПРЕДСТАВЛЕНЫ ТОЛЬКО В НИЗОВОЙ СИСТЕМЕ МЕСТНОГО УПРАВЛЕНИЯ, НА ДОЛЖНОСТИ ВОЛОСТНЫХ УПРАВИТЕЛЕЙ И АУЛЬНЫХ СТАРШИН, КОТОРЫЕ ВЫБИРАЛИСЬ НА ВОЛОСТНЫХ И АУЛЬНЫХ СЪЕЗДАХ ЧЕРЕЗ КАЖДЫЕ ТРИ ГОДА И УТВЕРЖДАЛИСЬ ВОЕННЫМ ГУБЕРНАТОРОМ ОБЛАСТИ. ВОЛОСТНОМУ УПРАВИТЕЛЮ И АУЛЬНОМУ СТАРШИНЕ ПРИСВАИВАЛИСЬ ОСОБЫЕ БРОНЗОВЫЕ ЗНАКИ, КОТОРЫЕ ДОЛЖНЫ БЫЛИ БЫТЬ ОБЯЗАТЕЛЬНЫМ АТРИБУТОМ ПРИ ИСПОЛНЕНИИ ИМИ СЛУЖЕБНЫХ ОБЯЗАННОСТЕЙ. КРОМЕ ТОГО, ДЛЯ ОРГАНИЗАЦИИ ДЕЛОПРОИЗВОДСТВА ИМ ВЫДАВАЛИСЬ ОСОБЫЕ ПЕЧАТИ, КОТОРЫЕ ИСПОЛЬЗОВАЛИСЬ В ОФИЦИАЛЬНОМ ДЕЛОПРОИЗВОДСТВЕ И ПРИКЛАДЫВАЛИСЬ К ИСХОДЯЩИМ ОТ НИХ БУМАГАМ, ВМЕСТО ТРАДИЦИОННОЙ ПОДПИСИ ИЛИ ТАМГИ. ПРИ ЭТОМ ФОРМА ПЕЧАТЕЙ И ЗНАКОВ УТВЕРЖДАЛАСЬ МИНИСТРОМ ВНУТРЕННИХ ДЕЛ, И ИЗГОТОВЛЕНИЕ ИХ ПРОИЗВОДИЛОСЬ ЗА СЧЕТ КАЗНЫ. ПРИ ОСТАВЛЕНИИ ДОЛЖНОСТЕЙ ВОЛОСТНЫЕ УПРАВИТЕЛИ ДОЛЖНЫ БЫЛИ ЗНАКИ И ПЕЧАТИ ВОЗВРАТИТЬ УЕЗДНОМУ НАЧАЛЬНИКУ $С$ ЦЕЛЬЮ ПЕРЕДАЧИ ИХ ПРИЕМНИКАМ ${ }^{69}$. ЖАЛОВАНИЕ ВОЛОСТНОМУ УПРАВИТЕЛЮ ТЕПЕРЬ ОПРЕДЕЛЯЛОСЬ ВОЛОСТНЫМИ СЪЕЗДАМИ ВЫБОРНЫХ И СОСТАВЛЯЛО ОТ 300 ДО 500 РУБЛЕЙ В ГОД. ВАРЬИРОВАНИЕ СУММЫ ЖАЛОВАНИЯ ЗАВИСЕЛО ОТ ПЛОЩАДИ ВОЛОСТИ,ЧИСЛЕННОСТИ КИБИТОК И « БЛАГОСОСТОЯНИЯ» НАСЕЛЕНИЯ, Т.Е. ВОЗМОЖНОСТИ СВОЕВРЕМЕННО СДАВАТЬ ПОДАТИ ${ }^{70}$

ДЛЯ ПРЕДСТАВИТЕЛЕЙ КАЗАХСКОГО НАСЕЛЕНИЯ БЫЛИ СОЗДАНЫ ДОЛЖНОСТИ И В ШТАТАХ ОБЛАСТНОГО И УЕЗДНОГО ПРАВЛЕНИЯ, А ИМЕННО ДОЛЖНОСТЬ МЛАДШЕГО ЧИНОВНИКА ОСОБЫХ ПОРУЧЕНИЙ ПРИ ВОЕННЫХ ГУБЕРНАТОРАХ ОБЛАСТЕЙ (2 ЕДИНИЦЫ), КОТОРАЯ ОТНОСИЛАСЬ К СЕКРЕТНОМУ ОТДЕЛЕНИЮ ОБЛАСТНОГО ПРАВЛЕНИЯ, И МЛАДШЕГО ПОМОЩНИКА УЕЗДНОГО НАЧАЛЬНИКА. ПРИМЕЧАТЕЛЕН ТОТ ФАКТ, ЧТО

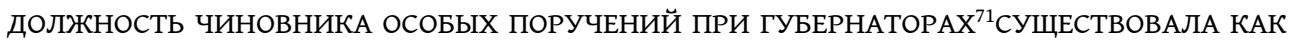
В ШТАТНЫХ РАСПИСАНИЯХ КАНЦЕЛЯРИЙ ВНУТРИРОССИЙСКИХ ГУБЕРНИЙ, ТАК И ИНОЭТНИЧНЫХ ГЕНЕРАЛ-ГУБЕРНАТОРСТВ (КАВКАЗ, КАЗАХСКАЯ СТЕПЬ). ЧИНОВНИКИ ОСОБЫХ ПОРУЧЕНИЙ ЗАНИМАЛИ В АДМИНИСТРАТИВНОЙ СТРУКТУРЕ ОСОБОЕ МЕСТО, ПОДЧИНЯЛИСЬ НЕПОСРЕДСТВЕННО ГУБЕРНАТОРУ, ИХ ДОЛЖНОСТНЫЕ ОБЯЗАННОСТИ НЕ ВПИСЫВАЛИСЬ В КРУГ ДЕЙСТВИЙ ОБЫЧНЫХ ШТАТНЫХ ЧИНОВ. ОСНОВНЫМ КРИТЕРИЕМ ДЛЯ НАЗНАЧЕНИЯ КАЗАХОВ НА ЭТУ ДОЛЖНОСТЬ ЯВИЛОСЬ НАЛИЧИЕ ОПЫТА УПРАВЛЕНИЯ И СТЕПЕНЬ ДОВЕРИЯ К НИМ РЕГИОНАЛЬНОЙ ВЛАСТИ, КОТОРОЕ МОЖНО БЫЛО ЗАРАБОТАТЬ, ПРОЯВИВ СВОЮ ВЕРНОСТЬ И ПРЕДАННОСТЬ РУССКОМУ ТРОНУ НА ПРЕДЫДУЩЕМ МЕСТЕ СЛУЖБЫ. НА ОСНОВАНИИ ИЗУЧЕНИЯ ПОСЛУЖНЫХ СПИСКОВ МНОЮ ВЫЯВЛЕНО ШЕСТЬ КАЗАХОВ, НАХОДИВШИХСЯ НА ДОЛЖНОСТЯХ МЛАДШИХ ЧИНОВНИКОВ ОСОБЫХ ПОРУЧЕНИЙ ПРИ ВОЕННЫХ ГУБЕРНАТОРАХ ТУРГАЙСКОЙ, АКМОЛИНСКОЙ И СЕМИРЕЧЕНСКОЙ ОБЛАСТЕЙ. ВСЕ ОНИ ИМЕЛИ ОПРЕДЕЛЕННЫЙ АДМИНИСТРАТИВНЫЙ ОПЫТ, ЗНАНИЯ И НАВЫКИ УПРАВЛЕНИЯ, НАХОДЯСЬ НА РАЗНЫХ ДОЛЖНОСТЯХ ОТ ЧИНОВНИКА ОБЛАСТНОГО ПРАВЛЕНИЯ ОРЕНБУРГСКИМИ КАЗАХАМИ (Т.СЕЙДАЛИН), СТАРШЕГО СУЛТАНА (ИБРАГИМ ДЖАИКПАЕВ), ЗАСЕДАТЕЛЯ ОБЛАСТНОГО ПРАВЛЕНИЯ ОРЕНБУРГСКИХ КАЗАХОВ (Б. КЕЙКИН), ДО ДИСТАНОЧНОГО НАЧАЛЬНИКА (Д. БЕРКИМБАЕВ, Б. КЕЙКИН). ЖАЛОВАНИЕ КАЗАХСКОГО ЧИНОВНИКА ОСОБЫХ ПОРУЧЕНИЙ СОСТАВИЛО 800 РУБЛЕЙ СЕРЕБРОМ В ГОД.

29 ЯНВАРЯ 1870 Г. В ШТАТ КАНЦЕЛЯРИИ ВОЕННЫХ ГУБЕРНАТОРОВ ОБЛАСТЕЙ БЫЛА ВВЕДЕНА ДОЛЖНОСТЬ СВЕРХШТАТНОГО ЧИНОВНИКА ОСОБЫХ ПОРУЧЕНИЙ, КАК И ВО 
ВНУТРИРОССИЙСКИХ ГУБЕРНИЯХ. ИХ ОТЛИЧИЕ ОТ ШТАТНЫХ ЧИНОВНИКОВ ОСОБЫХ ПОРУЧЕНИЙ СОСТОЯЛО В ТОМ, ЧТО СВЕРХШТАТНЫЕ ЧИНОВНИКИ НЕ ПОЛУЧАЛИ ЖАЛОВАНЬЯ, НО ПОЛЬЗОВАЛИСЬ ВСЕМИ ЛЬГОТАМИ ГОСУДАРСТВЕННОЙ СЛУЖБЫ, А ИМЕННО МОГЛИ ПОЛУЧИТЬ СЛЕДУЮЩИЙ ЧИН, ОРДЕНА, МЕДАЛИ. ВОЕННЫЙ ГУБЕРНАТОР ТУРГАЙСКОЙ ОБЛАСТИ Л. БАЛЛЮЗЕК СЧИТАЛ, ЧТО ВАЖНО ПРИВЛЕКАТЬ НА СЛУЖБУ ТЕХ КАЗАХОВ, КОТОРЫЕ « ... ДОРОЖА САМИМ ЗВАНИЕМ ДОЛЖНОСТНОГО ЛИЦА» МОГУТ СТАТЬ « ПОЛЕЗНЫМИ ДЕЯТЕЛЯМИ, КАК ПО ДОСТАВЛЕНИЮ ТОЧНЫХ СВЕДЕНИЙ, ТАК И ПО ИСПОЛНЕНИЮ ПОРУЧЕНИЙ» ${ }^{72}$. НА ДОЛЖНОСТИ СВЕРХШТАТНЫХ ЧИНОВНИКОВ НАЗНАЧАЛИ И ТЕХ ПРЕДСТАВИТЕЛЕЙ КАЗАХСКОЙ ЭЛИТЫ, КОТОРЫЕ «ВЫРАБОТАЛИ ПУТЕМ ВЛИЯНИЯ, ИЗ ПОКОЛЕНИЯ В ПОКОЛЕНИЕ ЭЛЕМЕНТЫ НАСЛЕДСТВЕННОЙ ВЛАСТИ» И ДЛЯ КОЧЕВНИКОВ «НЕПРИВЫЧНО БЫЛО БЫ ИХ ВИДЕТЬ НЕ У ДЕЛ» ${ }^{73}$. К ПРИМЕРУ, СВЕРХШТАТНЫМИ ЧИНОВНИКАМИ ОСОБЫХ ПОРУЧЕНИЙ БЫЛИ СУЛТАН ИШМУХАМЕД АБЛАЙХАНОВ (СЫН СУЛТАНА СТАРШЕГО ЖУЗА СУЮКА, ВНУК ХАНА АБЛАЯ), КАЗБЕК ЧЕГЕНЕВ, (ПОТОМОК ДЖАНИБЕК ТАРХАНА, СЫН БИЯ ЧЕГЕНЯ МУСИНА).

В ШТАТНОЕ РАСПИСАНИЕ УЕЗДНЫХ УПРАВЛЕНИЙ ВХОДИЛИ ДВА ПОМОЩНИКА НАЧАЛЬНИКА УЕЗДА. ДОЛЖНОСТИ СТАРШИХ ПОМОЩНИКОВ УЕЗДНОГО НАЧАЛЬНИКА МОГЛИ ЗАНЯТЬ ТОЛЬКО ПРЕДСТАВИТЕЛИ РУССКОГО ОФИЦЕРСТВА, А МЛАДШЕГО ПРЕДСТАВИТЕЛИ КАЗАХСКОЙ ЗНАТИ ${ }^{74}$. ТАК, ПЕРВЫМ МЛАДШИМ ПОМОЩНИКОМ НАЧАЛЬНИКА ИЛЕЦКОГО (АКТЮБИНСКОГО) УЕЗДА 1 ЯНВАРЯ 1869 Г. БЫЛ НАЗНАЧЕН ПОТОМОК ИЗВЕСТНОГО КАЗАХСКОГО СУЛТАНА АРУНГАЗЫ, ЕСАУЛ АЙМУХАМЕД АРУНГАЗИЕВ $^{75}$, А ИРГИЗСКОГО УЕЗДА НАЦИОНАЛЬНО-ОСВОБОДИТЕЛЬНОГО ДВИЖЕНИЯ КАЗАХОВ В 1856-1858 ГОДЫ ЕСЕТ КУТЕБАРОВ. ПРИВЛЕЧЕНИЕ НА СЛУЖБУ ЛИЦ, КОТОРЫЕ ИМЕЛИ СИЛЬНОЕ ВЛИЯНИЕ НА КОЧЕВОЕ ОБЩЕСТВО И ДОСТАВЛЯВШИЕ В ПРОШЛОМ НЕМАЛО БЕСПОКОЙСТВ РОССИЙСКОЙ ВЛАСТИ, СВИДЕТЕЛЬСТВУЮТ О ГИБКОЙ ТАКТИКЕ ПРАВИТЕЛЬСТВА С ОДНОЙ СТОРОНЫ, А С ДРУГОЙ - О ЖЕЛАНИИ ПРЕДСТАВИТЕЛЕЙ КАЗАХСКОЙ ЗНАТИ БЫТЬ ПРИЗНАННЫМИ РОССИЙСКИМ ПРАВИТЕЛЬСТВОМ И ПОЛУЧИТЬ ДАЛЬНЕЙШИЕ РЕСУРСЫ ДЛЯ СОХРАНЕНИЯ СВОЕГО ВЛИЯНИЯ НА КОЧЕВОЕ ОБЩЕСТВО. ПРОСЛУЖИВШИЙ В ДОЛЖНОСТИ В ТЕЧЕНИЕ ШЕСТИ ЛЕТ (1873-1879) Е. КОТЕБАРОВ БЫЛ ОТСТРАНЕН ОТ ДОЛЖНОСТИ. ПРИЧИНОЙ ЭТОМУ ЯВИЛСЯ ЕГО ПРЕКЛОННЫЙ ВОЗРАСТ, И, САМОЕ ГЛАВНОЕ, ТО, ЧТО ОФИЦИАЛЬНАЯ ПЕРЕПИСКА « ОСТАВАЛАСЬ БЕЗ ВСЯКОГО ДВИЖЕНИЯ» ИЗ-ЗА НЕЗНАНИЯ ИМ РУССКОГО ЯЗЫКА. В РЕЗУЛЬТАТЕ Е. КОТЕБАРОВУ ОПРЕДЕЛИЛИ ПЕНСИЮ В РАЗМЕРЕ 800 РУБЛЕЙ В ГОД, А МЛАДШИМ ПОМОЩНИКОМ ИРГИЗСКОГО УЕЗДНОГО НАЧАЛЬНИКА СТАЛ СВЕРХШТАТНЫЙ ЧИНОВНИК ОСОБЫХ ПОРУЧЕНИЙ ПРИ ВОЕННОМ ГУБЕРНАТОРЕ ТУРГАЙСКОЙ ОБЛАСТИ, АБИЛЬ ТЮЛЬКУБАЕВ ${ }^{76}$.

СПУСТЯ 25 ЛЕТ, НА ОСНОВАНИИ ПОЛОЖЕНИЯ ОТ 25 МАРТА 1891 ГОДА, ДОЛЖНОСТЬ МЛАДШЕГО ПОМОЩНИКА НАЧАЛЬНИКА УЕЗДА БЫЛА УПРАЗДНЕНА.

ТАКИМ ОБРАЗОМ, ВКЛЮЧЕНИЕ ТРАДИЦИОННЫХ СТРУКТУР И СЛОЖИВШИХСЯ ОБЫЧАЕВ В ОФИЦИАЛЬНУЮ СИСТЕМУ УПРАВЛЕНИЯ НА ПРОТЯЖЕНИИ ПЕРВОЙ ПОЛОВИНЫ ХІХ В. ПРОИСХОДИЛО МЕТОДОМ САНКЦИОНИРОВАНИЯ НОВЫХ ЗАКОНОДАТЕЛЬНЫХ ОСНОВАНИЙ И СОЗДАНИЯ СЕТИ НОВЫХ ДОЛЖНОСТЕЙ ДЛЯ ПРЕДСТАВИТЕЛЕЙ КАЗАХСКОЙ ЭЛИТЫ НЕ СТОЛЬКО ДЛЯ ПОВЫШЕНИЯ ЭФФЕКТИВНОСТИ УПРАВЛЕНИЯ, СКОЛЬКО ДЛЯ СОЗДАНИЯ И УКРЕПЛЕНИЯ АДМИНИСТРАТИВНОЙ ВЕРТИКАЛИ. РЕЗУЛЬТАТОМ ЭТОЙ ПОЛИТИКИ СТАЛО ЕСТЕСТВЕННЫМ ОБРАЗОМ СОЗДАНИЕ С КОНЦА 60-Х ГОДОВ ХІХ В. ОБЩЕРОССИЙСКОЙ 
СИСТЕМЫ УПРАВЛЕНИЯ (ОБЛАСТЬ-УЕЗД-ВОЛОСТЬ) НА ВСЕЙ ТЕРРИТОРИИ КАЗАХСКОЙ СТЕПИ.

\section{Военные чины, ордена и медали казахских чиновников}

ОДНИМ ИЗ АТРИБУТОВ ПРИВЛЕЧЕНИЯ КАЗАХОВ НА СЛУЖБУ РОССИЙСКОЙ ИМПЕРИИ СТАЛА СИСТЕМА НАГРАЖДЕНИЯ. ЕСЛИ В ХVIII В. ПО ОТНОШЕНИЮ К КАЗАХАМ, ПРОЯВИВШИМ ЛОЯЛЬНОСТЬ К РОССИЙСКОЙ ВЛАСТИ, ИСПОЛЬЗОВАЛСЯ МЕТОД «ОДАРИВАНИЯ», Т.Е. ВЫДАЧА ПОДАРКОВ В ВИДЕ ХАЛАТОВ, РАЗЛИЧНЫХ ТКАНЕЙ И ОТРЕЗОВ, ВЕЩЕЙ (ТАБАКЕРКИ, СЕРЕБРЯНЫЕ КРУЖКИ, СТЕКЛЯННЫЕ ИЗДЕЛИЯ И ДР.), ТО, НАЧИНАЯ С ХІХ В., НАЧАЛСЯ ПРОЦЕСС НАГРАЖДЕНИЯ КАЗАХОВ ВОЕННЫМИ ЧИНАМИ ${ }^{77}$, А НЕ ГРАЖДАНСКИМИ. ПРИЧИНОЙ ЭТОМУ БЫЛ РЯД ФАКТОРОВ. ВО-ПЕРВЫХ, РОССИЙСКИЕ ВЛАСТИ УЛОВИЛИ, ЧТО В КУЛЬТУРЕ КОЧЕВНИКА БОЛЬШЕЕ ЗНАЧЕНИЕ ИМЕЕТ ПРИЗНАНИЕ ВОЕННЫХ ДОБЛЕСТЕЙ, ПОЭТОМУ ПОЛУЧЕНИЕ ВОЕННОГО ЧИНА, РАССМАТРИВАЛОСЬ СОПЛЕМЕННИКАМИ КАК СИМВОЛ ПРИЗНАНИЯ РУССКОЙ ВЛАСТЬЮ ЕГО ЗАСЛУГ, СОХРАНЕНИЯ ИМ ВЛАСТНЫХ ПОЛНОМОЧИЙ, ХОТЯ КАЗАХСКОЕ НАСЕЛЕНИЕ НИКОГДА НЕ НЕСЛО ВОЕННОЙ СЛУЖБЫ В ИМПЕРИИ. НЕСМОТРЯ НА ТО, ЧТО ПОЛУЧЕНИЕ ВОЕННОГО ЧИНА ПО «ТАБЕЛЮ О РАНГАХ» МОГЛО ИМЕТЬ МЕСТО ТОЛЬКО ПРИ НАЗНАЧЕНИИ НА ДОЛЖНОСТЬ, В КАЗАХСКОЙ СТЕПИ НАГРАЖДЕНИЕ ВОЕННЫМ ЧИНОМ ДОЛЖНО БЫЛО СПОСОБСТВОВАТЬ « ...ОДОБРЕНИЮ ЛЮДЕЙ ДОСТОЙНЫХ И СПОСОБНЫХ» ЗА ИХ ОСОБЫЕ ЗАСЛУГИ» ${ }^{78}$. ИСХОДЯ ИЗ ЭТОГО, ОСНОВНЫМ КРИТЕРИЕМ ПРИ ВЫДВИЖЕНИИ КАНДИДАТА НА ВОЕННЫЙ ЧИН СТАЛО «УСЕРДНОЕ ИСПОЛНЕНИЕ» ПОРУЧЕНИЙ РЕГИОНАЛЬНОЙ АДМИНИСТРАЦИИ ИЛИ ОКАЗАНИЕ ОПРЕДЕЛЕННОЙ У УСЛГИ» В ДЕЯТЕЛЬНОСТИ РУССКИХ ВОЕННЫХ ЭКСПЕДИЦИЙ В СТЕПИ, В « РАЗЫСКАНИИ» УКРАДЕННОГО СКОТА, ВОЗВРАЩЕНИИ ПЛЕНЕННЫХ КАЗАКОВ, БАШКИР, РУССКИХ ИЗ КАЗАХСКИХ КОЧЕВИЙ НА ПОГРАНИЧНУЮ ЛИНИЮ И Т.Д. ПРИ ЭТОМ ЗАСЛУЖИТЬ НАГРАДУ В ВИДЕ ЧИНА МОГЛИ КАЗАХИ НЕЗАВИСИМО ОТ СОЦИАЛЬНОГО ПРОИСХОЖДЕНИЯ, МАТЕРИАЛЬНОГО СОСТОЯНИЯ. КАЗАХИ, ПОЛУЧИВШИЕ ВОЕННЫЕ ЧИНЫ, НЕ БЫЛИ ПРИКРЕПЛЕНЫ К ВОИНСКИМ ЧАСТЯМ ИМПЕРИИ, НЕ НЕСЛИ ОФИЦИАЛЬНОЙ СЛУЖБЫ. ИСКЛЮЧЕНИЕ СОСТАВЛЯЛИ КАЗАХИ, ВЫПУЩЕННЫЕ ИЗ СТЕН КАДЕТСКИХ КОРПУСОВ. К ПРИМЕРУ, СУЛТАНЫ АЛЬМУХАМЕД И ТЛЕУ-МУХАММЕД СЕЙДАЛИНЫ, ВЫПУСКНИКИ ОРЕНБУРГСКОГО КАДЕТСКОГО КОРПУСА 1855 ГОДА, ПОЛУЧИВ ПЕРВЫЙ ОФИЦЕРСКИЙ ЧИН - ПРАПОРЩИКА, БЫЛИ НАПРАВЛЕНЫ НА СЛУЖБУ В ОРЕНБУРГСКИЙ ЛИНЕЙНЫЙ №4 БАТАЛЬОН ${ }^{79}$.

ВО-ВТОРЫХ, В ПЕРВОЙ ПОЛОВИНЕ ХІХ В. НАЧАЛОСЬ ОТЧАЯННОЕ СОПРОТИВЛЕНИЕ КАЗАХСКОГО НАСЕЛЕНИЯ В ОТВЕТ НА МАСШТАБНЫЙ ПРОЦЕСС ТЕРРИТОРИАЛЬНО-АДМИНИСТРАТИВНОГО РЕФОРМИРОВАНИЯ СТЕПИ ${ }^{80}$. В СЛОЖИВШЕЙСЯ СИТУАЦИИ, ПРИ ДОВОЛЬНО СУЩЕСТВЕННОЙ КУЛЬТУРНОЙ И ЯЗЫКОВОЙ ДИСТАНЦИИ МЕЖДУ РУССКИМИ ЧИНОВНИКАМИ И МЕСТНЫМ НАСЕЛЕНИЕМ, ВАЖНО БЫЛО СОЗДАТЬ БОЛЕЕ ШИРОКУЮ СОЦИАЛЬНУЮ ОПОРУ В ЛИЦЕ КАЗАХСКИХ БИЕВ, СТАРШИН, ИБО ОТ ИХ «УМЕНИЯ И ТАКТА» ЗАВИСЕЛ УСПЕХ «ПРЕДПРИНЯТОГО РУССКИМ ПРАВИТЕЛЬСТВОМ НАЧИНАНИЙ». ПОЭТОМУ В ЭТОТ ПЕРИОД НАБЛЮДАЛСЯ НАИБОЛЕЕ АКТИВНЫЙ ПРОЦЕСС НАГРАЖДЕНИЯ КАЗАХОВ ВОЕННЫМИ ЧИНАМИ И ПОСТЕПЕННОГО ПРЕВРАЩЕНИЯ РАЗНЫХ « УСЛУГ» В ПОСТОЯННЫЕ ОБЯЗАННОСТИ. БОЛЕЕ ТОГО, В КАЧЕСТВЕ ПООЩРЕНИЯ КАЗАХОВ К СЛУЖБЕ ИСПОЛЬЗОВАЛАСЬ ПРАКТИКА НАГРАЖДЕНИЯ ПОСЛЕДУЮЩИМ ВОЕННЫМ 
ЧИНОМ БЕЗ ПОВЫШЕНИЯ В ДОЛЖНОСТИ И БЕЗ УЧЕТА СРОКА СЛУЖБЫ. К ПРИМЕРУ, СУЛТАН СУЛЕЙМАН ДЖИГАНГЕРОВ, БУДУЧИ НАЧАЛЬНИКОМ 53-Й ДИСТАНЦИИ КАЗАХОВ ОРЕНБУРГСКОГО ВЕДОМСТВА, ПОЛУЧИЛ ЧИН СОТНИКА В 1847 ГОДУ, А ЧЕРЕЗ ГОД ЕСАУЛА, ЗАТЕМ ПО ИСТЕЧЕНИИ ДЕСЯТИ ЛЕТ ЧИН ВОЙСКОВОГО СТАРШИНЫ, А ЧЕРЕЗ ГОД ПОДПОЛКОВНИКА $(1858)^{81}$. ПРАВИТЕЛЬ ЗАПАДНОЙ ЧАСТИ ОРЕНБУРГСКИХ КАЗАХОВ БАЙМУХАМЕД АЙЧУВАКОВ (ГОДЫ СЛУЖБЫ 1830-1847) В ТЕЧЕНИЕ ПОЧТИ ДЕСЯТИ ЛЕТ ПРОШЕЛ ОТ ЧИНА ВОЙСКОВОГО СТАРШИНЫ (1836) ДО ГЕНЕРАЛ-МАЙОРА $(1847)^{82}$.

К СЕРЕДИНЕ 50-Х ГОДАХ ХІХ В. РЕГИОНАЛЬНЫЕ ВЛАСТИ ОСОЗНАЛИ, ЧТО РАСПРОСТРАНЕНИЕ ТАКОГО ВИДА ПООЩРЕНИЯ КАЗАХОВ, КАК НАГРАЖДЕНИЕ ВОЕННЫМИ ЧИНАМИ ПРИВЕЛО К ННЕСООБРАЗИЮ» СО СТЕПЕНЬЮ ЗАНИМАЕМОЙ ИМИ ДОЛЖНОСТИ. ТАК, ПРИ СОСТАВЛЕНИИ СПИСКА ШТАБ- И ОБЕР-ОФИЦЕРОВ СРЕДИ КАЗАХСКОГО НАСЕЛЕНИЯ ОРЕНБУРГСКОГО ВЕДОМСТВА В 1853 ГОДУ ВЫЯВИЛОСЬ БОЛЕЕ 80 ЧЕЛОВЕК, ИМЕВШИХ ВОЕННЫЕ ЧИНЫ, НО МНОГИЕ ИЗ НИХ НЕ БЫЛИ НА ГОСУДАРСТВЕННОЙ СЛУЖБЕ 83. НЕ СЛУЧАЙНО И ТО, ЧТО В ЭТОТ ПЕРИОД СТАЛ ОБСУЖДАТЬСЯ ВОПРОС О ТОМ, ЧТО ПЕРВЫМИ ПРЕТЕНДЕНТАМИ НА ПОЛУЧЕНИЕ ОПРЕДЕЛЕННЫХ ОПЛАЧИВАЕМЫХ ДОЛЖНОСТЕЙ В МЕСТНЫХ СТРУКТУРАХ УПРАВЛЕНИЯ МОГУТ СТАТЬ ТЕ ЛИЦА, КОТОРЫЕ УЖЕ ИМЕЛИ ОФИЦЕРСКИЕ ЧИНЫ (СМ. РАЗДЕЛ 1 ДАННОЙ СТАТЬИ). В РЕЗУЛЬТАТЕ, 2 НОЯБРЯ 1855 Г. ПРЕДСЕДАТЕЛЬ ПОГРАНИЧНОЙ КОМИССИИ В. ГРИГОРЬЕВ ПРЕДЛОЖИЛ НЕ ПРИСВАИВАТЬ КАЗАХСКИМ СТАРШИНАМ «ЧИНОВ НИ ДЕЙСТВИТЕЛЬНЫХ, НИ ЗАУРЯД», СЧИТАЯ, ЧТО «ПРИЛИЧНЕЕ ВЫДАТЬ ИМ КАФТАНЫ ИЛИ ВЕЩИ В ПОДАРОК», ИБО ПОЛУЧЕНИЕ ЧИНОВ СПОСОБСТВОВАЛА, ПО ЕГО МНЕНИЮ, «РАЗМНОЖЕНИЮ ЧИНОВНИЧЕСТВА В ОРДЕ ${ }^{84}$. ЭТУ ИДЕЮ ДАЛЬШЕ РАЗВИЛ Г.ГАСФОРТ, ГЕНЕРАЛ-ГУБЕРНАТОР ЗАПАДНОЙ СИБИРИ (В 1851-1861 ГГ.), НАПРАВИВШИЙ ДИРЕКТИВУ НАЧАЛЬНИКУ АЛАТАВСКОГО ОКРУГА О НЕОБХОДИМОСТИ СОБЛЮДАТЬ СТРОГУЮ УПОРЯДОЧЕННОСТЬ В НАГРАЖДЕНИИ КАЗАХОВ, А ИМЕННО «СПЕРВА МЕДАЛИ СЕРЕБРЯНЫЕ И ЗОЛОТЫЕ, А ПОТОМ УЖЕ ЧИНЫ». ЭТА ПОСЛЕДОВАТЕЛЬНОСТЬ, ПО ЕГО МНЕНИЮ, ПРИДАЛА БЫ «БОЛЬШЕЕ ЗНАЧЕНИЕ НАГРАДАМ» В ГЛАЗАХ КАЗАХОВ. ИСКЛЮЧЕНИЕМ К ПОЛУЧЕНИЮ ЧИНА МОГЛИ БЫТЬ ТОЛЬКО ТЕ «УСЛУГИ», КОТОРЫЕ БЫ « ВЫХОДИЛИ ИЗ РЯДА ОБЫКНОВЕННЫХ ${ }^{85}$.

РЕЗУЛЬТАТОМ ЭТИХ ОБСУЖДЕНИЙ И ПРЕДЛОЖЕНИЙ ОТ РЕГИОНАЛЬНЫХ ВЛАСТЕЙ СТАЛ ИМЕННОЙ УКАЗ АЛЕКСАНДРА ІІ ОТ 2 АПРЕЛЯ 1867 ГОДА « О ЗАПРЕЩЕНИИ ИСПРАШИВАТЬ ВОИНСКИЕ ЧИНЫ...» КОЧЕВЫМ НАРОДАМ ИМПЕРИИ (КАЗАХАМ, БАШКИРАМ, КАЛМЫКАМ). ПРИЧИНУ ЭТОМУ, ВЛАСТИ ОБЪЯСНЯЛИ ТЕМ, ЧТО ПОЛИТИКА РОССИЙСКОГО ПРАВИТЕЛЬСТВА В ЭТОТ ПЕРИОД НАПРАВЛЕНА НА «РАЗВИТИЕ У НИХ ГРАЖДАНСТВЕННОСТИ», А НЕ «ПОДДЕРЖАНИЯ СРЕДИ НИХ ВОИНСТВЕННЫХ НАКЛОННОСТЕЙ ${ }^{86}$, ТАК КАК ИНТЕГРАЦИЯ В ЕДИНОЕ ПОЛИТИКО-АДМИНИСТРАТИВНОЕ ПРОСТРАНСТВО ЗАВЕРШИЛОСЬ.

НЕСМОТРЯ НА ТО, ЧТО ПРАКТИКА НАГРАЖДЕНИЯ ВОЕННЫМИ ЧИНАМИ СТАЛА ИСПОЛЬЗОВАТЬСЯ С НАЧАЛА ХІХ В., ВОПРОС О ФОРМЕННОЙ ОДЕЖДЕ КАЗАХСКИХ ЧИНОВНИКОВ, ВКЛЮЧАВШИЙ ПОГОНЫ, СООТВЕТСТВУЮЩИЕ ИХ ОФИЦЕРСКИМ ЧИНАМ, СТАЛ РАЗРАБАТЫВАТЬСЯ НАМНОГО ПОЗЖЕ. ОДНИМ ИЗ ПЕРВЫХ ЭТОТ ВОПРОС ПОДНЯЛ ЗАПАДНО-СИБИРСКИЙ ГЕНЕРАЛ-ГУБЕРНАТОР ГУСТАВ ХРИСТИАНОВИЧ ГАСФОРД, ПОДГОТОВИВШИЙ ДОКЛАДНЫЕ НА ИМЯ ИМПЕРАТОРА О НЕОБХОДИМОСТИ РАЗРАБОТКИ ЕДИНОЙ ФОРМЫ ОДЕЖДЫ ДЛЯ КАЗАХСКИХ ЧИНОВНИКОВ, ИМЕВШИЙ ВОЕННЫЕ ЧИНЫ. НА ОСНОВАНИИ ЕГО ПРЕДЛОЖЕНИЙ 13 НОЯБРЯ 1856 ГОДА АЛЕКСАНДР ІІ ПОДПИСАЛ УКАЗ « О 
ФОРМЕ ОДЕЖДЫ ВСЕХ ИМЕЮЩИХ ВОЕННЫЕ ОФИЦЕРСКИЕ ЧИНЫ КИРГИЗСКИХ [КАЗАХСКИХ] СУЛТАНОВ И ПОЧЕТНЫХ КИРГИЗОВ [КАЗАХОВ] СРЕДНЕЙ И БОЛЬШОЙ ОРД», СОГЛАСНО КОТОРОМУ КАЗАХИ, ИМЕВШИЕ ОФИЦЕРСКИЕ ЧИНЫ, ДОЛЖНЫ БЫЛИ НОСИТЬ ПЛЕЧЕВЫЕ ПОГОНЫ СО ЗВЕЗДОЧКАМИ, НАШИТЫЕ НА КАФТАНАХ, ПО ОБРАЗЦУ СЛУЖАЩИХ В АРМИИ ШТАБ- ИЛИ ОБЕР-ОФИЦЕРОВ И САБЛИ КАВАЛЕРИЙСКИЕ НА ЗОЛОТЫХ ПОРТУПЕЯХ 87. ПОЛНАЯ ОФИЦЕРСКАЯ ФОРМА ПРЕДОСТАВЛЯЛАСЬ ТОЛЬКО КАЗАХАМ, ВЫПУЩЕННЫХ ИЗ СТЕН КАДЕТСКИХ КОРПУСОВ С ОФИЦЕРСКИМИ ЧИНАМИ (ХОРУНЖИЙ, СОТНИК, ПРАПОРщИК И Т.Д.) И ПРИКОМАНДИРОВАННЫМ НА СЛУЖБУ К ВОЕННЫМ ПОДРАЗДЕЛЕНИЯМ, РАСПОЛОЖЕННЫМ НА ТЕРРИТОРИИ ЗАПАДНО-СИБИРСКОГО ИЛИ ОРЕНБУРГСКОГО ВЕДОМСТВА. СПУСТЯ ТРИ ГОДА БЫЛИ ВНЕСЕНЫ ДОПОЛНЕНИЯ К ФОРМЕННОЙ ОДЕЖДЕ И ОБМУНДИРОВАНИЮ НЕРУССКИХ ЧИНОВНИКОВ СИБИРСКОГО, АСТРАХАНСКОГО И ОРЕНБУРГСКОГО ВЕДОМСТВ, ИМЕВШИХ ВОЕННЫЕ ЧИНЫ, НО НЕ ПРИЧИСЛЕННЫХ К ВОЙСКАМ ${ }^{88}$. ИМ РАЗРЕШАЛОСЬ ПРИШИВАТЬ ПЛЕЧЕВЫЕ ПОГОНЫ « ...В УСТАНОВЛЕННОМ ПОРЯДКЕ» НА НАЦИОНАЛЬНОМ КОСТЮМЕ. ИСКЛЮЧЕНИЕ СОСТАВЛЯЛИ «ЗОЛОТЫЕ ПЛЕЧЕВЫЕ ПОГОНЫ», КОТОРЫЕ МОЖНО БЫЛО ПРИШИВАТЬ ТОЛЬКО НА СПЕЦИАЛЬНЫЙ КАФТАН. ОБМУНДИРОВАНИЕ ДОПОЛНЯЛИ ЭПОЛЕТЫ, « ТАКЖЕ ЗОЛОТЫЕ, ЧЕШУЙЧАТЫЕ БЕЗ НОМЕРА СО ЗВЕЗДОЧКАМИ ДЛЯ РАЗЛИЧИЯ ЧИНОВ», А ТАКЖЕ КАВАЛЕРИЙСКАЯ САБЛЯ НА ЗОЛОТОЙ ПОЯСНОЙ ПОРТУПЕЕ С КРАСНЫМ ПОДБОЕМ. ЗАПАДНО-СИБИРСКИЙ ГЕНЕРАЛ-ГУБЕРНАТОР Г. ГАСФОРТ, УЧИТЫВАЯ ОСОБЕННОСТИ ОДЕЖДЫ КАЗАХСКОГО НАРОДА, ВНЕС КОРРЕКТИВЫ В ОПИСАНИЕ ГОЛОВНОГО УБОРА КАЗАХСКИХ ЧИНОВНИКОВ. ОН ПОСЧИТАЛ ВАЖНЫМ СОХРАНИТЬ ОБЫЧНЫЙ ГОЛОВНОЙ УБОР КАЗАХОВ (ОСТРОКОНЕЧНЫЕ ШАПКИ), НО КАЧЕСТВО МЕХА ДОЛЖНО БЫЛО ОТРАЖАТЬ ИЕРАРХИЮ ДОЛЖНОСТЕЙ. ТАК, СТАРШИЕ СУЛТАНЫ И ПРАВИТЕЛИ ДОЛЖНЫ БЫЛИ НОСИТЬ ШАПКУ С СОБОЛЬИМ ИЛИ КУНЬИМ МЕХОМ И ЗЕЛЕНОГО БАРХАТА ВЕРХУШКОЮ, А ГОЛОВНОЙ УБОР ШТАБ- И ОБЕР-ОФИЦЕРОВ ПРЕДПОЛАГАЛСЯ ИЗ ЧЕРНОЙ МЕРЛУШКИ С ТЕМНО-ЗЕЛЕНОЙ СУКОННОЙ ВЕРХУШКОЙ» ${ }^{89}$. НЕ СЛУЧАЙНО, ПРЕДСЕДАТЕЛЬ ОРЕНБУРГСКОЙ ПОГРАНИЧНОЙ КОМИССИИ В. ГРИГОРЬЕВ ПОДЧЕРКИВАЛ, ЧТО ДОЛЖНОСТЬ СУЛТАНА ПРАВИТЕЛЯ ЧАСТИ ЕСТЬ «ЗВАНИЕ ПРЕДСТАВИТЕЛЬНОЕ, ТРЕБУЮЩЕЕ ПОДДЕРЖАНИЯ И ВНУШАЮЩЕЙ УВАЖЕНИЕ ВНЕШНОСТИ» ${ }^{90}$. КОНЕЧНО, НЕ ВСЕ КАЗАХИ, ИМЕВШИЕ ОФИЦЕРСКИЕ ЧИНЫ, НОСИЛИ ФОРМЕННУЮ ОДЕЖДУ, НО К 60-М ГОДАМ ХІХ В., ПОЯВИЛИСЬ КАЗАХСКИЕ ЧИНОВНИКИ (МУХАМЕД - САЛИХ БАБАДЖАНОВ, АЛЬМУХАМЕД СЕЙДАЛИН И ДР.), КОТОРЫЕ ПОСТОЯННО ХОДИЛИ В ОФИЦЕРСКОЙ ФОРМЕ ${ }^{91}$. ОТРАЖЕНИЕМ ПРОЦЕССА ВХОЖДЕНИЯ СТЕПИ В ОБЩЕРОССИЙКСОЕ ПРОСТРАНСТВО СТАЛ ТОТ ФАКТ, ЧТО БОЛЬШИНСТВО ИЗ КАЗАХСКИХ ЧИНОВНИКОВ СТАЛИ КАВАЛЕРАМИ ОРДЕНОВ СВ. СТАНИСЛАВА, СВ. АННЫ 2-Й - 3-Й СТЕПЕНЕЙ. КРОМЕ ТОГО, КАЗАХИ, ИМЕВШИЕ ВОЕННЫЕ ЧИНЫ, НАРАВНЕ С ДРУГИМИ ПРЕДСТАВИТЕЛЯМИ ИРРЕГУЛЯРНЫХ ВОЙСК РОССИЙСКОЙ ИМПЕРИИ, НАГРАЖДАЛИСЬ СВЕТЛО-БРОНЗОВЫМИ МЕДАЛЯМИ В ПАМЯТЬ ВОЙНЫ 1853-1856 ГГ. РЕШЕНИЕ ВОПРОСА О ПОСТЕПЕННОЙ УНИФИКАЦИИ НАГРАДНОЙ СИСТЕМЫ ИМПЕРИИ ДЛЯ НАСЕЛЕНИЯ ЮГО-ВОСТОЧНЫХ ОКРАИН, НЕ ИСПОВЕДУЮЩИХ ХРИСТИАНСТВО, ВЫЛИЛСЯ В ИМЕННОЙ УКАЗ О ПОМЕЩЕНИИ НА ОРДЕНАХ, ЖАЛУЕМЫХ МУСУЛЬМАНАМ, ВМЕСТО ИЗОБРАЖЕНИЯ СВ. ГЕОРГИЯ НА КРЕСТЕ, ИМПЕРАТОРСКОГО ОРЛА» ОТ 9 АВГУСТА 1844 Г. ${ }^{92}$ ЗА ДОЛГОЛЕТНЮЮ СЛУЖБУ И ОСОБЫЕ ЗАСЛУГИ РЯД КАЗАХСКИХ ЧИНОВНИКОВ БЫЛИ НАГРАЖДЕНЫ ОРДЕНОМ СВ. ВЛАДИМИРА, ЧТО ДАВАЛО ПРАВО ВХОЖДЕНИЯ В ПОТОМСТВЕННОЕ РОССИЙСКОЕ ДВОРЯНСТВО. ТАК, ДЕРБИСАЛЫ БЕРКИМБАЕВА, ПРОСЛУЖИВШИЙ БОЛЕЕ 30 ЛЕТ В СИСТЕМЕ ТУРГАЙСКОГО ОБЛАСТНОГО ПРАВЛЕНИЯ, КАК КАВАЛЕР ОРДЕНА СВ. ВЛАДИМИРА IV-Й СТЕПЕНИ 
РЕШЕНИЕМ ПРАВИТЕЛЬСТВУЮЩЕГО СЕНАТА 13 ДЕКАБРЯ 1900 Г. БЫЛ ПРИЧИСЛЕН К ПОТОМСТВЕННОМУ ДВОРЯНСТВУ РОССИЙСКОЙ ИМПЕРИИ, КОТОРОЕ БЫЛО ЗАФИКСИРОВАНО ОРЕНБУРГСКИМ СОБРАНИЕМ ДВОРЯН ЗА №22993. ПОЯВЛЕНИЕМ НОВЫХ ТЕРРИТОРИАЛЬНО-АДМИНИСТРАТИВНЫХ СТРУКТУР И НОВЫХ ДОЛЖНОСТНЫХ ЛИЦ ИЗМЕНИЛОСЬ НЕ ТОЛЬКО ПРЕДСТАВЛЕНИЕ КАЗАХСКОГО НАСЕЛЕНИЯ О ТОМ, КАКИМ ДОЛЖЕН БЫТЬ УПРАВЛЕНЕЦ В СТЕПИ, НО ВОСПРИЯТИЕ САМИХ СЕБЯ, СВОИХ КЛАНОВ И СВОИХ ВЗАИМООТНОШЕНИЙ С РОССИЙСКОЙ ВЛАСТЬЮ. ЕСЛИ В XVII-XVIII ВВ. ВАЖНЫ БЫЛИ ТАКИЕ КАЧЕСТВА В УПРАВЛЕНИИ КАК МУЖЕСТВО, ОТВАГА, УМЕНИЕ ОРГАНИЗОВАТЬ ЗАЩИТУ ПАСТБИЩНЫХ ТЕРРИТОРИЙ КОЧЕВАНИЯ РОДОВЫХ ИЛИ ПЛЕМЕННЫХ ОБЪЕДИНЕНИЙ, ТО В ИЗМЕНИВШИХСЯ УСЛОВИЯХ ХІХВ. КАЗАХСКИЙ ЧИНОВНИК, НАХОДИВШИЙСЯ НА СЛУЖБЕ ИМПЕРИИ, ДОЛЖЕН БЫЛ БЫТЬ « ПРЕДСТАВИТЕЛЕМ НАШИМ ПРЕД ПРАВИТЕЛЬСТВОМ», НАСТАВНИКОМ, УМЕЮЩИМ АДЕКВАТНО «ПЕРЕДАВАТЬ ВСЕ РАСПОРЯЖЕНИЯ ПРАВИТЕЛЬСТВА» ${ }^{99}$. В ХІХ В. МЕСТО 
ПРЕДСТАВИТЕЛЕЙ КАЗАХСКОЙ ЗНАТИ ОПРЕДЕЛЯЛОСЬ НЕ ПРИНАДЛЕЖНОСТЬЮ К ОПРЕДЕЛЕННЫМ КЛАНАМ, А ВЕРНОСТЬЮ ПРИСЯГЕ «ЦАРЮ И ОТЕЧЕСТВУ», ЛИЧНЫМИ СПОСОБНОСТЯМИ И УМЕНИЕМ ПРИВЛЕЧЬ СВОЙ РОД, ОТДЕЛЕНИЕ, ИЛИ ПЛЕМЯ НА СЛУЖБУ ИМПЕРИИ И ЭТИМ САМЫМ СОХРАНИТЬ СВОЕ ВЛИЯНИЕ И ВЛАСТЬ.

СВИДЕТЕЛЬСТВОМ ДОСТАТОЧНОЙ ИНТЕГРАЦИИ КАЗАХОВ В РЕАЛИИ БЮРОКРАТИЧЕСКОЙ СИСТЕМЫ ИМПЕРИИ ЯВЛЯЕТСЯ ОСОЗНАНИЕ ИМИ ПРИНЦИПОВ ВЗАИМОДЕЙСТВИЯ С РУССКОЙ ВЛАСТЬЮ, ПРИНЯТИЯ НОВЫХ ФОРМ СОТРУДНИЧЕСТВА С РОССИЙСКОЙ АДМИНИСТРАЦИЕЙ. ЕСЛИ В ПЕРВОЙ ТРЕТИ ХІХ В. РЕГИОНАЛЬНЫЕ ВЛАСТИ ОТМЕЧАЛИ МЕДЛИТЕЛЬНОСТЬ, НЕПОСЛЕДОВАТЕЛЬНОСТЬ В ДЕЙСТВИЯХ КАЗАХСКИХ ЧИНОВНИКОВ, А В НЕКОТОРЫХ СЛУЧАЯХ СОВЕРШЕННУЮ БЕЗДЕЯТЕЛЬНОСТЬ, КОТОРАЯ ОГРАНИЧИВАЛАСЬ СОБСТВЕННО « ОДНОЮ ПЕРЕПИСКОЮ» И БОЛЕЕ ТОГО ИГНОРИРОВАНИЕМ П ПРДПИСАНИЙ НАЧАЛЬСТВА» ${ }^{100}$, НАЛИЧИЕМ «БЕСПОРЯДКА» В КАНЦЕЛЯРИИ ДОЛЖНОСТНЫХ ЛИЦ В СТЕПИ ${ }^{101}$, ТО В ПОСЛЕДУЮЩЕМ СИТУАЦИЯ ИЗМЕНИЛАСЬ. С 40-Х ГОДОВ ХІХ В. ПРАВИТЕЛИ ЧАСТЕЙ СЧИТАЛИ СВОЕЙ ОБЯЗАННОСТЬЮ СТАВИТЬ В ИЗВЕСТНОСТЬ ВЫШЕСТОЯЩИЕ ОРГАНЫ, В ДАННОМ СЛУЧАЕ ОРЕНБУРГСКУЮ АДМИНИСТРАЦИЮ, ОБ ИЗМЕНЕНИЯХ СВОИХ ДИСЛОКАЦИЙ В СТЕПИ, ДАБЫ «СВОЕВРЕМЕННО ПОЛУЧАТЬ КОРРЕСПОНДЕНЦИЮ И СВОЕВРЕМЕННО ОТВЕЧАТЬ НА НЕЕ». А С 60-Х ГОДОВ ХІХ В. НАБЛЮДАЕТСЯ ТАКАЯ ЖЕ ТЕНДЕНЦИЯ УЖЕ У ДИСТАНОЧНЫХ НАЧАЛЬНИКОВ, ИЗВЕЩАВШИЕ СУЛТАНОВ-ПРАВИТЕЛЕЙ О ВРЕМЕННОМ ВОЗЛОЖЕНИИ ОБЯЗАННОСТЕЙ НАЧАЛЬНИКА ДИСТАНЦИИ СВОЕМУ ПОМОЩНИКУ В ПЕРИОД ИХ ОТСУТСТВИЯ НА ПОДВЕДОМСТВЕННОЙ ЕМУ ТЕРРИТОРИИ ИЛИ КОМАНДИРОВОК «ПО ДЕЛАМ СЛУЖБЫ» ${ }^{102}$. ТАКОГО ХАРАКТЕРА ДОКУМЕНТЫ, ОТЛОЖИВШИЕСЯ В ФОНДАХ ГОСУДАРСТВЕННОГО АРХИВА РЕСПУБЛИКИ КАЗАХСТАН, СВИДЕТЕЛЬСТВУЮТ О ТОМ, ЧТО ДОЛЖНОСТНЫЕ ЛИЦА СТЕПИ (СУЛТАНЫ-ПРАВИТЕЛИ, ДИСТАНОЧНЫЕ ИЛИ МЕСТНЫЕ НАЧАЛЬНИКИ, ВОЛОСТНЫЕ И ДР.) НАЧАЛИ ВПИТЫВАТЬ АДМИНИСТРАТИВНЫЙ СТИЛЬ, ПОНИМАТЬ ОБЩИЕ ТРЕБОВАНИЯ, ПРЕДЪЯВЛЯЕМЫЕ РУССКОЙ ВЛАСТЬЮ К КАЗАХСКИМ УПРАВЛЕНЦАМ, ФОРМИРОВАТЬ СЛУЖЕБНЫЕ ОТНОШЕНИЯ С РЕГИОНАЛЬНОЙ АДМИНИСТРАЦИЕЙ. ПРЕДСЕДАТЕЛЬ ОРЕНБУРГСКОЙ ПОГРАНИЧНОЙ КОМИССИИ В.В.ГРИГОРЬЕВ ТОНКО ПОДМЕТИЛ, ЧТО МНОГИЕ ИЗ КАЗАХСКИХ ЧИНОВНИКОВ К КОНЦУ 50-Х ГОДОВ ХІХВ. СТАЛИ ПОНИМАТЬ « ПОРЯДОК НАШЕГО ДЕЛОПРОИЗВОДСТВА» ${ }^{103}$.

ПРОЦЕСС РАЗРУШЕНИЯ ПРЕДСТАВЛЕНИЙ КАЗАХОВ О ВЛАСТИ И ИХ АДАПТАЦИИ К НОВЫМ УСЛОВИЯМ МОЖНО ПРОСЛЕДИТЬ И ЧЕРЕЗ ПРОШЕНИЯ, ХОДАТАЙСТВА, ПИСЬМА ПРЕДСТАВИТЕЛЕЙ КАЗАХСКОЙ ЗНАТИ О ПРЕДОСТАВЛЕНИИ ИМ ВОЗМОЖНОСТИ ЗАНЯТЬ ОПРЕДЕЛЕННУЮ ДОЛЖНОСТЬ В МЕСТНЫХ ОРГАНАХ УПРАВЛЕНИЯ. В СВЯЗИ С ЭТИМ ИНТЕРЕС ПРЕДСТАВЛЯЕТ ПРОШЕНИЕ ОРЕНБУРГСКОМУ ВОЕННОМУ ГУБЕРНАТОРУ ДВУХ ЖЕН ЕСАУЛА, КАРАУЛ-ХОДЖИ БАБАДЖАНОВА, ДАТИРУЕМОЕ ОТ 20 ДЕКАБРЯ 1855 ГОДА ${ }^{104}$. ВО-ПЕРВЫХ, ОНИ ОБРАТИЛИ ВНИМАНИЕ ГУБЕРНАТОРА НА « СТОЛЬ ДОЛГОВРЕМЕННУЮ И БЕСПОРОЧНУЮ СЛУЖБУ» (БОЛЕЕ 45 ЛЕТ) ИХ ПОКОЙНОГО МУЖА, КАРАУЛ-ХОДЖИ БАБАДЖАНОВА. И ПОДНЯЛИ ВОПРОС О ТОМ, МОГУТ ЛИ ЕГО СЫНОВЬЯ, КАК «ДЕТИ ЧИНОВНИКА» ИМЕТЬ ПРЕИМУЩЕСТВО В ОПРЕДЕЛЕНИИ НА СЛУЖБУ ПЕРЕД ДЕТЬМИ НЕ ДОЛЖНОСТНЫХ СУЛТАНОВ, ТАК И «ТЕХ ДЕТЕЙ ПРОСТОЛЮДИНОВ», КОТОРЫЕ ТОЖЕ «УДОСТАИВАЮТСЯ СЛУЖБЫ». ВО-ВТОРЫХ, ПОНИМАЯ, ЧТО ИЗМЕНИЛИСЬ ТРЕБОВАНИЯ К ПРЕТЕНДЕНТАМ НА ДОЛЖНОСТЬ В СРАВНЕНИИ С ПЕРИОДОМ СЛУЖБЫ ИХ МУЖА, КОГДА ЗНАНИЕ РУССКОЙ ГРАМОТНОСТИ НЕ ЯВЛЯЛОСЬ ОПРЕДЕЛЯЮЩИМ, ОНИ ПОДЧЕРКНУЛИ В СВОЕМ ПРОЩЕНИИ, ЧТО ИХ СЫНОВЬЯ ОТЛИЧАЮТСЯ «ХОРОШИМ ЗНАНИЕМ РУССКОГО ЯЗЫКА» ${ }^{105}$. ДЕЙСТВИТЕЛЬНО, ЕСЛИ В СЕРЕДИНЕ 20-Х ГОДАХ ХІХ В. ОБУЧЕНИЕ В ТАКИХ 
УЧЕБНЫХ ЗАВЕДЕНИЯХ КАК ОРЕНБУРГСКИЙ КАДЕТСКИЙ КОРПУС ВОСПРИНИМАЛОСЬ КАК « ОПАСНОЕ», ТЕМ БОЛЕЕ ЧТО ОРЕНБУРГ ВОСПРИНИМАЛСЯ КАК « НЕДОСТУПНАЯ ДАЛЬ», ТО НАЧИНАЯ С КОНЦА 40-Х ГОДОВ ХІХ В. ОБУЧЕНИЕ КАЗАХСКИХ ДЕТЕЙ В КАДЕТСКОМ КОРПУСЕ СТАЛО МОДНЫМ ${ }^{106}$, А К НАЧАЛУ 60-Х ГОДОВ КАЗАХСКОЕ НАСЕЛЕНИЕ УЖЕ РАССМАТРИВАЛО ЗНАНИЕ УСТНОГО И ПИСЬМЕННОГО РУССКОГО ЯЗЫКА КАК ОДНУ ИЗ ВОЗМОЖНОСТЕЙ ПОЛУЧЕНИЯ ДОЛЖНОСТИ В СТЕПИ, СОХРАНЕНИЯ УВАЖЕНИЯ СРЕДИ РОДСТВЕННИКОВ. В-ТРЕТЬИХ, В ЭТОМ ПРОШЕНИИ ПРОСЛЕЖИВАЮТСЯ НЕ ТОЛЬКО ЖЕЛАНИЕ СОХРАНИТЬ ВЛИЯНИЕ СЕМЬИ НА СОПЛЕМЕННИКОВ ЧЕРЕЗ РЫЧАГИ ВЛАСТИ В УЖЕ НОВЫХ УСЛОВИЯХ, НО И МОТИВАЦИЯ СОЗДАНИЯ СЕМЕЙНОЙ ДИНАСТИИ ЧИНОВНИКОВ. И ЭТО НЕ СЛУЧАЙНО, ТАК КАК С 30-Х ГОДОВ ХІХ В. СТАЛИ СКЛАДЫВАТЬСЯ СЕМЕЙНЫЕ ДИНАСТИИ СРЕДИ СТАРШИХ СУЛТАНОВ И СУЛТАНОВ-ПРАВИТЕЛЕЙ. К ПРИМЕРУ, БАЙМУХАММЕТ АЙЧУАКОВ БЫЛ СУЛТАНОМ-ПРАВИТЕЛЕМ ЗАПАДНОЙ ЧАСТИ, А ЕГО СЫН М. БАЙМУХАМЕДОВ СТАЛ СУЛТАНОМ-ПРАВИТЕЛЕМ СРЕДНЕЙ ЧАСТИ; БРАТЬЯ АХМЕД И АРСЛАН ДЖАНТЮРИНЫ УПРАВЛЯЛИ В ВОСТОЧНОЙ И СРЕДНЕЙ ЧАСТЯХ. ЭТУ ТЕНДЕНЦИЮ МОЖНО ПРОСЛЕДИТЬ И ПРИ НАЗНАЧЕНИИ ДИСТАНОЧНЫХ ${ }^{107}$ ИЛИ МЕСТНЫХ НАЧАЛЬНИКОВ. ЗАЧАСТУЮ, ПОСЛЕ СМЕРТИ СВОИХ ОТЦОВ, ИХ СЫНОВЬЯ ЗАНИМАЛИ ЭТИ ДОЛЖНОСТИ, ОПИРАЯСЬ НА ОПЫТ СВОИХ РОДИТЕЛЕЙ И ИХ СЛУЖЕБНЫЕ СВЯЗИ. ПРИ ЭТОМ СОРОДИЧИ ВОСПРИНИМАЛИ ЭТО ФАКТ ПЕРЕХОДА ВЛАСТИ ОТ ОТЦА К СЫНУ ДОСТАТОЧНО СПОКОЙНО И, БОЛЕЕ ТОГО, САМИ ПОДДЕРЖИВАЛИ. НО, ПОСТЕПЕННО В ХОДЕ ТРАНСФОРМАЦИИ СОЦИАЛЬНОЙ СТРУКТУРЫ ЭТА ТРАДИЦИЯ В КОЧЕВЫХ ОБЩИНАХ ОСЛАБЕВАЛА, НО НОВАЯ НЕ УСПЕВАЛА СЛОЖИТЬСЯ И ПРОИСХОДИЛО СЛОЖНОЕ ВЗАИМОДЕЙСТВИЕ МЕЖДУ « ТРАДИЦИОННЫМ» И « НОВЫМ», КОТОРОЕ СОПРОВОЖДАЛОСЬ ИЗМЕНЕНИЕМ СОДЕРЖАНИЯ ТОГО И ДРУГОГО, ПЕРЕСТАНОВКОЙ АКЦЕНТОВ В ТОМ И ДРУГОМ.

НА ПРОТЯЖЕНИИ ХІХ В. ПРОИСХОДИЛ ПРОЦЕСС ИЗМЕНЕНИЯ ПРЕДСТАВЛЕНИЙ КАЗАХСКОГО НАСЕЛЕНИЯ НЕ ТОЛЬКО О НЕОБХОДИМОСТИ ЗНАНИЯ РУССКОЙ ГРАМОТЫ НА ГОСУДАРСТВЕННОЙ СЛУЖБЕ, НО И ВОСПРИЯТИЕ СОПЛЕМЕННИКОВ, ПОЛУЧИВШИХ ОБРАЗОВАНИЕ В РУССКИХ ЗАВЕДЕНИЯХ. ТЕНДЕНЦИЮ « НАСТОРОЖЕННОСТИ» СО СТОРОНЫ РОДОПРАВИТЕЛЕЙ, НЕ ЗНАВШИХ РУССКОГО ЯЗЫКА И ГРАМОТНОСТИ, ТОНКО ПОДМЕТИЛ НАЧАЛЬНИК 34-Й ДИСТАНЦИИ ВОСТОЧНОЙ ЧАСТИ ОРЕНБУРГСКОГО ВЕДОМСТВА ИСЕНГАЗЫ БАБИН. ОН ДОКЛАДЫВАЛ, ЧТО «ВСЕ ДОЛЖНОСТНЫЕ ЛИЦА И РОДОНАЧАЛЬНИКИ ВООБЩЕ НЕ РАСПОЛОЖЕНЫ К ПОДОБНЫМ МНЕ ЧИНОВНИКАМ», А ИМЕННО ВЫПУСКНИКАМ ОРЕНБУРГСКОГО КАДЕТСКОГО КОРПУСА, ИБО В НИХ ОНИ ВИДЯТ «...ДЛЯ СЕБЯ КАКУЮ-ТО ОПАСНОСТЬ» ${ }^{108}$. НО ЭТА ТЕНДЕНЦИЯ ПОСТЕПЕННО ПРЕОДОЛЕВАЛАСЬ, ПЕРЕЛОМНЫМ МОМЕНТОМ ТРАНСФОРМАЦИИ СОЗНАНИЯ КАЗАХСКОГО НАСЕЛЕНИЯ СТАЛА УСПЕШНАЯ ДЕЯТЕЛЬНОСТЬ СУЛТАНОВ-ПРАВИТЕЛЕЙ (А. ДЖАНТЮРИНА, М. БАЙМУХАМЕДОВА, М. ТАУКИНА, А. СЕЙДАЛИНА) НА РОССИЙСКОЙ СЛУЖБЕ, ХОРОШО ЗНАВШИХ НЕ ТОЛЬКО ТАТАРСКИЙ, НО И РУССКИЙ ЯЗЫК. КРОМЕ ТОГО, КАЗАХСКОЕ НАСЕЛЕНИЕ СТАЛО ОСОЗНАВАТЬ, ЧТО ЛЮБОЕ ПОРУЧЕНИЕ, РАСПОРЯЖЕНИЯ ОТ РУССКИХ ВЛАСТЕЙ, НАГРАДА ИЛИ ПООЩРЕНИЕ КАЗАХАМ ПЕРЕДАВАЛИСЬ ТОЛЬКО НА БУМАГЕ. УМЕНИЕ ПРОЧИТАТЬ ИХ И РАСТОЛКОВАТЬ СОПЛЕМЕННИКАМ ПОКАЗЫВАЛО КАЗАХСКОМУ НАСЕЛЕНИЮ СИЛУ ЗНАНИЯ, ГРАМОТНОСТИ. И КАЗАХ, КОТОРЫЙ МОГ СВОБОДНО ПРОЧИТАТЬ РУССКИЙ ТЕКСТ, СТАНОВИЛСЯ УВАЖАЕМЫМ И ПОЧЕТНЫМ ЧЕЛОВЕКОМ В СТЕПИ. И БОЛЕЕ ТОГО, К СЕРЕДИНЕ 60-Х ГОДОВ ХІХ В. ПОЯВИЛИСЬ ХОДАТАЙСТВА ОТ КАЗАХСКОГО НАСЕЛЕНИЯ О ТОМ, ЧТО ЛУЧШЕ УТВЕРЖДАТЬ НА ДОЛЖНОСТЬ ТОГО КАЗАХА, КТО ПОЛУЧИЛ ОБРАЗОВАНИЕ В РУССКИХ УЧЕБНЫХ ЗАВЕДЕНИЯХ. ОНИ МОТИВИРОВАЛИ 
ТЕМ, ЧТО ДОЛЖНОСТНОЕ ЛИЦО, ИМЕЮЩЕЕ ОБРАЗОВАНИЕ, МОГ БЫ ПЕРЕДАВАТЬ РАСПОРЯЖЕНИЯ ПРАВИТЕЛЬСТВА «НЕ ТАК ПРЕВРАТНО И ЛОЖНО, КАК БЫВАЛО, ЭТО ДЕЛАЛОСЬ ПРЕЖДЕ» ${ }^{109}$. ДЕЙСТВИТЕЛЬНО, В 60-Х ГОДАХ ХІХ В. НАЧАЛАСЬ ПРАКТИКА НАЗНАЧЕНИЯ НА ДОЛЖНОСТИ ДИСТАНОЧНЫХ И МЕСТНЫХ НАЧАЛЬНИКОВ ВЫПУСКНИКОВ ШКОЛЫ ДЛЯ КАЗАХСКИХ ДЕТЕЙ ПРИ ОРЕНБУРГСКОЙ ПОГРАНИЧНОЙ КОМИССИИ. К ПРИМЕРУ, ВЫПУСКНИК ЭТОЙ ШКОЛЫ, КАНЧУВАК БАЙТОКОВ ЗАНИМАЛ ДОЛЖНОСТЬ НАЧАЛЬНИКА ПЕРВОЙ ПОЛОВИНЫ 8-Й ДИСТАНЦИИ $1862-1864$ ГГ. ${ }^{110}$ В 1865 ГОДУ ОБЛАСТНОЕ ПРАВЛЕНИЕ ОРЕНБУРГСКИМИ КАЗАХАМИ ПРЕДПИСАЛА СУЛТАНУ-ПРАВИТЕЛЮ ВОСТОЧНОЙ ЧАСТИ ПРЕДОСТАВИТЬ ДОЛЖНОСТЬ ВЫПУСКНИКУ ШКОЛЫ ДЛЯ КАЗАХСКИХ ДЕТЕЙ ПРИ ОРЕНБУРГСКОЙ ПОГРАНИЧНОЙ КОМИССИИ ИДИГУ АЙТУКИНУ ПРИ ПЕРВОЙ ОТКРЫВШЕЙСЯ ВАКАНСИИ В СИСТЕМЕ МЕСТНОГО УПРАВЛЕНИЯ В СТЕПИ ${ }^{111}$. К КОНЦУ 90-Х ГОДОВ ХІХ В., ПО МНЕНИЮ ВОЕННОГО ГУБЕРНАТОРА ТУРГАЙСКОЙ ОБЛАСТИ Я.Ф. БАРАБАША, КАЗАХИ СТАЛИ ЯСНО ОСОЗНАВАТЬ ПОЛЬЗУ РУССКОГО ОБРАЗОВАНИЯ И НЕОБХОДИМОСТЬ РУССКОГО ЯЗЫКА ДЛЯ ДОЛЖНОСТНЫХ ЛИЦ ОБЩЕСТВЕННОГО УПРАВЛЕНИЯ» ${ }^{112}$.

СЛЕДУЮЩИМ ХАРАКТЕРНЫМ ПРИЗНАКОМ В ПРОШЕНИЯХ КАЗАХОВ О ПРИЕМЕ НА РАБОТУ В ТУ ИЛИ ИНУЮ СТРУКТУРУ СТАЛ НЕ ТОЛЬКО ОБРАЗОВАТЕЛЬНЫЙ ФАКТОР, НО НАЛИЧИЕ ОПЫТА РАБОТЫ В АДМИНИСТРАТИВНЫХ ОРГАНАХ. ТАК, СУЛТАН ИШИМЖАН САМАТОВ ПИСАЛ УПРАВЛЯЮЩЕМУ ОБЛАСТЬЮ ОРЕНБУРГСКИХ КАЗАХОВ Л.Ф. БАЛЛЮЗЕКУ, ЧТО ОН «СПОСОБЕН ЗАНЯТЬ ВСЯКУЮ ДОЛЖНОСТЬ», КАК ВЫПУСКНИК КАЗАХСКОЙ ШКОЛЫ ПРИ ОРЕНБУРГСКОМ ОБЛАСТНОМ ПРАВЛЕНИИ, ИМЕВШИЙ ОПЫТ РАБОТЫ В КАНЦЕЛЯРИИ ОРЕНБУРГСКОГО ГЕНЕРАЛ-ГУБЕРНАТОРА В ТЕЧЕНИЕ ЧЕТЫРЕХ ЛЕТ (1859 ПО 1863 Г.). БОЛЕЕ ТОГО, ОН ПОДЧЕРКИВАЛ В СВОЕМ ПИСЬМЕ, ЧТО О ЕГО ПРЕЖНЕЙ СЛУЖБЕ МОГУТ « ЗАСВИДЕТЕЛЬСТВОВАТЬ» ВСЕ НАЧАЛЬНИКИ И СОСЛУЖИВЦЫ, КАК ГЕНЕРАЛ-ГУБЕРНАТОРСКОЙ КАНЦЕЛЯРИИ, ТАК И ОБЛАСТНОГО ПРАВЛЕНИЯ ${ }^{113}$.

\section{Заключение}

НА ПРОТЯЖЕНИИ ХІХВ. В КАЗАХСКОЙ СТЕПИ ПРОИЗОШЛО НЕ ТОЛЬКО СМЕЩЕНИЕ АДМИНИСТРАТИВНО-ОРГАНИЗАЦИОННОГО ЦЕНТРА ОТ КОЧЕВЫХ ИНСТИТУТОВ ВЛАСТИ (КУРУЛТАЙ, СЪЕЗДЫ СТАРШИН) К РОССИЙСКИМ ГОСУДАРСТВЕННЫМ УЧРЕЖДЕНИЯМ (ОБЛАСТНОЕ, УЕЗДНОЕ ПРАВЛЕНИЕ, ВОЛОСТНЫЕ, АУЛЬНЫЕ СЪЕЗДЫ), НО И ИЗМЕНИЛОСЬ ПОЛОЖЕНИЕ КАЗАХСКОЙ ЭЛИТЫ, ИХ РОЛЬ В КОЧЕВОМ ОБЩЕСТВЕ. ПОДОБНАЯ ПРАКТИКА НЕ ЯВЛЯЛАСЬ ИСКЛЮЧЕНИЕМ ПО ОТНОШЕНИЮ К СТЕПИ. РОССИЙСКОЕ ПРАВИТЕЛЬСТВО ОСУЩЕСТВЛЯЛО ШИРОКОМАСШТАБНЫЕ РЕФОРМЫ, КАК ПО АДМИНИСТРАТИВНОМУ УСТРОЙСТВУ РЕГИОНОВ ИМПЕРИИ, ТАК И ПО ИНКОРПОРАЦИИ МЕСТНЫХ ЭЛИТ НЕРУССКИХ НАРОДОВ (ТАТАРЫ, БАШКИРЫ, МИШАРИ, КАЛМЫКИ И ДР.) В НОВЫЕ ПРАВЯЩИЕ СОСЛОВИЯ КАК РОССИЙСКОЕ ДВОРЯНСТВО, ЧИНОВНИЧЕСТВО. КОНЕЧНО, ЭТОТ ПРОЦЕСС ИМЕЛ В РАЗНЫХ РЕГИОНАХ СВОЮ СПЕЦИФИКУ И СВОИ ЗАКОНОДАТЕЛЬНЫЕ ОСНОВАНИЯ, НО В ЦЕЛОМ ПРАВИТЕЛЬСТВО ПОСТЕПЕННО ПРОВОДИЛО ПОЛИТИКУ ПО ВВЕДЕНИЮ ИХ В ОБЩЕРОССИЙСКУЮ ВЕРТИКАЛЬ УПРАВЛЕНИЯ.

НА ПРОТЯЖЕНИИ ХІХ В. РОССИЙСКОЕ ПРАВИТЕЛЬСТВО ОСУЩЕСТВЛЯЛО ПОЛИТИКУ ПО СОЗДАНИЮ НАДЕЖНОЙ СОЦИАЛЬНОЙ ОПОРЫ ПОСРЕДСТВОМ ФОРМИРОВАНИЯ МЕСТНЫХ ГОСУДАРСТВЕННЫХ ЧИНОВНИКОВ, СТАВШИХ ПАРТНЕРАМИ РОССИЙСКОЙ ВЛАСТИ И 
ПРОВОДНИКАМИ ИХ ВОЛИ В СТЕПИ. ЭТОТ ПРОЦЕСС БЫЛ СЛОЖНЫМ И ПРОТИВОРЕЧИВЫМ, ВКЛЮЧАВШИЙ ДВА ЭТАПА :

1. 20-50-Е ГОДЫ ХІХВ. ОПОЗНАВАТЕЛЬНЫЕ ЗНАКИ ЭТОГО ПЕРИОДА - СОЗДАНИЕ ОПРЕДЕЛЕННОЙ АДМИНИСТРАТИВНОЙ ВЕРТИКАЛИ ВЛАСТИ И ПОСТЕПЕННЫЙ ПЕРЕХОД К НАЗНАЧАЕМОСТИ ПРЕДСТАВИТЕЛЕЙ КАЗАХСКОЙ РОДОВОЙ ЗНАТИ НА СИСТЕМУ ДОЛЖНОСТЕЙ, СОЗДАННЫХ В СТЕПИ. СОЗДАНИЕ НОВОЙ ИЕРАРХИИ ДОЛЖНОСТЕЙ В КАЗАХСКОМ КОЧЕВОМ ОБЩЕСТВЕ И ОТВЕТСТВЕННОСТЬ НАЗНАЧЕННЫХ ЛИЦ НА ОТДЕЛЬНОМ АДМИНИСТРАТИВНО-ТЕРРИТОРИАЛЬНОМ УЧАСТКЕ ДЕЛАЛО СТЕПЬ БОЛЕЕ УПРАВЛЯЕМОЙ.

ПРАКТИКА ВЫБОРА, МОТИВЫ И ТРЕБОВАНИЯ, ПРЕДЪЯВЛЯЕМЫЕ К ПРЕДСТАВИТЕЛЯМ КАЗАХСКОЙ ЭЛИТЫ ПРИ НАЗНАЧЕНИЯ НА СОЗДАВАЕМЫЕ В ПРОЦЕССЕ АДМИНИСТРАТИВНОГО РЕФОРМИРОВАНИЯ СТЕПИ ДОЛЖНОСТИ ПОСТЕПЕННО МЕНЯЛИСЬ. НА ПЕРВОМ ЭТАПЕ РОССИЙСКИЕ ВЛАСТИ СОСТАВЛЯЛИ СПИСКИ ПРЕДСТАВИТЕЛЕЙ ВЛИЯТЕЛЬНЫХ КАЗАХОВ, ИМЕВШИЕ СПО-СОБНОСТИ К ЗАНЯТИЮ ДОЛЖНОСТИ В СИСТЕМЕ МЕСТНОГО УПРАВЛЕНИЯ. САМОЕ ГЛАВНОЕ МЕРИЛО ДЛЯ КООПТАЦИИ ПРЕД-СТАВИТЕЛЕЙ КАЗАХСКОГО НАРОДА НА СЛУЖБУ - «ПРЕДАННОСТЬ РУССКОЙ ВЛАСТИ», « ИСПОЛНИТЕЛЬНОСТЬ» И “УСЕРДИЕ» В ДЕЛАХ. НЕ ЯВЛЯЛОСЬ ОПРЕДЕЛЯЮЩИМ ДЛЯ РЕГИОНАЛЬНОЙ АДМИНИСТРАЦИИ В ПЕРВОЙ ПОЛОВИНЕ ХІХ В. И ТОТ ФАКТ, НАХОДИЛСЯ ЛИ « ПОД СЛЕДСТВИЕМ» ПРЕТЕНДЕНТ НА ДОЛЖНОСТЬ ИЛИ НЕТ. ИЗВЕСТНЫЙ ВОСТОКОВЕД В.В. ГРИГОРЬЕВ, ПРОСЛУЖИВШИЙ НА ДОЛЖНОСТИ ПРЕДСЕДАТЕЛЯ ОРЕНБУРГСКОЙ ПОГРАНИЧНОЙ КОМИССИИ ОКОЛО ДЕСЯТИ ЛЕТ, ХОРОШО ЗНАВШИЙ БЫТ И ОБРАЗ ЖИЗНИ КАЗАХСКОГО КОЧЕВОГО ОБЩЕСТВА СЧИТАЛ, ЧТО «ЕСЛИ ЗАТРУДНЯТЬСЯ ПОДОБНЫМИ ОБСТОЯТЕЛЬСТВАМИ В СЛУЖЕБНЫХ НАЗНАЧЕНИЯХ ОРДЫНЦЕВ, ТО ПРИШЛОСЬ БЫ ОПРЕДЕЛЯТЬ БОЛЬШЕЙ ЧАСТЬЮ ЛЮДЕЙ НЕСПОСОБНЫХ. КИРГИЗ [КАЗАХ] УМНЫЙ И ВЛИЯТЕЛЬНЫЙ НИКАК НЕ МОЖЕТ ПРОЖИТЬ БЕЗ ТОГО, ЧТОБ НЕ ЗАПУТАТЬСЯ В КАКИЕ-ЛИБО ИНТРИГИ, В ТОМ ИЛИ ДРУГОМ СЛУЧАЕ НЕ УПОТРЕБИТЬ ВЛИЯНИЕ СВОЕ ВО ЗЛО И НЕ ПОДПАСТЬ ВСЛЕДСТВИЕ ЭТОГО ПОД ОТВЕТСТВЕННОСТЬ ${ }^{114}$.

МОЖНО СКАЗАТЬ И О ТОМ, ЧТО НА ЭТОМ ЭТАПЕ КАЗАХСКИЕ ЧИНОВНИКИ ВОЗГЛАВИЛИ ПРОЦЕСС МОДЕРНИЗАЦИИ КАЗАХСКОГО КОЧЕВОГО ОБЩЕСТВА, ОТПРАВЛЯЯ СВОИХ ДЕТЕЙ В ОТКРЫВАВШИЕСЯ УЧЕБНЫЕ ЗАВЕДЕНИЯ РЕГИОНА (ОРЕНБУРГСКИЙ НЕПЛЮЕВСКИЙ КАДЕТСКИЙ КОРПУС, ОМСКИЙ КАДЕТСКИЙ КОРПУС, ШКОЛА ДЛЯ КАЗАХСКИХ ДЕТЕЙ ПРИ ОРЕНБУРГСКОЙ ПОГРАНИЧНОЙ КОМИССИИ И ДР.). ИМЕННО ИЗ ИХ СЕМЕЙ ВПОСЛЕДСТВИИ НАЧНЕТ ФОРМИРОВАТЬСЯ ПЕРВАЯ ПЛЕЯДА КАЗАХСКОЙ ИНТЕЛЛИГЕНЦИИ (ЧОКАН ВАЛИХАНОВ, САЛИХ БАБАДЖАНОВ, СЕЙТЖАН ДЖАНТЮРИН, МУХАМЕД-ГАЛИ ТАУКИН И дР.).

52 2. НА ВТОРОМ ЭТАПЕ (ВТОРАЯ ПОЛОВИНА ХІХ ВЕКА) РОССИЙСКИЕ ВЛАСТИ ПЕРЕШЛИ ОТ ПОЛИВАРИАНТНОГО ПОДХОДА В АДМИНИСТРАТИВНОМ УСТРОЙСТВЕ РАЗНЫХ РЕГИОНОВ СТЕПИ К МОНОВАРИАНТНОЙ МОДЕЛИ. НА ВСЕЙ ТЕРРИТОРИИ КАЗАХСКОЙ СТЕПИ ПРОИСХОДИТ УНИФИКАЦИЯ ВСЕХ ЗВЕНЬЕВ УПРАВЛЕНИЯ И ВВОДИТСЯ ЕДИНАЯ ТЕРРИТОРИАЛЬНО-АДМИНИСТРАТИВНАЯ СИСТЕМА (ОБЛАСТЬ - УЕЗД - ВОЛОСТЬ - АУЛ). ПРИ ЭТОМ ПО ОТНОШЕНИЮ К НИЗОВОМУ ЗВЕНУ УПРАВЛЕНИЯ ВВОДИТСЯ ТЕРМИН « ОБЩЕСТВЕННОЕ УПРАВЛЕНИЕ», ПОД КОТОРЫМ ПОНИМАЛОСЬ ВЫПОЛНЕНИЕ ОБЩЕСТВОМ (ВОЛОСТЬ, АУЛ) ПОРУЧЕННЫХ ЕМУ ГОСУДАРСТВОМ ЗАДАЧ. ПОКАЗАТЕЛЕМ ИНКОРПОРИРОВАННОСТИ КАЗАХСКОГО КОЧЕВОГО ОБЩЕСТВА В ОБЩЕРОССИЙСКУЮ АДМИНИСТРАТИВНО-УПРАВЛЕНЧЕСКУЮ СИСТЕМУ СТАЛ И ТОТ ФАКТ, ЧТО НА 
ПРОТЯЖЕНИИ БОЛЕЕ СОРОКА ЛЕТ (1870-1916) НА ТЕРРИТОРИИ СТЕПИ НЕ ПРОИЗОШЛО НИ ОДНОГО НАЦИОНАЛЬНО-ОСВОБОДИТЕЛЬНОГО ДВИЖЕНИЯ КАЗАХСКОГО НАРОДА ПРОТИВ ПОЛИТИКИ РОССИЙСКОЙ ВЛАСТИ.

СОДЕРЖАНИЕ И ПОНИМАНИЕ СЛУЖЕБНОЙ ДЕЯТЕЛЬНОСТИ КАЗАХАМИ, ЗАНИМАВШИЕ ДОЛЖНОСТИ В СИСТЕМЕ ОБЛАСТНОГО И УЕЗДНОГО ПРАВЛЕНИЯ ПРЕТЕРПЕЛИ ИЗМЕНЕНИЯ. ЭТО НАШЛО СВОЕ ВЫРАЖЕНИЕ В ПОВЫШЕНИИ ОБРАЗОВАТЕЛЬНОГО УРОВНЯ КАЗАХСКИХ ЧИНОВНИКОВ. ТЕПЕРЬ РЕАЛЬНЫЕ ДОСТОИНСТВА (ОБРАЗОВАНИЕ, СПОСОБНОСТИ, А НЕ ПРИНАДЛЕЖНОСТЬ КЛАНУ), ОПЫТ АДМИНИСТРАТИВНОЙ РАБОТЫ, ЗНАНИЕ БЫТА И КУЛЬТУРЫ КАЗАХСКОГО НАРОДА ПРЕДОПРЕДЕЛЯЛИ ИХ ДАЛЬНЕЙШИЙ КАРЬЕРНЫЙ РОСТ, Т.Е. НАЧАЛАСЬ ТАК НАЗЫВАЕМАЯ ПРОФЕССИОНАЛИЗАЦИЯ ГОСУДАРСТВЕННОЙ СЛУЖБЫ. ОТРАЖЕНИЕМ ИЗМЕНИВШЕЙСЯ СИТУАЦИИ СТАЛО И ЗАСЕДАНИЕ ПРАВИТЕЛЬСТВУЮЩЕГО СЕНАТА ОТ 23 ДЕКАБРЯ 1885 Г., КОНТАТИРОВАВШЕГО ФАКТ, ЧТО КАЗАХИ, НАХОДИВШИЕСЯ НА СЛУЖБЕ ИМЕРАТОРУ И ПРАВЯЩЕЙ ДИНАСТИИ, «ВЫШЛИ ИЗ СОСТОЯНИЯ СЕЛЬСКИХ ОБЫВАТЕЛЕЙ И ПОЛЬЗУЮТСЯ ПРАВАМИ ДРУГИЙ СОСЛОВИЙ» И СООТВЕТСТВЕННО ВСЕ УГОЛОВНЫЕ И ГРАЖДАНСКИЕ ДЕЛА, СВЯЗАННЫЕ С НИМИ ДОЛЖНЫ РАССМАТРИВАТЬСЯ НА ОСНОВАНИИ ОБЩИХ ЗАКОНОВ ИМПЕРИИ» ${ }^{115}$.

\section{NOTES}

1. СМ. : В.А. ИВАНОВ, ГУБЕРНСКИЕ ЧИНОВНИКИ 50-60 ГГ. ХІХ В. В РОССИИ. (ПО МАТЕРИАЛАМ МОСКОВСКОЙ И КАЛУЖСКОЙ ГУБЕРНИЙ) : ИСТОРИКО-ИСТОЧНИКОВЕДЧЕСКИЕ ОЧЕРКИ, КАЛУГА : КГПИ ИМ. к.э. ЦИОЛКОВСКОГО, 1994.

2. В.О. БОБРОВНИКОВ, «ВОЕННО-НАРОДНОЕ УПРАВЛЕНИЕ НА СЕВЕРНОМ КАВКАЗЕ (ДАГЕСТАН) : МУСУЛЬМАНСКАЯ ПЕРИФЕРИЯ В РОССИЙСКОМ ИМПЕРСКОМ ПРОСТРАНСТВЕ ХIX-ХХ ВВ.» В Б.В. АНАНЬИЧ, С.И. БАРЗИЛОВ, НАУЧНЫЕ РЕДАКТОРЫ, ПРОСТРАНСТВО ВЛАСТИ : ИСТОРИЧЕСКИЙ ОПЫТ РОССИИ И ВЫЗОВЫ СОВРЕМЕННОСТИ, М. : МОСКОВСКИЙ ОБЩЕСТВЕННЫЙ НАУЧНЫЙ ФОНД, 2001, с. 372-391.

3. G. Sultangalieva, "The role of the pristavstvo institution in the context of Russian imperial policies in the Kazakh Steppe in the nineteenth century", Central Asian Survey, 33 (1), 2014, c. 62-79.

4. R.G. Robbins, Jr., The Tsar's Viceroys : Russian Provincial Governors in the Last Years of the Empire, Ithaca - London, 1987 ; Н.П. МАТХАНОВА, ГЕНЕРАЛ-ГУБЕРНАТОРЫ ВОСТОЧНОЙ СИБИРИ СЕРЕДИНЫ ХІХ В. : В.Я. РУПЕРТ, Н.Н. МУРАВЬЕВ-АМУРСКИЙ, М.С. КОРСАКОВ, НОВОСИБИРСК : ИЗД-ВО СО РАН, 1998 ; ГУБЕРНАТОРЫ ОРЕНБУРГСКОГО КРАЯ, ОРЕНБУРГ : ОРЕНБ. КН.ИЗД-ВО, 1999 ; А.В. РЕМНЕВ, «РЕГИОНАЛЬНЫЕ ПАРАМЕТРЫ ИМПЕРСКОЙ «ГЕОГРАФИИ ВЛАСТИ»: СИБИРЬ И ДАЛЬНИЙ ВостОК», Аb Imperio, 2000, № 3-4, с. 343-358 ; J.P. LeDonne, “Administrative regionalization in the Russian empire, 1802-1826", Cahiers du Monde russe, 43 (1), janvier-mars 2002, c. 5-28; Thomas S. Pearson, Russian Officialdom in Crisis: Autocracy and Local Self-Government, 1861-1900, Cambridge University Press, 2004; С.В. ЛюБИчАНковский, ГУБЕРНСКОЕ ПРАВЛЕНИЕ В СИСТЕМЕ ГУБЕРНАТОРСКОЙ ВЛАСТИ В ПОСЛЕДНЕЕ ДЕСЯТИЛЕТИЕ СУЩЕСТВОВАНИЯ РОССИЙСКОЙ ИМПЕРИИ: НА МАТЕРИАЛАХ УРАЛА, ЕКАТЕРИНБУРГ : ИЗД-ВО УРАЛЬСКОГО УН-ТА, 2003 ; К. МАЦУЗАТО, « ГЕНЕРАЛ-ГУБЕРНАТОРСТВА В РОССИЙСКОЙ ИМПЕРИИ : 
ОТ ЭТНИЧЕСКОГО К ПРОСТРАНСТВЕННОМУ ПОДХОДУ», НОВАЯ ИМПЕРСКАЯ ИСТОРИЯ ПОСТСОВЕТСКОГО ПРОСТРАНСТВА, КАЗАНЬ : ИЗД-ВО КАЗАНСКОГО УН-ТА, 2004, с. 427-458; А. БИКТАШЕВА, КАЗАНСКОЕ ГУБЕРНАТОРСТВО ПЕРВОЙ ПОЛОВИНЫ ХІХ ВЕКА : БРЕМЯ ВЛАСТИ, М. : РУКОПИСНЫЕ ПАМЯТНИКИ ДРЕВНЕЙ РУСИ, 2014.

5. ИНКОРПОРАЦИЯ ПРЕДСТАВИТЕЛЕЙ НЕРУССКИХ НАРОДОВ НА ГОСУДАРСТВЕННУЮ СЛУЖБУ В КОНТЕКСТЕ НАЦИОНАЛЬНОЙ ПОЛИТИКИ ИМПЕРСКОЙ РОССИИ ПРЕДСТАВЛЕНА В ИССЛЕДОВАНИИ НЕМЕЦКОГО УЧЕНОГО АНДРЕАС КАППЕЛЕРА. АНДРЕАС КАППЕЛЕР, РОССИЯ МНОГОНАЦИОНАЛЬНАЯ ИМПЕРИЯ: ВОЗНИКНОВЕНИЕ, ИСТОРИЯ, РАСПАД (ПЕРЕВОД С НЕМ.ЯЗ. С.ЧЕРВОННОЙ),

М. : ПРОГРЕСС-ТРАДИЦИЯ, 2000.

6. см. РАБоты : V. Martin, Law and Custom in the Steppe : The Kazakhs of the Middle Horde and Russian Colonialism in the Nineteenth Century, Richmond : Curzon Press, 2001.

7. CM. : Charles Steindwedel, "How Bashkiria became part of European Russia, 1762-1881" B Jane Burbank, Mark von Hagen and Anatolyi Remnev eds., Russian Empire : Space, People, Power, 1700-1930, Indiana University Press, 2007, c. 94-125; Н. ТАГИРОВА, КАНТОННЫЕ НАЧАЛЬНИКИ БАШКИРИИ: НАЦИОНАЛЬНАЯ РЕГИОНАЛЬНАЯ ЭЛИТА ПЕРВОЙ ПОЛОВИНЫ ХІХ В., УФА: УНЦ ииял, 2012.

8. К.Н. МАКСИМОВ, КАЛМЫКИЯ В НАЦИОНАЛЬНОЙ ПОЛИТИКЕ, СИСТЕМЕ ВЛАСТИ И УПРАВЛЕНИЯ РОССИИ, М.: НАУКА, 2002 ; Е.А. КОМАНДЖАЕВ, ОРГАНЫ УПРАВЛЕНИЯ И СУДА В КАЛМЫКИИ XVIII-XIX ВВ., ЭЛИСТА : АПП « ДЖАНГАР», 2003.

9. В СОСТАВ ПОГРАНИЧНОГО СУДА НАРЯДУ С РУССКИМИ ОФИЦЕРАМИ ВОШЛИ ШЕСТЬ КАЗАХСКИХ СТАРШИН И ОДИН СУЛТАН, ИХ ЖАЛОВАНИЕ СОСТАВИЛО 850 РУБЛЕЙ В ГОД (ПО 142 РУБ. КАЖДОМУ). «О ЕЖЕГОДНОМ ОТПУСКЕ СУММ НА СОДЕРЖАНИЕ УЧРЕЖДАЕМОГО В ОРЕНБУРГЕ ПОГРАНИЧНОГО СУДА, СТАРШИН, КИРГИЗСКИХ РАСПРАВ И НАЧАЛЬНИКОВ В ОРДЕ», ПСЗ РИ (ПОЛНОЕ СОБРАНИЕ ЗАКОНОВ РОССИЙСКОЙ ИМПЕРИИ)Т.22, СПБ., 1830, №16403, ОТ 4 ИЮНЯ 1786 Г, с. 611-612.

10. ОБ УЧРЕЖДЕНИИ В КИРГИЗ-КАЙСАЦКОЙ ОРДЕ ТРЕХ РАСПРАВ. С ПРИЛОЖЕНИЕМ ШТАТА ОНЫМ. 7 ДЕКАБРЯ 1787 Г. ПСЗ РИ -1, Т. 22, №16592, СПБ., 1830, с. 950.

11. См. : Allen Frank, "Islamic Transformation on the Kazakh Steppe, 1742-1917 : Toward an Islamic History of Kazakhstan under Russian rule" in Hayashi Tadayuki, ed., The Construction and Deconstruction of National Histories in Slavic Eurasia, Sapporo, 2003, c. 261-290; G. Sultangalieva, "The Russian Empire and the Intermediary Role of Tatars in Kazakhstan: The Politics of Cooperation and Rejection, From the Second Half of the Eighteenth to the Early Twentieth Century" B Tomohiko Uyama, ed., Asiatic Russia : Imperial Power in Regional and International Contexts, London : Routledge, 2012, c. 52-79.

12. Г.С. СУЛТАНГАЛИЕВА, « ТАТАРСКИЕ И БАШКИРСКИЕ СЛУЖАЩИЕ В КАЗАХСКОЙ СТЕПИ В ХVIIIХІХ ВВ.», ЭТНОПОНАРАМА (ОРЕНБУРГ), 2000, №3, с. 48-54 ; ОНА ЖЕ : «КАРАТОЛМАЧ, ШТАБС-КАПИТАН МУХАММЕД-ШАРИФ АИТОВ В КАЗАХСКОЙ СТЕПИ (ПЕРВАЯ ПОЛОВИНА ХІХ В.)», ПАНОРАМА ЕВРАЗИИ, УФА, 2008, № 2, с. 13-22.

13. ИСТОРИЯ РАЗРАБОТКИ ТАБЕЛИ О РАНГАХ И ИЗМЕНЕНИЕ ПРИНЦИПОВ ЧИНОПРОИЗВОДСТВА В СРАВНИТЕЛЬНОМ КОНТЕКСТЕ С ЕВРОПЕЙСКИМИ СТРАНАМИ РАССМОТРЕНА В МОНОГРАФИИ А.Н. МЕДУШЕВСКОГО. А.Н. МЕДУШЕВСКИЙ, УТВЕРЖДЕНИЕ АБСОЛЮТИЗМА В РОССИИ : СРАВНИТЕЛЬНОЕ ИСТОРИЧЕСКОЕ ИССЛЕДОВАНИЕ, М. :ТЕКСТ,1994. ОПРЕДЕЛЕННУЮ ЛЕПТУ В ИЗУЧЕНИЕ СИСТЕМЫ ВОЕННЫХ, ГРАЖДАНСКИХ, ПРИДВОРНЫХ ТИТУЛОВ И ЧИНОВ И СООТВЕТСТВОВАВШИХ ИМ МУНДИРОВ И ОРДЕНОВ В РОССИЙСКОЙ ИМПЕРИИ (XVIII В.-1917) ВНЕС РОССИЙСКИЙ УЧЕНЫЙ Л.Е. ШЕПЕЛЕВ. СМ : Л.Е. ШЕПЕЛЕВ, ТИТУЛЫ, МУНДИРЫ, ОРДЕНА В РОССИЙСКОЙ ИМПЕРИИ, М.: НАУКА,1991; ОН ЖЕ, ЧИНОВНЫЙ МИР РОССИИ : XVIII- НАЧАЛО ХІХ в., СПБ. : ИСКУССтВО, 2001. 
14. СМ. : Д.И. АРАПОВ, « МУСУЛЬМАНСКОЕ ДВОРЯНСТВО В РОССИЙСКОЙ ИМПЕРИИ», МЕЖДУНАРОДНЫЙ ИСТОРИЧЕСКИЙ ЖУРНАЛ, МАЙ-ИЮНЬ 1999, №3 ; Б.А. АЗНАБАЕВ, УФИМСКОЕ ДВОРЯНСТВО В КОНЦЕ XVI - ПЕРВОЙ ТРЕТИ ХVШВ. (ЗЕМЛЕДЕЛИЕ, СОЦИАЛЬНЫЙ СОСТАВ, СЛУЖБА), УФА : БГУ, 1999 ; С. ЕНИКЕЕВ, ОЧЕРК ИСТОРИИ ТАТАРСКОГО ДВОРЯНСТВА, УФА,1999 ; А.Я. ИЛЬЯСОВА, « ФОРМИРОВАНИЕ БАШКИРСКОГО ДВОРЯНСТВА», НАЦИОНАЛЬНЫЕ И ЯЗЫКОВЫЕ ПРОЦЕССЫ В РЕСПУБЛИКЕ БАШКОРТОСТАН : ИСТОРИЯ И СОВРЕМЕННОСТЬ. ИНФОРМАЦИОННЫЙ БЮЛЛЕТЕНЬ, УФА, 2006, с. 138-144; Kelly O’Neill, “Rethinking elite Integration. The Crimean Murzas and the Evolution of Russian Nobility", Cahiers du Monde russe, 51 (2-3), April-September 2002, с. 397-418; Г. СУЛТАНГАЛИЕВА, Т. ДАЛАЕВА, « ДИПЛОМ НА ДВОРЯНСКОЕ ДОСТОИНСТВО СУЛТАНУ», ИСТОРИЧЕСКИЙ АРХИВ, МОСКВА, 2014, №4, с. 174-186.

15. СМ. С.З. ЗИМАНОВ, ПОЛИТИЧЕСКИЙ СТРОЙ КАЗАХСТАНА КОНЦА ХVIII - ПЕРВОЙ ПОЛОВИНЫ ХІХ ВЕКА, АЛМА-АТА : НАУКА, 1960 ; Б. АБДРАХМАНОВА, ИСТОРИЯ КАЗАХСТАНА : ВЛАСТЬ, СИСТЕМА УПРАВЛЕНИЯ, ТЕРРИТОРИАЛЬНОЕ УСТРОЙСТВО В ХІХ ВЕКЕ, АСТАНА: ПОЛИГРАФИЯ, 1998.

16. С.У. СОЗАКБАЕВ, « ПЕТЕРБУРГСКИЙ УНИВЕРСИТЕТ В ИСТОРИИ ПОЛИТИЧЕСКОЙ И ПРАВОВОЙ МЫСЛИ КАЗАХСТАНА (ВТОРАЯ ПОЛОВИНА ХІХ - НАЧАЛО ХХ ВВ.)», АВТОРЕФ. ДИСС... К.Ю.Н. АЛМА-АТА, 1985 ; Б.А. КЕНЖЕТАЕВ, КАЗАНСКИЕ УЧЕБНЫЕ ЗАВЕДЕНИЯ И ПРОЦЕСС ФОРМИРОВАНИЯ КАЗАХСКОЙ ИНТЕЛЛИГЕНЦИИ В СЕР. ХІХ - НАЧАЛЕ ХХ ВВ., КАЗАНЬ : « ПИФ», 1996.

17. С.З. ЗИМАНОВ, К.З. ИДРИСОВ, ОБЩЕСТВЕННО-ПОЛИТИЧЕСКИЕ ВЗГЛЯДЫ МУХАМЕДЖАНА СЕРАЛИНА, АЛМА-АТА :НАУКА, 1989.

18. Ж. КАСЫМБАЕВ, ГЕНЕРАЛ, СУЛТАН-ПРАВИТЕЛЬ БАЙМУХАМЕД АЙШУАКОВ (1790-1847), АЛМАТЫ: ОЛКЕ, 2000 ; Г.С.СУЛТАНГАЛИЕВА, «КАЗАХСКОЕ ЧИНОВНИЧЕСТВО ОРЕНБУРГСКОГО ВЕДОМСТВА : И ФОРМИРОВАНИЕ И НАПРАВЛЕНИЕ ДЕЯТЕЛЬНОСТИ (ХІХ В)», Acta Slavica Japonica, САППОРО, 27, 2009, с. 77-101.

19. С. АБАШИН, « ИМПЕРИЯ И МЕСТНОЕ САМОУПРАВЛЕНИЕ: ИДЕОЛОГИЯ РЕФОРМ В РУССКОМ ТУРКЕСТАНЕ В КОНЦЕ ХІХ-НАЧАЛЕ ХХ ВВ.», ПРОСТРАНСТВО ВЛАСТИ : ИСТОРИЧЕСКИЙ ОПЫТ РОССИИ И ВЫЗОВЫ СОВРЕМЕННОСТИ, М. : МОСКОВСКИЙ ОБЩЕСТВЕННЫЙ НАУЧНЫЙ ФОНД, 2001, c. $391-413$.

20. О ПОЧЕТНЕЙШИХ И ВЛИЯТЕЛЬНЕЙШИХ ОРДЫНЦАХ : АЛФАВИТНЫЕ, ИМЕННЫЕ, ФОРМУЛЯРНЫЕ И ПОСЛУЖНЫЕ СПИСКИ. 12 НОЯБРЯ 1827 Г. - 9 АВГУСТА 1917 Г., АЛМАТЫ : ДАЙК ПРЕСС, 2006, Т. VIII, ч. 1-2.

21. Г.С. СУЛТАНГАЛИЕВА, ОТВ. РЕД., Г.С. СУЛТАНГАЛИЕВА, Т.Т. ДАЛАЕВА, С.К. УДЕРБАЕВА, СОСТ., КАЗАХСКИЕ ЧИНОВНИКИ НА СЛУЖБЕ РОССИЙСКОЙ ИМПЕРИИ :СБОРНИК ДОКУМЕНТОВ И МАТЕРИАЛОВ, АЛМАТЫ : ҚАЗАҚ УНИВЕРСИТЕТІ, 2014.

22. 22 ИЮЛЯ 1822 ГОДА БЫЛ УТВЕРЖДЕН «УСТАВ О СИБИРСКИХ КАЗАХАХ», ПСЗ РИ -1, Т. 38. №29127, с. 417-433

23. СУЛТАНЫ - ПРИВИЛЕГИРОВАННОЕ СОСЛОВИЕ КАЗАХСКОГО КОЧЕВОГО ОБЩЕСТВА «ТОРЕ», ПРИЧИСЛЯВШИЕ СЕБЯ К ПОТОМКАМ ЧИНГИЗ-ХАНА. ОНИ СТОЯЛИ ВО ГЛАВЕ КАЗАХСКИХ ОБЩИН, НО НЕ ПРИНАДЛЕЖАЛИ К ИХ СОСТАВУ. ТОЛЬКО СУЛТАНЫ МОГЛИ БЫТЬ ХАНАМИ. СМ. В. БАРТОЛЬД ХАН, В.В. БАРТОЛЬД, СОЧИНЕНИЯ, Т. V, М. : НАУКА, 1968, С. 604.

24. И. КРАФТ, ИЗ КИРГИЗСКОЙ СТАРИНЫ, ОРЕНБУРГ : ТИПО- ЛИТОГРАФИЯ Ф.Б. САЧКОВА,1900, c. 81 .

25. М.Г. МАСЕВИЧ, СОСТ., МАТЕРИАЛЫ ПО ИСТОРИИ ПОЛИТИЧЕСКОГО СТРОЯ КАЗАХСТАНА, АЛМА-АТА : ИЗДАТЕЛЬСТВО АН КАЗССР, 1960, Т. 1, ДОК. 54, С. 94.

26. ЦГА РК, Ф. 4, ОП. 1, Д. 303, Л. 4-8.

27. ОРЕНБУРГСКАЯ ПОГРАНИЧНАЯ КОМИССИЯ БЫЛА СОЗДАНА В 1799 ГОДУ И ЗАНИМАЛАСЬ ВОПРОСАМИ КАЗАХСКОГО НАСЕЛЕНИЯ ОРЕНБУРГСКОГО ВЕДОМСТВА ДО1859 Г.

28. ТЕРРИТОРИИ МЛАДШЕГО И СРЕДНЕГО ЖУЗОВ ДО 20-ХГОДОВ ХІХ В. НАХОДИЛИСЬ В УПРАВЛЕНИИ ОРЕНБУРГСКОГО ГУБЕРНАТОРА. С ВВЕДЕНИЕМ УСТАВА О СИБИРСКИХ КАЗАХАХ 
1822 Г. УПРАВЛЕНИЕ КАЗАХАМИ СРЕДНЕГО ЖУЗА НАХОДИЛОСЬ В ВВЕДЕНИИ НАЧАЛЬНИКА ОМСКОЙ ОБЛАСТИ, КОТОРЫЙ ПОДЧИНЯЛСЯ НЕПОСРЕДСТВЕННО ЗАПАДНО-СИБИРСКОМУ ГЕНЕРАЛ-ГУБЕРНАТОРУ И ЯВЛЯЛСЯ РЕАЛИЗАТОРОМ ПОЛИТИКИ РОССИЙСКОГО ПРАВИТЕЛЬСТВА НА ПОДВЕДОМСТВЕННОЙ ЕМУ ТЕРРИТОРИИ. В 1822 Г. НАЧАЛЬНИКОМ ОМСКОЙ ОБЛАСТИ СТАЛ СЕМЕН БРОНЕВСКИЙ, КОТОРЫЙ ПРИЛОЖИЛ МНОГО УСИЛИЙ ДЛЯ ПРОВЕДЕНИЯ В ЖИЗНЬ РЕФОРМЫ 1822 Г. В 1838 ГОДУ ОМСКОЕ ОБЛАСТНОЕ ПРАВЛЕНИЕ БЫЛО УПРАЗДНЕНО И СОЗДАНО ПОГРАНИЧНОЕ УПРАВЛЕНИЕ СИБИРСКИМИ КАЗАХАМИ.

29. ЦГА РК, Ф. 374, ОП. 1, Д. 914, Л. 26-29.

30. С.З. ЗИМАНОВ, ОБЩЕСТВЕННЫЙ СТРОЙ КАЗАХОВ ПЕРВОЙ ПОЛОВИНЫ И БУКЕЕВСКОЕ ХАНСТВО, АЛМАТЫ : АРЫС, 2009, с. 196.

31. ЦГА РК, Ф. 345, ОП. 1, Д. 707, Л. 5-8.

32. СМ. КОММЕНТАРИИ К СНОСКЕ 41 .

33. « 1844. 14 ИЮНЯ. ПОЛОЖЕНИЕ ОБ УПРАВЛЕНИИ ОРЕНБУРГСКИМИ КИРГИЗАМИ», ПСЗ РИ -2, T. XIX, №17998, с. 392-401.

34. В КАЖДОМ ВНЕШНЕМ ОКРУГЕ КАЗАХСКИЕ ЗАСЕДАТЕЛИ ОКРУЖНОГО ПРИКАЗА ИЗБИРАЛИСЬ ИЗ «ПОЧЕТНЫХ» КАЗАХОВ НА ДВА ГОДА. ПРИ ЭТОМ КАК РОССИЙСКИЕ, ТАК И КАЗАХСКИЕ ЗАСЕДАТЕЛИ СЧИТАЛИСЬ ЧИНОВНИКАМИ 9 КЛАССА. МАСЕВИЧ, СОСТ., МАТЕРИАЛЫ ПО ИСТОРИИ ПОЛИТИЧЕСКОГО СТРОЯ КАЗАХСТАНА, Т. 1, с. 94-95.

35. К ПРИМЕРУ, ДЖИЛГАРА БАЙТОКИН, БУДУЧИ ЗАСЕДАТЕЛЕМ КОКЧЕТАВСКОГО ОКРУЖНОГО ПРИКАЗА, ИСПОЛНЯЛ ОБЯЗАННОСТИ СТАРШЕГО СУЛТАНА С 1824 ПО ИЮЛЬ 1826 ГГ, КОГДА СТАРШИЙ СУЛТАН ЭТОГО ОКРУГА ГАБАЙДУЛЛА ВАЛИХАНОВ СТАЛ ВЫРАЖАТЬ ПРОТЕСТ ПРОТИВ ВВОДИМОЙ НОВОЙ РОССИЙСКОЙ СИСТЕМЫ ОКРУЖНОГО ДЕЛЕНИЯ. «О ПОЧЕТНЕЙШИХ И ВЛИЯТЕЛЬНЕЙШИХ ОРДЫНЦАХ», ИСТОРИЯ КАЗАХСТАНА В РУССКИХ ИСТОЧНИКАХ XVI-XX ВВ.», Т. VIII, АЛМАТЫ : ДАЙК-ПРЕСС, 2006, Ч. 1, ДОК. №154, с. 607- 609.

36. К ПРИМЕРУ, ПОСЛЕ ГИБЕЛИ СУЛТАНА-ПРАВИТЕЛЯ СРЕДНЕЙ ЧАСТИ КАЗАХОВ ОРЕНБУРГСКОГО ВЕДОМСТВА ПОДПОЛКОВНИКА АРАСЛАНА ДЖАНТЮРИНА ИСПОЛНЕНИЕ ОБЯЗАННОСТЕЙ ПРАВИТЕЛЯ ЭТОЙ ЧАСТИ ПЕРЕШЛО ПОМОЩНИКУ, ЕСАУЛУ, СУЛТАНУ МАХМУД АЛГАЗЫЕВУ. БУДУЩИЕ СУЛТАНЫ ПРАВИТЕЛИ МУХАММЕД ДЖАНТЮРИН (ВОСТОЧНАЯ ЧАСТЬ) И МУХАМЕД-ГАЛИ ТАУКИН (ЗАПАДНАЯ ЧАСТЬ), НАХОДЯСЬ НА ДОЛЖНОСТИ ПОМОЩНИКОВ ДЛИТЕЛЬНОЕ ВРЕМЯ ПОЛУЧАЛИ НОВЫЙ ОПЫТ АДМИНИСТРАТИВНОГО УПРАВЛЕНИЯ. БОЛЕЕ ТОГО М-Г. ТАУКИН БЫЛ ПРИЗНАН ПОГРАНИЧНОЙ КОМИССИЕЙ, КАК “...ЛУЧШИЙ ИЗ ПОМОЩНИКОВ» ПРАВИТЕЛЕЙ ЧАСТЕЙ, «О ПОЧЕТНЕЙШИХ И ВЛИЯТЕЛЬНЕЙШИХ ОРДЫНЦАХ», ИСТОРИЯ КАЗАХСТАНА В РУССКИХ ИСТОЧНИКАХ XVI-XX ВВ., АЛМАТЫ : ДАЙК-ПРЕСС, 2006, Т. VIII, Ч. 2, ДОК. №.228, с. 67 ; ДОК. №330, с. 368-374 ; ЦГА РК Ф. 4, ОП. 1, Д. 2745, л. 1-2.

37. СТАРШИНЫ ДЛЯ УПРАВЛЕНИЯ АУЛАМИ ИЗБИРАЛИСЬ ЧЕРЕЗ КАЖДЫЕ ТРИ ГОДА КАЗАХСКОЙ ОБЩИНОЙ И УТВЕРЖДАЛИСЬ ОКРУЖНЫМ ПРИКАЗОМ, МАСЕВИЧ, СОСТ., МАТЕРИАЛЫ ПО ИСТОРИИ ПОЛИТИЧЕСКОГО СТРОЯ КАЗАХСТАНА, Т. 1, с. 94.

38. В 1824 Г. БЫЛИ СОЗДАНЫ ПЕРВЫЕ ВНЕШНИЕ ОКРУГА - КАРКАРАЛИНСКИЙ И КОКЧЕТАВСКИЙ, В 1831 ОТКРЫТ ТРЕТИЙ - АЯГУСКИЙ, ЧЕРЕЗ ГОД АКМОЛИНСКИЙ ВНЕШНИЙ ОКРУГ. К 1838 ГОДУ БЫЛИ ОТКРЫТЫ СЕМЬ ВНЕШНИХ ОКРУГОВ, ПСЗ РИ - 2, Т. VI, №4870.

39. ЦГА РК, Ф.338, ОП. 1 , Д. 435, Л. 2, 2ОБ. МАСЕВИЧ, СОСТ., МАТЕРИАЛЫ ПО ИСТОРИИ ПОЛИТИЧЕСКОГО СТРОЯ КАЗАХСТАНА, Т. 1, ДОК. №70, 71, с. 146, 149.

40. ЦГА РК, Ф. 4, ОП. 1, Д. 2303, Л. 6-8ОБ ; д. 2427, л. 1 ; д. 2428, л. 12-13.

41. В 1831 ГОДУ ОРЕНБУРГСКИЙ ГУБЕРНАТОР П.П. СУХТЕЛЕН (1830-1833) РАЗРАБОТАЛ И ВВЕЛ В ДЕЙСТВИЕ ТАК НАЗЫВАЕМУЮ СИСТЕМУ « ДИСТАНОЧНОГО» УПРАВЛЕНИЯ В КАЗАХСКОЙ СТЕПИ, А ИМЕННО СОЗДАНИЕ ТЕРРИТОРИАЛЬНО-АДМИНИСТРАТИВНЫХ СТРУКТУР - ДИСТАНЦИЙ (АДМИНИСТРАТИВНЫЕ УЧАСТКИ МЕЖДУ ДВУМЯ КРЕПОСТЯМИ). КАЖДУЮ ДИСТАНЦИЮ ВОЗГЛАВЛЯЛ ДИСТАНОЧНЫЙ НАЧАЛЬНИК. 
42. ВНУТРИ КАЖДОЙ ДИСТАНЦИЙ, НАПРОТИВ КАЖДОГО ФОРПОСТА ОБРАЗОВЫВАЛАСЬ СВОЕОБРАЗНАЯ АДМИНИСТРАТИВНО-ТЕРРИТОРИАЛЬНАЯ ЕДИНИЦА, ВОЗГЛАВЛЯЕМАЯ МЕСТНЫМИ НАЧАЛЬНИКАМИ ИЗ « ПОЧЕТНЫХ» КАЗАХОВ.

43. МАСЕВИЧ, СОСТ., МАТЕРИАЛЫ ПО ИСТОРИИ ПОЛИТИЧЕСКОГО СТРОЯ КАЗАХСТАНА, ДОК. №101, c. 209.

44. ИСТОРИЯ БУКЕЕВСКОГО ХАНСТВА 1801-1852: СБОРНИК ДОКУМЕНТОВ И МАТЕРИАЛОВ, АЛМАТЫ : ДАЙК-ПРЕСС,2002 ДОК. 271, с. 378.

45. ЦГА РК, Ф. 345 , ОП. 1 , Д. 234. ДЕЛО ОБ ИСХОДАТАЙСТВОВАНИИ ПОЛКОВНИКАМ БАЙТОКИНУ И ЧИНГИСОВУ ДВОРЯНСКОГО ДИПЛОМА, Ф.338, ОП. 1, Д.207. ДЕЛО ПО ПРЕДПИСАНИЮ Г. ГЕНЕРАЛ-ГУБЕРНАТОРА ЗАПАДНОЙ СИБИРИ О ВЫДАЧЕ СТАРШЕМУ СУЛТАНУ АКМОЛИНСКОГО ОКРУГА КОНЫР-КУЛЬДЖЕ ХУДАЙМЕНДИНУ ВСЕМИЛОСТИВЕЙШЕ ПОЖАЛОВАННОГО ЕМУ ДИПЛОМА НА ДВОРЯНСКОЕ ДОСТОИНСТВО. ЦГА РК, Ф. 25, оП. 2, д. 71, Л. 1-22 ; д. 848, Л. 1-3 ; Ф. 4, ОП. 1, Д. 2303, л. 34-53.

46. ЦГА РК, Ф. 78, ОП. 2, Д. 43.

47. МАСЕВИЧ, СОСТ., МАТЕРИАЛЫ ПО ИСТОРИИ ПОЛИТИЧЕСКОГО СТРОЯ КАЗАХСТАНА, Т. 1 , С. 95, 99.

48. Ф.М. ЛАЗАРЕВСКИЙ, «О СОСТОЯНИИ ЗАПАДНОЙ ЧАСТИ КИРГИЗСКОЙ ОРДЫ И УРАЛЬСКОЙ ЛИНИИ. 1852 Г.», ИСТОРИЯ КАЗАХСТАНА В ДОКУМЕНТАХ И МАТЕРИАЛАХ : АЛЬМАНАХ, ВЫП. 3 , КАРАГАНДА :ЭКОЖАН, 2013, с. 205.

49. МАСЕВИЧ, СОСТ., МАТЕРИАЛЫ ПО ИСТОРИИ ПОЛИТИЧЕСКОГО СТРОЯ КАЗАХСТАНА, Т. 1, с. 99.

50. КАК ЧИНОВНИКАМ ПОГРАНИЧНОЙ КОМИССИИ ИМ БЫЛО НАЗНАЧЕНО ЖАЛОВАНИЕ В РАЗМЕРЕ 350 РУБЛЕЙ В ГОД, ЦГА РК, Ф. 4, ОП. 1, Д. 230, Л. 4 ОБ.

51. ЦГА РК, Ф. 4, ОП. 1, Д. 259, Л. 256.

52. ЦГА РК, Ф. 4, ОП. 1, Д. 4668, Л. 20.

53. ТУРДУБЕК КОЧЕНОВ, СОВЕТНИК ПОГРАНИЧНОГО УПРАВЛЕНИЯ НА ПРОТЯЖЕНИИ ПЯТИ ЛЕТ (1842 - 1847) ОТПРАВЛЯЛ РАПОРТЫ О КОЛИЧЕСТВЕ СКОТА БАГАНАЛИНСКОЙ ВОЛОСТИ АКМОЛИНСКОГО ВНЕШНЕГО ОКРУГА, О СБОРАХ ПОДАТИ И Т. Д. ПРИМЕЧАТЕЛЬНО, ЧТО СПУСТЯ ПОЧТИ ДВАДЦАТЬ ЛЕТ, В 1862 ГОДУ НА ДОЛЖНОСТЬ СОВЕТНИКА БЫЛ УТВЕРЖДЕН СЫН ТУРДУБЕК КОЧЕНОВА, НОГУРБЕК. ПРИ ЭТОМ, В ФОРМУЛЯРНОМ СПИСКЕ НОГУРБЕКА КОЧЕНОВА ОТ 1866 Г. ЗНАЧИТСЯ, ЧТО ОН ОТНОСИТСЯ К СОСЛОВИЮ ПОТОМСТВЕННЫХ ДВОРЯН РОССИЙСКОЙ ИМПЕРИИ, ЦГА РК, Ф. 345, оП. 1, Д. 949, Л. 66-69 ; Ф. 374, оП. 1, Д. 1253, л. 1, 1 ОБ.

54. ЦГА РК, Ф. 374, ОП. 1, Д. 2494, л. 1ОБ.

55. ЦГА РК, Ф.4. ОП.1, Д. 2350, Л. 108-118.

56. МАСЕВИЧ, СОСТ., МАТЕРИАЛЫ ПО ИСТОРИИ ПОЛИТИЧЕСКОГО СТРОЯ КАЗАХСТАНА, Т. 1.

57. ГАОРО, Ф. 6, ОП. 8, Д. 13, Л. 3.

58. ЦГА РК, Ф. 374, ОП. 1, Д. 3853, Л. 1-3.

59. ЦГА РК, Ф. 4, ОП. 1, Д. 2833, Л. 63-69.

60. К ПРИМЕРУ, ЗАСЕДАТЕЛЬ ОРЕНБУРГСКОЙ ПОГРАНИЧНОЙ КОМИССИИ ОТ ПОКОЛЕНИЯ БАЙУЛЫ МЛАДШЕГО ЖУЗА (С 1801 Г.) БАЯЗЫЛ КУЧУКБАЕВ БЫЛ ОТСТРАНЕН ОТ ДОЛЖНОСТИ В 1815 Г. И СОСЛАН В ССЫЛКУ В АРХАНГЕЛЬСКУЮ ГУБЕРНИЮ, ОТКУДА ВЕРНУЛСЯ ЧЕРЕЗ ТРИ ГОДА И ВНОВЬ ПО РАСПОРЯЖЕНИЮ ОРЕНБУРГСКОГО ВОЕННОГО ГУБЕРНАТОРА П. ЭССЕНА СТАЛ ЗАСЕДАТЕЛЕМ ПОГРАНИЧНОЙ КОМИССИИ. НО 7 ДЕКАБРЯ 1821 Г. БАЯЗЫК КУЧУКБАЕВ ОПЯТЬ БЫЛ ОТСТРАНЕН ОТ ДОЛЖНОСТИ И ЗАКЛЮЧЕН ПОД СТРАЖУ ГОРОДСКОЙ ПОЛИЦИИ ИЗ-ЗА НЕДОБРОСОВЕСТНЫХ ИСПОЛНЕНИЙ ОБЯЗАННОСТЕЙ НА ОРЕНБУРГСКОМ МЕНОВОМ ДВОРЕ. ЦГА РК, Ф. 4, ОП. 1, Д. 259, л. 210-219.

61. К ПРИМЕРУ, 30 СЕНТЯБРЯ 1859 Г. ПО РЕШЕНИЮ ПРАВИТЕЛЬСТВУЮЩЕГО СЕНАТА ЗЮЛКАРНЕЙ НУРАЛИХАНОВ БЫЛ ЛИШЕН ЧИНА ХОРУНЖЕГО И СОСЛАН СНАЧАЛА ЖИТЬ В ВЯТСКУЮ, ЗАТЕМ ОРЕНБУРГСКУЮ ГУБЕРНИЮ. ОДНАКО ЧЕРЕЗ ДВА ГОДА, 12 ИЮНЯ 1861 Г. БЫЛ ВОЗВРАЩЕН ВО 
ВНУТРЕННЮЮ ОРДУ И ОПРЕДЕЛЕН НА СЛУЖБУ СНАЧАЛА ПЕРЕВОДЧИКОМ, ЗАТЕМ ПОМОЩНИКОМ ПРАВИТЕЛЯ ТАЛОВСКОЙ ЧАСТИ ВНУТРЕННЕЙ ОРДЫ. ЦГА РК, Ф.4, ОП. 1, Д.5936. ДЕЛО О НАГРАЖДЕНИИ СЛУЖАЩИХ ВРЕМЕННОГО СОВЕТА БРОНЗОВЫМИ МЕДАЛЯМИ ЗА УСЕРДНУЮ СлУЖБУ», Л. 29.

62. ТАК, 13 АПРЕЛЯ 1820 Г. РЕГИОНАЛЬНЫЕ ВЛАСТИ ПОТРЕБОВАЛИ ОТ ЗАСЕДАТЕЛЯ ОРЕНБУРГСКОЙ ПОГРАНИЧНОЙ КОМИССИИ НУРМУХАМЕД АБЗЕЛИЛОВА, КАК ЧИНОВНИКА, ПОЛУЧАВШЕГО ЖАЛОВАНИЕ, ПОСТОЯННОЕ ПРИСУТСТВИЕ И УЧАСТИЕ В РАБОТЕ КОМИССИИ, В ПРОТИВНОМ СЛУЧАЕ, ПРИГРОЗИЛИ « ПРЕКРАТИТЬ ВЫДАЧУ ЕМУ ЖАЛОВАНИЯ», ЦГА РК, Ф. 4 ОП. 1, Д. 259. ДЕЛО О НАЗНАЧЕНИИ СУЛТАНОВ ЗАСЕДАТЕЛЯМИ ОРЕНБУРГСКОЙ ПОГРАНИЧНОЙ комиссии, Л. 75, 78, 97.

63. 5 МАЯ 1855 ЗАПАДНО-СИБИРСКИЙ ГЕН-ГУБЕРНАТОР ИЗДАЛ РАСПОРЯЖЕНИЕ ОБ АРЕСТЕ НА ТРОЕ СУТОК КАЗАХСКИХ СЛУЖАЩИХ В СЛУЧАЕ МЕДЛЕННОГО ИСПОЛНЕНИЯ ПОРУЧЕНИЙ.

64. ЦГА РК, Ф. 4, ОП. 1, Д. 6287, Л. 14 ОБ.

65. ЦГА РК, Ф. 4, ОП. 1, Д. 6287, Л. 17ОБ.

66. О ПОРЯДКЕ ИЗБРАНИЯ ПО КИРГИЗСКОЙ СТЕПИ В СТАРШИЕ СУЛТАНЫ, ПСЗ РИ -2, Т. 30, №29069 ОТ 23 ФЕВРАЛЯ 1855 Г., с. 177.

67. ОБ ИЗМЕНЕНИИ ПОРЯДКА ВЫБОРА ВОЛОСТНЫХ УПРАВИТЕЛЕЙ В КИРГИЗСКОЙ СТЕПИ И СЕМИПАЛАТИНСКОЙ ВОЛОСТИ, ПСЗ РИ -2, Т. 36,. №36816 ОТ 4 АПРЕЛЯ 1861 Г., с. 557-558.

68. Г.В. ВЕРНАДСКИЙ, ОЧЕРК ИСТОРИИ ПРАВА РУССКОГО ГОСУДАРСТВА ХVIII-ХІХ ВВ. (ПЕРИОД ИМПЕРИИ) , М. : ГОСУДАРСТВЕННАЯ ИСТОРИЧЕСКАЯ БИБЛИОТЕКА, 1998, С. 117.

69. МАСЕВИЧ, СОСТ., МАТЕРИАЛЫ ПО ИСТОРИИ ПОЛИТИЧЕСКОГО СТРОЯ КАЗАХСТАНА, ДОК. 54 , 120 , с. 328.

70. ПОЛОЖЕНИЕ ОБ УПРАВЛЕНИИ АКМОЛИНСКОЙ, СЕМИПАЛАТИНСКОЙ, СЕМИРЕЧЕНСКОЙ, УРАЛЬСКОЙ И ТУРГАЙСКОЙ ОБЛАСТЯМИ, САНКТ-ПЕТЕРБУРГ : ИЗД-ВО ГОС.СОВЕТА,1892, С.11.

71. ЗАКЛЮЧЕНИЕ ГОСУДАРСТВЕННОГО СОВЕТА «О ЧИНОВНИКАХ ОСОБЫХ ПОРУЧЕНИЙ РАЗНЫХ ВЕДОМСТВ», ПСЗ РИ-2, Т. 10, Ч. 2, СПБ., 1835, №8595, с. 115-117.

72. ЦГА РК, Ф. 25, ОП. 1, Д. 1841, Л. 2.

73. ЦГА РК, Ф. 25, ОП. 2, Д. 103, Л. 2-3.

74. ЖАЛОВАНИЕ МЛАДШЕГО ПОМОЩНИКА НАЧАЛЬНИКА УЕЗДА СОСТАВЛЯЛО 400 РУБЛЕЙ В ГОД, ЦГА РК, Ф. 25, ОП. 2, Д. 103, Л. 2-3.

75. АЙМУХАМЕД АРУНГАЗИЕВ УМЕР В МАРТЕ 1873 Г., ЦГА РК, Ф. 25, ОП. 3, Д. 20, Л. 5-7.

76. ЦГА РК, Ф. 25, ОП. 2, Д. 487, Л. 20-21 ; Д. 846, Л. 1-3.

77. КАЗАХАМ ПРИСВАИВАЛИСЬ ОФИЦЕРСКИЕ ЧИНЫ, КОТОРЫЕ ПОДРАЗДЕЛЯЛИСЬ НА АРМЕЙСКИЕ (ПОДПРАПОРЩИК, ПРАПОРЩИК, ПОРУЧИК, КАПИТАН, МАЙОР, ПОДПОЛКОВНИК, ПОЛКОВНИК, ГЕНЕРАЛ-МАЙОР), КАЗАЧЬИ (УРЯДНИК, ХОРУНЖИЙ, СОТНИК, ЕСАУЛ, ВОЙСКОВОЙ СТАРШИНА), ЗА ОСОБЫЕ ЗАСЛУГИ ИЛИ ЗА ДОЛГОЛЕТНЮЮ СЛУЖБУ, КОТОРЫЕ УТВЕРЖДАЛИСЬ ИМПЕРАТОРОМ. КРОМЕ ТОГО ПРИСВАИВАЛИСЬ ЗАУРЯД-ЧИНЫ ( ЗАУРЯД-ХОРУНЖИЙ, ЗАУРЯД-СОТНИК, ЗАУРЯД-ЕСАУЛ), КОТОРЫЕ УТВЕРЖДАЛИСЬ ГЕНЕРАЛ-ГУБЕРНАТОРАМИ ОРЕНБУРГСКОГО, ЗАПАДНО-СИБИРСКОГО ГЕН-ГУБЕРНАТОРСТВА.

78. О ПРАВИЛАХ ПРОИЗВОДСТВА В СТАТСКИЕ ЧИНЫ ОТ 16 ДЕКАБРЯ 1790 Г., ПСЗ РИ, Т. ХХІІІ, №16930, с. 201-203.

79. ЦГА РК, Ф. 25, ОП. 2, Д. 764, Л. 18-27ОБ. ; Ф. 4, ОП. 1., Д. 3100, Л. 186-196.

80. ОСНОВНЫЕ ВОССТАНИЯ КАЗАХСКОГО НАРОДА В ЭТОТ ПЕРИОД ПРОИСХОДИЛИ ПОД РУКОВОДСТВОМ Ж. ТЛЕНШИ (1820-1825), И. ТАЙМАНОВА И М. УТЕМИСОВА (1836-1838), СУЛТАНА К. КАСЫМОВА (1837-1847), Е. КОТЕБАРОВА (1854-1856).

81. ЦГА РК, Ф. 25, ОП. 2, Д. 263, Л. 1-6.

82. ЦГА РК, Ф. 4, ОП. 1, Д. 2465, Л. 1-6.

83. ЦГА РК, Ф. 4, ОП. 1 , Д. 4443, Л. 303-314. 
84. ЦГА РК, Ф. 4, ОП. 1, Д. 5746, Л. 25.

85. ЦГА РК, Ф. 3, ОП. 1, Д. 86.

86. О ЗАПРЕЩЕНИИ ИСПРАШИВАТЬ ВОИНСКИЕ НАГРАДЫ И В ОСОБЕННОСТИ ВОИНСКИЕ ЧИНЫ БАШКИРАМ, КИРГИЗАМ, КАЛМЫКАМ И ДРУГИМ ИНОРОДЧЕСКИМ ПЛЕМЕНАМ, ПСЗ РИ, 1869, Т. 44,

Ч. 2, №44424A, С. 8.

87. ПСз РИ-2, т. ХХХІ, Ч. 1, 1856, ( СПБ., 1857), №31138, с. 1002.

88. пСз РИ-2, т. ХХХІV, ч. 1, 1859, (спь., 1862), с. 781.

89. ЦГА РК, Ф. 345, ОП. 1, Д. 567, л. 1-8.

90. ГАОРО, Ф. 6, ОП. 10, Д. 7425, Л. 1-2.

91. П. НЕБОЛЬСИН, « ПУТЕШЕСТВУЮЩИЕ КИРГИЗЫ», РУССКИЙ ВЕСТНИК МОСКВА, Т. 29, СЕНТЯБРЬ, с. 42-45; Л. ПЛОТНИКОВ, «ПО ПОВОДУ СТАТЬИ “ПУТЕШЕСТВУЮЩИЕ КИРГИЗЫ”», РУССКИЙ ВЕСТНИК, 1860, Т. 30, с. 245-277; М-С. БАБАДЖАНОВ, ЗАМЕТКИ КИРГИЗА О КИРГИЗАХ / М-С. БАБАДЖАНОВ, СОЧИНЕНИЯ, АЛМАТЫ : САНАТ, 1996, С. 64.

92. ПСз РИ-2, СПБ.1844, Т. 19, ч. 1, №18137, с. 499.

93. ЦГА РК, Ф. 25, ОП. 2, Д. 107, л. 1-6.

94. ОРЕНБУРГСКИЙ ГЕН-ГУБЕРНАТОР ПРИЗНАВАЛ ПОЛЕЗНЫМ И НЕОБХОДИМЫМ ПОСЫЛАТЬ В САНКТ-ПЕТЕРБУРГ, ЕЖЕГОДНО ИЛИ ЧЕРЕЗ ДВА ГОДА ПОЧЕТНЕЙШИХ И ВЛИЯТЕЛЬНЕЙШИХ ОРДЫНЦЕВ. А. АРТЕМЬЕВ, «НЕСКОЛЬКО ЗАМЕТОК О КИРГИЗСКОЙ СТЕПИ ОРЕНБУРГСКОГО ВЕДОМСТВА», ЖУРНАЛ МИНИСТЕРСТВА ВНУТРЕННИХ ДЕЛ 1859Г., Т. 38, №10, с. 10-12.

95. ЦГА РК, Ф. 338, ОП. 1, Д. 410, Л. 238.

96. ГАОРО, Ф. 6, ОП. 10, Д. 6057/Б, Л. 5-6, 22-27 ; ЦГА РК, Ф. 4, ОП. 1, Д. 2983, Л. 89-94.

97. ЦГА РК, Ф.4, ОП. 1 , Д. 3519, Л. 49-50. О ПОЕЗДКЕ В ПЕТЕРБУРГ СУЛТАНА-ПРАВИТЕЛЯ ВОСТОЧНОЙ ЧАСТИ ДЖАНТЮРИНА АХМЕТА (1848-1851).

98. ПЛОТНИКОВ, « ПО ПОВОДУ СТАТЬИ “ПУТЕШЕСТВУЮЩИЕ КИРГИЗЫ”», с. 245-277.

99. ЦГА РК, Ф. 4, ОП. 1, Д. 4413, л. 59.

100. ОСОБЕННО ЭТО ЯРКО ПРОЯВИЛОСЬ В ДЕЯТЕЛЬНОСТИ СУЛТАНОВ-ПРАВИТЕЛЕЙ СРЕДНЕЙ ЧАСТИ ОРЕНБУРГСКОГО ВЕДОМСТВА. ЗА 1824-1826 ГГ. СМЕНИЛОСЬ ТРИ СУЛТАНА-ПРАВИТЕЛЯ (ТЕМИР ЕРАЛИЕВ, МАТИ МУХАММЕТГАЛИЕВ ИСПОЛНЯЛИ ДОЛЖНОСТЬ ТОЛЬКО ГОД, А СУЛТАН МЕДЕТГАЛИ ТУРДАЛИЕВ - ДВА ГОДА). ВЕРОЯТНО, ЭТО БЫЛО СВЯЗАНО НЕ ТОЛЬКО С НЕПОНИМАНИЕМ СУЛТАНАМИ СВОЕЙ РОЛИ В СТРУКТУРЕ РОССИЙСКОЙ ВЛАСТИ, НО И ОТСУТСТВИЕМ ОПЫТА УПРАВЛЕНИЯ.

101. ЦГА РК, Ф. 4, ОП. 1, Д. 261А, Л. 48.

102. ТАК, УПРАВЛЯЮЩИЙ РОДОМ ШОМЕКЕЙ ИРМУХАМЕД КАСЫМОВ В 1866 Г. СТАВИЛ В ИЗВЕСТНОСТЬ ОРЕНБУРГСКУЮ АДМИНИСТРАЦИЮ, ЧТО В СВЯЗИ С ПЕРЕХОДОМ НА МЕСТО ЗИМНИХ СТОЯНОК МОЖЕТ ПОЛУЧАТЬ ОФИЦИАЛЬНЫЕ ПИСЬМА ЧЕРЕЗ ФОРТ №2, ЦГА РК, Ф. 4, ОП. 1, Д. 4413, Л. 585.

103. ЦГА РК, Ф. 4, ОП. 1, Д. 2745, Л. 1-2.

104. КАРАУЛ-ХОДЖА БАБАДЖАНОВ (1775- 26.02.1850) - СТАРШИНА, ПОЛКОВОЙ ЕСАУЛ (С 1826), УПРАВЛЯЮЩИЙ 1-Й ЧАСТЬЮ ПРИМОРСКИХ КАЗАХОВ И ЧАСТЬЮ РОДА АДАЙ ВНУТРЕННЕЙ ОРДЫ (С 1834).

105. ЦГА РК , Ф. 4, ОП. 1 , Д. 5742, Л. 2-3.

106. СМ. БАБАДЖАНОВ, ЗАМЕТКИ КИРГИЗА О КИРГИЗАХ / М-С. БАБАДЖАНОВ, СОЧИНЕНИЯ, АЛМАТЫ : САНАТ, 1996, с. 77-78.

107. К ПРИМЕРУ, КУЛЬДЖАН АТАНОВ, ПОСТУПИЛ НА ДОЛЖНОСТЬ НАЧАЛЬНИКА 40-Й ДИСТАНЦИИ В 1849 ГОДУ, ВМЕСТО ОТЦА СВОЕГО, ИЗВЕСТНОГО БИЯ АТАНА ИСЕНЕВА, ЦГА РК, Ф. 4 , оП. 1, Д. 5594, л. 253.

108. ЦГА РК, Ф. 4, ОП. 1 , Д. 4413, л. 383-386.

109. ЦГА РК, Ф. 4, ОП. 1, Д. 4413, Л. 59. 
110. ЦГА РК, Ф. 4, ОП. 1, Д. 3261, Л. 1-2.

111. ЦГАРК, Ф. 4, ОП. 1 , Д. 4413, Л. 477.

112. ЦГА РК, Ф. 25, ОП. 1, Д. 1613, Л. 34-35.

113. ГАОРО, И- Ф. 6, ОП. 10 , Д. 7805 , Л. 8-9.

114. ЦГА РК, Ф. 4. ОП. 1 , Д. 2745 , Л. 1-2.

115. ЦГА РК, Ф. 25 ОП. 1, Д. 2658, ОБ ОСКОРБЛЕНИИ КИРГИЗАМИ ЧИНОВНИКОВ, ПРОИСХОДЯЩИХ ИЗ КИРГИЗ, НАХОДЯЩИХСЯ В ОТСТАВКЕ ИЛИ НА СЛУЖБЕ, Л. 1-24.

\section{RÉSUMÉS}

Dans cet article, l'auteur produit une analyse comparative du processus de formation du corps des fonctionnaires kazakhs dans différentes parties de la Steppe au cours du XIX ${ }^{\mathrm{e}}$ siècle à travers le prisme de la politique impériale russe de mise en place d'un système administratif vertical de gestion locale, d'un réseau de fonctions pour les représentants de la noblesse kazakhe, et de leur gratification par le biais de grades militaires, de médailles, d'ordres et du droit de porter l'uniforme. L'analyse de différents documents (pétitions, lettres, demandes de nomination, rapports sur l'exécution des obligations de service et missions de l'administration régionale) permet d'examiner la manière dont les Kazakhs percevaient les attributs du fonctionnaire de l'empire. L'auteur dégage ainsi différentes étapes qui marquent l'évolution qualitative du processus d'adaptation de la population kazakhe au nouveau système d'administration et aux membres de leur tribu devenus fonctionnaires et, de ce fait, relais du pouvoir russe dans la Steppe.

The article presents a comparative analysis of the formation of the corps of Kazakh civil servants in various areas of the Steppe during the nineteenth century. The frame of reference is Imperial Russia's implementation of a local vertical administrative system, a network of positions for Kazakh noblemen, and a reward system involving military promotion, medals, and the right to wear a uniform. An analysis of various documents such as petitions, letters, petitions for nomination, reports on the fulfillment of the service obligations and missions of the local administration allows the author to examine how the Kazakhs perceived the attributes of imperial civil servants. The author thus identifies qualitatively differing stages in the Kazakh population's adaptation to the new administrative system and to members of tribes who had become civil servants, that is, intermediaries of Russian power in the Steppe.

\section{AUTEUR}

\section{GUL'LMIRA S. SULTANGALIEVA}

Université nationale Al-Farabi, Almaty, Gulmira.Sultangalieva@kaznu.kz 